\title{
Análisis multivariante ambiental de los melojares de Quercus pyrenaica Willd. de Sierra Nevada
}

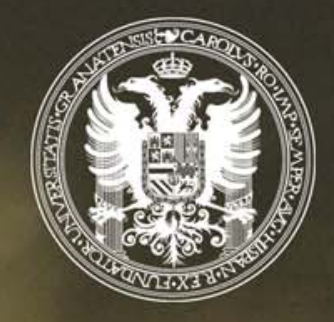

Universidad de Granada

\section{Proyecto Fin de Master Antonio Jesús Pérez Luque Octubre 2011}

Máster Oficial en Estadística Aplicada 


\title{
Análisis multivariante ambiental de los melojares de Quercus pyrenaica Willd. de Sierra Nevada
}

\author{
Antonio Jesús Pérez Luque
}

Octubre 2011

Tutor: Pedro Antonio García López

Trabajo Fin de Master

Master Oficial en Estadística Aplicada

Universidad de Granada

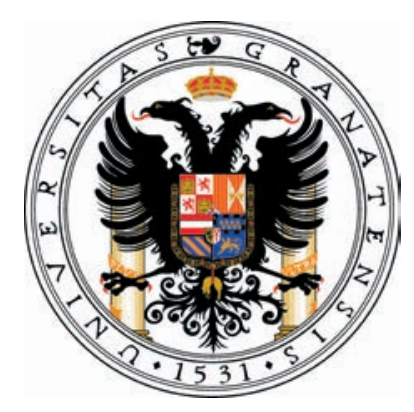


Entréme donde no supe: y quedéme no sabiendo, toda ciencia trascendiendo

San Juan de la Cruz. Poesías 


\section{Resumen}

En la actualidad existen evidencias científicas de los efectos del cambio global sobre los sistemas naturales. Para los ecosistemas mediterráneos se espera que los efectos del cambio climático sean mas fuertes que en otras regiones, y concretamente en los ecosistemas forestales mediterráneos estos impactos tendrán efectos significativos. Por otro lado las áreas de montaña están consideradas como sistemas de alerta temprana de los efectos del cambio global, debido a la alta vulnerabilidad y sensibilidad de sus ecosistemas. Sierra Nevada es una de las regiones de montaña de mayor importancia del sur de Europa y está considerada uno de los centros de diversidad mas importantes de la cuenca Mediterránea. De los diferentes ecosistemas forestales que habitan en ella, los melojares o robledales de Quercus pyrenaica se consideran unos los bosques mas sensibles y frágiles debido a su caracter relicto y las grandes presiones antrópicas a los que han estado sometidos en las últimas épocas (talas, roturaciones para cultivos, explotación de leña, etc.). Para llevar a cabo tareas de gestión y adaptación al cambio global de este tipo de ecosistemas se precisan de estudios a escala de detalle que permitan una mejor comprensión del funcionamiento de éstos y obtener así conocimiento útil para realizar tareas de conservación y gestión de los recursos naturales con información científica contrastada. En este sentido se plantea el presente trabajo como un análisis multivariante ambiental de alta resolución de los robledales de Sierra Nevada, con el que utilizando diferentes ténicas estadísticas se analiza el comportamiento de los diferentes núcleos existentes en Sierra Nevada respecto a diferentes variables ambientales y forestales. Concretamente los objetivos fueron: (i) caracterizar los robledales nevadenses respecto a varaiables ambientales y forestales; para (ii) establecer los valores del hábitat óptimo y marginal de esta formación; (iii) analizar si existe un patrón de comportamiento diferente entre los diferentes núcleos de robledal en Sierra Nevada; y (iv) establecer cuales son los parámetros ambientales mas importantes que definen dicho patrón de comportamiento.

Se han utilizado análisis univariantes para determinar el hábitat óptimo y marginal de las poblaciones de robledal en Sierra Nevada. Mediante un ánalisis de componentes principales que explicó el $72 \%$ de la variabilidad, hemos detectado que las principales variables mas importanes que explican la distribución de los robledales en Sierra Nevada son la distancia al mar y la precipitación, en mayor medida, y las temperaturas máximas y mínimas. Para identificar los diferentes grupos de comportamiento realizamos un análisis discriminante de las ocho poblaciones de robledal de Sierra Nevada que agrupó a estas (explicando las dos primeras funciones discrimiantes cerca del $90 \%$ de la variabilidad) en tres grupos de poblaciones diferentes: por un lado la población de la Dehesa del Camarate situada mas al norte; por otro lado un grupo con las poblaciones de la zona nordeste (poblaciones de los valles del río Genil, río Monachil, río Dílar y río Durcal; y por último las poblaciones del sur de Sierra Nevada (valles de los ríos Chico, Poqueira y Trevelez). Las variables mas importantes a la hora de discriminar entre estos grupos de poblaciones son, en orden de importancia: la distancia al mar, las precipitaciones de primeravera y la radiación solar. Destaca con una importancia mas débil el índice de influencia humana, como variable a la hora de realizar la discriminación entre grupos.

Posteriormente realizamos comparaciones entre estos tres grupos de poblaciones respecto a la variables ambien- 
tales y a los atributos forestales. Para ello utilizamos análisis ANOVA's y el test no paramétrico de Kruskal-Wallis cuando no se cumplian los supuestos de normalidad y homocedaticidad, y realizamos comparación cuando las diferencias eran significativas utilizando la prueba de Tukey y la prueba U de Mann-Whitney. Los resultados de estos análisis mostraron que para los atributos forestales no existen diferencias significativas entre los grupos, excepto para el índice de diversidad de Shanno-Weiner. Sin embargo respecto de las carcterísticas ambientales si encontramos diferencias entre las poblaciones en la mayoría de las varibles estudiadas. Esto pone de manifiesto que el comportamiento forestal de las poblaciones no está influenciado tanto por las condiciones ambientales sino por el uso humano que se ha realizado de los ecosistemas naturales, evidenciando la importancia del impacto humano como motor principal motor de cambio en los ecosistemas meditarráneos, tal y como han apuntado otros autores.

Por último se realizó un estudio de la similitud de la composición florística de las diferentes poblaciones de robledal. Para ello se utilizó un escalamiento multidimensional no métrico (NMDS) y se ajustaron superficies de respuesta utilizando modelos generalizados aditivos $(\mathrm{gam})$. Los resultados indican que existe un acoplamiento entre la ordenación de las poblaciones ofrecida en base a la composición específica y el agrupamiento de poblaciones derivado de las condiciones ambientales obtenido con los análisis anteriores.

keywords: robledales; Sierra Nevada; caracterización ambiental; Quercus pyrenaica; discriminante; escalamiento multidimensional; análisis de componentes principales. 


\section{Índice general}

$\begin{array}{ll}\text { 1. Introducción } & 5\end{array}$

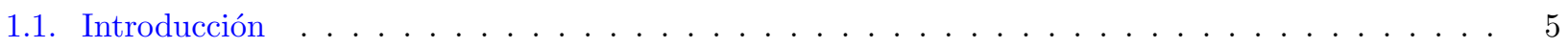

1.2. Revisión de trabajos relacionados. $\ldots \ldots \ldots \ldots \ldots \ldots \ldots \ldots \ldots$

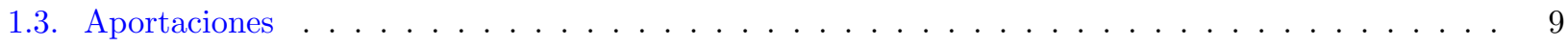

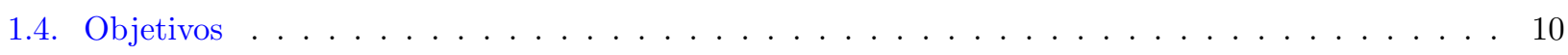

$\begin{array}{ll}\text { 2. Metodologías } & 11\end{array}$

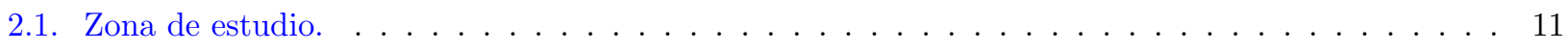

2.2. Robledales de Quercus pyrenaica. . . . . . . . . . . . . . . . . . . . . . 12

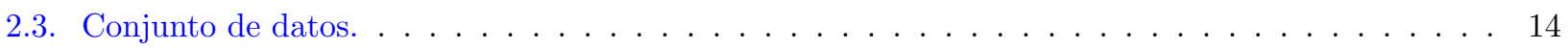

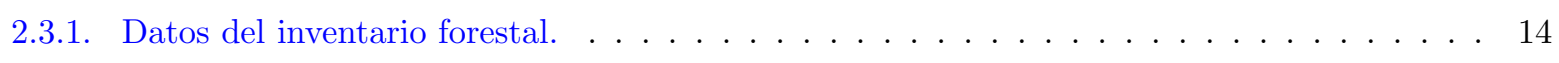

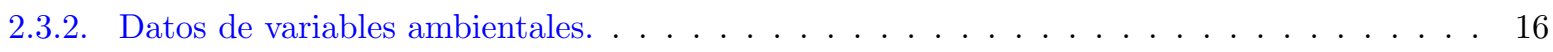

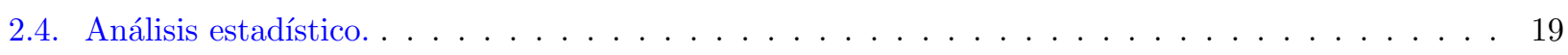

3. Resultados 23

4. Discusión 442

4.1. Discusión y conclusiones . . . . . . . . . . . . . . . . . . . . . . . . . . . 42

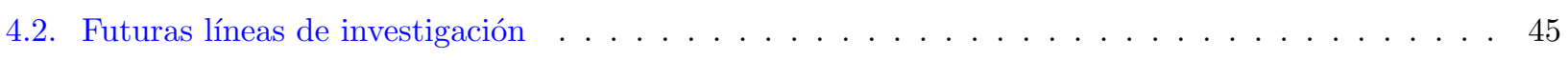

5. Bibliografía 44

6. Anexos 152

6.1. Anexo I: Listado de especies presentes en los inventarios florísticos . . . . . . . . . . . . . . 53

6.2. Anexo II: Análisis preliminar ACP . . . . . . . . . . . . . . . . . . . . . . . . 54

6.3. Anexo III. Caracterización del hábitat óptimo y marginal de Quercus pyrenaica en Sierra Nevada 57

6.4. Anexo IV. Análisis discriminante . . . . . . . . . . . . . . . . . . . . . . . . . . . . . . . 59

6.5. Escalamiento multidimensional no métrico . . . . . . . . . . . . . . . . . . . . . . 62 


\section{Capítulo 1}

\section{Introducción}

\subsection{Introducción}

En la actualidad existen evidencias científicas de los efectos del cambio global sobre los sistemas naturales (IPCC 2007). Muchos procesos se están viendo alterados debido al cambio climático: cambios en el área de distribución de especies (Thuiller et al. 2005), alteraciones fenológicas (Gordo \& Sanz, 2010), invasiones de especies (Tausch, 2008), alteraciones en las interacciones ecológicas (Hughes, 2000), etc. Estos y otros cambios están modificando la composición, la estructura y el funcionamiento de los ecosistemas, así como los beneficios que éstos proporcionan a las personas (EPA, 2010). Para la región mediterránea, los efectos del cambio climático se espera que sean mas fuertes que en otras regiones de la Tierra (McCarthy et al. 2001), y en los ecosistemas forestales mediterráneos estos cambios tendrán impactos significativos (Regato, 2008).

Muchos indicadores estan mostrando un declive en la biodiversidad, así como un aumento de la presión sobre la misma (Butchart et al. 2010), poniendo de manifiesto que, además del clima, las actividades humanas son uno de los principales motores de cambio que afectan a la biodiversidad (Sala et al. 2000), y como consecuencia estamos sobrepasando algunos de los principales límites ambientales del sistema tierra (Rockström et al. 2009).

Las áreas de montaña son repositorios de diversidad biológica, albergando aproximadamente la mitad de la biodiversidad mundial (Spehn \& Körner 2009), así como de diversidad cultural (Macchi \& ICIMOD, 2010). Debido a la alta sensibilidad y vulnerabilidad de los ecosistemas existentes en las áreas de montaña, los científicos los han considerado como sistemas de alerta temprana de los impactos del cambio climático (Macchi \& ICIMOD, 2010), pudiendo informar de algunos de los efectos que tendrá en otros ambientes. Así el estudio del cambio global en las áreas de montañas es una preocupación global (Kohler \& Maselli, 2009), y el reto de la investigación en el ámbito de las montañas pasa, entre otras, por el establecimiento de programas de seguimiento a largo plazo del cambio global (Zamora, 2010) que mejore el conocimiento de los componentes de los sitemas montañosos (Borsdorf \& Braun, 2008). En este sentido existe una gran cantidad de información disponible sobre los efectos del cambio global, pero se refiere en su mayor parte a escalas globales y regionales, lo que hace difícil su interpretación a escalas mas locales (Lawler et al. 2009), como los espacios naturales. Es por ello que se precisan, además de 
estudios a gran escala, otros tantos mas locales que permitan obtener conocimiento útil para que la gestión de los recursos naturales se realice basándose en información científica contrastada, hecho que generalmente no ocurre (Zavala et al. 2004). Por otro lado, la adaptación de los ecosistemas forestales al cambio climático implica la necesidad de comprensión del funcionamiento de estos sistemas; y para el diseño de actuaciones encaminadas a la conservación y restauración de los ecosistemas forestales es clave la caracterización de las poblaciones (Falk et al. 1996).

Los robledales de roble melojo o melojares ${ }^{1}$ son formaciones escasas y raras dominadas por Quercus pyreanica Willd. que se distribuyen en la Península Ibérica (Figura 1.1), noroeste de Marruecos y en el occidente de Francia (Martínez-Parras \& Molero 1982). En Sierra Nevada esta formación vegetal ocupa 2000 has aproximadamente (Benito et al. 2011) distribuidas entre los 1000 y 2000 metros de altitud, situados sobre suelos silíceos. Aparece en aquellos enclaves mas húmedos y de menor índice de insolación, principalmente barrancos y fondos de valle.

Al igual que otras formaciones forestales han sido objeto de intensas presiones de origen antrópico, principalmente actividades de pastoreo y de extracción de madera, que han provocado la reducción de su área de distribución así como modificación en sus patrones florísticos (Gavilán et al. 2000; Gavilán et al. 2007). Esta presión antrópica también se ha obsevado en los robledales de Sierra Nevada (Jiménez-Olivencia, 1991), donde el intenso aprovechamiento ganadero y forestal, la roturación de espacios para nuevos cultivos y pastos, la explotación de leña para uso doméstico o industrial, e incluso los incendios forestales, han ocasionado una reducción de la superficie ocupada por los robledales (Camacho-Olmedo et al. 2002).

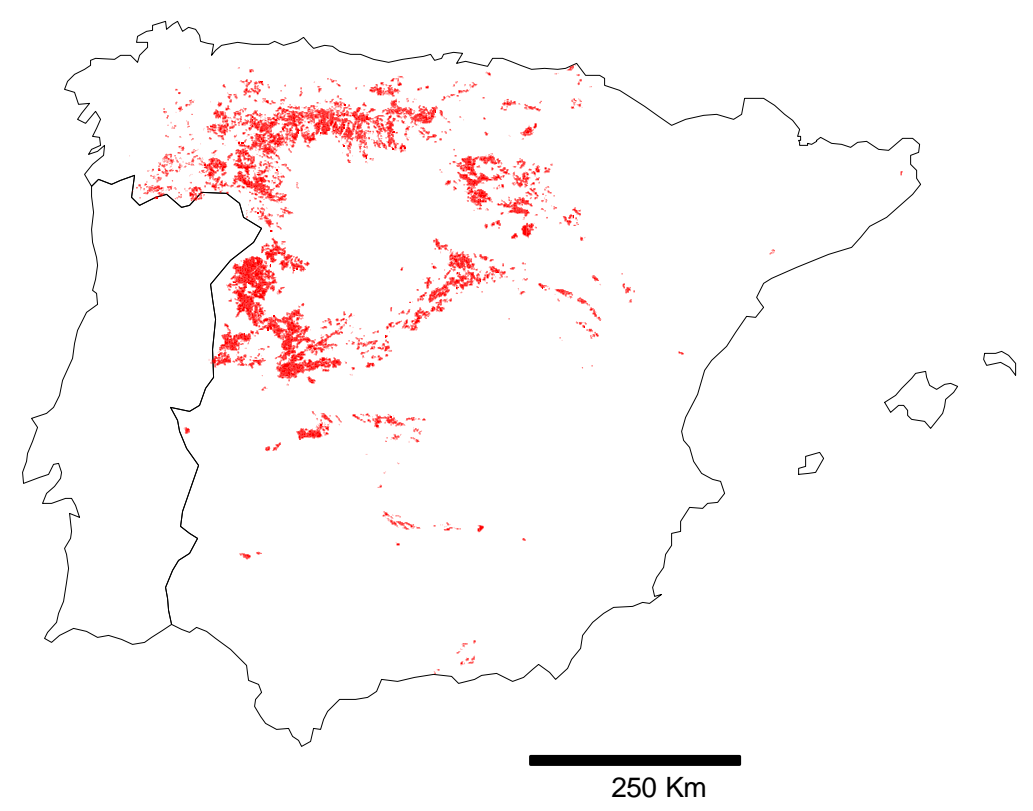

Figura 1.1. Distribución de los robledales de Quercus pyrenaica en la Península Iberica. Elaboración propia a partir de los datos del tercer inventario forestal nacional

\footnotetext{
${ }^{1}$ En este trabajo nos referiremos a esta formación como melojares o robledales indistintamente.
} 
Actualmente los bosques de robledal en Sierra Nevada se consideran relictos (Melendo \& Valle, 1996) con un estado avanzado de degradación (Camacho-Olmedo et al. 2002). El hecho de que se encuentren en el límite mas meridional de distribución natural de la especie y que sea una formación forestal que ha estado sometida a grandes presiones en las últimas décadas, sitúa a estas formaciones en un estado de debilitamiento general, debido a su fragilidad y al carácter único de sus comunidades. Este panorama no es alentador, si además tenemos en cuenta que las simulaciones de cambio climático para Sierra Nevada indican un aumento medio de la temperatura de $+4.8{ }^{\circ} \mathrm{C}\left(2.3-7.0{ }^{\circ} \mathrm{C}\right.$ ) para final del siglo XXI (Benito 2009; Benito et al. 2011) y algunos estudios indican que el robledal puede sufrir una disminución de su área de ocupación asi como una migración altitudinal (Benito 2008; Benito et al. 2011).

La realización de actuaciones que permitan la recuperación y conservación de estos ecosistemas forestales ha sido demandada por parte de diversos frentes (Entroncasi et al. 2004, Gavilán et al. 2007) y mas especialmente las poblaciones Béticas y del Norte de África, debido a su composición y estructura, y al cortejo de especies raras, endémicas y/o amenazadas que albergan los robledales (Lorite et al.. 2008). Un aspecto importante para diseñar herramientas que permitan la recuperación y conservación de los robledales, así como las actuaciones de gestión adaptativa frente al cambio global, es reducir la incertidumbre, para lo cual se necesita ámplio conocimiento del funcionamiento a todos los niveles (composición, estructura, dinámica, óptimos ecológicos, etc.) de estos ecosistemas.

En este trabajo nos centramos en la caracterización ambiental y forestal de los diferentes núcleos de Quercus pyrenaica existentes en Sierra Nevada, utilizando para ello datos de variables ambientales de alta resolución asi como atributos forestales derivados del inventario forestal realizado en el Espacio Natural de Sierra Nevada.

\subsection{Revisión de trabajos relacionados.}

Los melojares ibéricos han sido ampliamente estudiados desde el punto de vista de la composición de especies presentes en ellos, existiendo numerosos trabajos fitosociológicos ${ }^{2}$ (ver revisiones de Entroncasi et al. 2004; Gavilán et al. 2007; Lorite et al. 2008). Existen varios trabajos de síntesis a escala nacional (Entrocassi et al. 2004; Lorite et al. 2008), a nivel de provincia biogeográfica (Martínez-Parras \& Molero 1982) y a nivel de Sierra Nevada (Melendo \& Valle 1996). En líneas generales estos trabajos ofrecen una caracterización de los robledales desde un punto de vista fitosociológico, llevando a cabo clasificaciones en base exclusivamente de la composición y abundancia de especies. Estos análisis de similtud, realizados a diferentes escalas geográficas, han permitido establecer diferencias dentro de esta formación forestal, y como resultado de ellos se han llevado a cabo clasificaciones de los robledales.

\footnotetext{
${ }^{2}$ La fitosociología es un método de estudio de las comunidades vegetales, que utilizando una metodología particular (inventarios fitosociológicos), pretende reconocerlas e interpretarlas, así como incluirlas dentro de un esquema de clasificación jerárquica.
} 
Respecto a las condiciones ambientales, existen muchos trabajos han aportado algunas de las condiciones ecológicas sobre las que se desarrollan los melojares ibéricos, como por ejemplo el trabajo de Costa et al. (2005) para la Península Ibérica, y mas a escala regional el trabajo de Navarro-Cerrillo et al. (2003). García \& Jiménez (2009) dentro del proyecto "Bases ecológicas preliminares para la conservación de los tipos de hábitat de interés comunitario en España", ofrece una revisión detallada de los trabajos relacionados con los robledales, aportando una sintesis sobre los principales requerimientos ecológicos de estas formaciones. A escala nacional se han llevado a cabo trabajos que han realizado una caracterización de los robledales atendiendo principalmente a parámetros climáticos (principalmente precipitación y temperatura) (Gavilán et al.. 2007; del Río et al. 2007). En ellos se han relacionado la composición de especies de diferentes robledades ofrecidos por los inventarios fitosociológicos publicados hasta el momento con los parámetros climáticos aportados por las estaciones meteorológicas mas cercanas a dichos inventarios fitosociológicos. La aproximación realizada en estos trabajos ha sido analizar los vínculos entre las diferencias de los robledales (respecto a especies) y algunas variables ambientales. Aunque se trata de unos trabajos que han definido las principales principales características climáticas que explican los patrones de distribución fitogeográfica de esta formación a escala nacional, y que han obtenido las envueltas climáticas que mejor definen los tipos de vegetación de los robledales ibéricos, resultan insuficientes para la caracterización ambiental detallada de poblaciones de una zona concreta, como es nuestro caso. Igualmente las variables ambientales analizadas se refieren a la estación meteorológica mas cercana a cada inventario fitosociológico, no pudiendo ser estos datos utilizados para una caracterización con un mayor nivel de detalle.

Con una escala de mayor resolución se han realizado estudios de caracterización forestal, ambiental y/o ecológica de los robledales en diversas zonas de la Península Ibérica, como por ejemplo en los robledales de Galicia (Grandas, 1997; Grandas et al. 1997; Díaz-Maroto et al. 2006; 2007), en el Sistema Central (Gavilán \& FernándezGonzález, 1997), y en algunos parques naturales andaluces: Sierra de Aracena y Picos de Aroche, (Castillo-Marín \& Castillo-Marín, 2010), Parque Natural de la Sierra Norte de Sevilla (Castillo-Marín \& Castillo-Marín, 2006), entre otros. Por otro lado, existen estudios sobre las características de las regiones de procedencia de Quercus pyrenaica empleados en tareas de reforestación, tanto a nivel nacional (Jiménez et al. 1998; Martín-Albertos et al. 1998) como regional (López del Hierro et al. 2001). Aquellos no están referidos a las poblaciones de robledales de Sierra Nevada y en estos últimos estudios, aunque se analizan algunas de las poblaciones conocidas de los melojares nevadenses, el nivel de detalle que presenta respecto de las características ambientales analizadas, resulta insuficiente para un análisis en detalle de diferencias entres las poblaciones presentes en Sierra Nevada.

Desde el punto de vista ecológico, en Sierra Nevada se han realizado numerosos estudios en los que se han analizado de forma puntual diferentes aspectos de la ecología de Quercus pyrenaica: análisis de los factores abióticos que afectan al establecimiento de semillas (Baraza et al. 2004); utilización de plantas nodrizas para la restauración de robledales (Castro et al. 2006); estudios de reclutamiento de juveniles bajo diferentes tratamientos de contenido hídrico (Mendoza et al. 2009); efectos de la herviboría (Baraza et al. 2010; Gómez et al. 2003); efectos de la heterogeneidad ambiental generada por plantas nodriza sobre el crecimiento y la supervivencia de Q. pyrenaica (Gómez-Aparicio et al. 2005); respuestas de los juveniles a diferentes tratamientos de 
luz (Gómez-Aparicio et al. 2008); factores que afectan al tamaño de la semilla (Quero et al. 2007), etc. Todos estos estudios se refieren a aspectos concretos ecológicos y se han llevado a cabo en algunas poblaciones de los robledales de Sierra Nevada, y aunque aportan un gran conocimiento en detalle de la ecología de esta especie, no analizan las diferencias entre las diferentes poblaciones de Sierra Nevada.

\subsection{Aportaciones}

Como hemos visto en el apartado anterior los estudios relacionados con los robledales no están exclusivamente enfocados en las poblaciones de Sierra Nevada. Por otro lado, no existen trabajos con la escala de trabajo suficiente para poder caracterizar los distintos nucleos poblacionales y poder establecer las posibles diferencias entre ellos. Por todo ello con el presente trabajo pretendemos realizar una caracterizción ambiental de las poblaciones de robledal de Sierra Nevada, cuyas principales aportaciones son:

- Caracterización de las poblaciones basadas en variables ambientales de alta resolución, principalmente topográficas y climáticas.

- Identificación de los patrones ambientales que diferencian entre las poblaciones de robledal presentes en Sierra Nevada.

- Diferenciación entre grupos de poblaciones debido a características ambientales y forestales.

Con ello este trabajo sirve como análisis preliminar que permite optimizar esfuerzos a la hora de realizar estudios específicos sobre diferentes aspectos relacionados con el cambio global, ya que identifica los diferentes grupos de poblaciones de un ecosistema sensible y de alta fragilidad como son los robledales, en una región montañosa, que como se comentó anteriormente son considerados lugares de alerta temprana de los efectos del cambio global.

Por otro lado esta caracterización aporta mas conocimiento científico útil a la hora de planear actuaciones de conservación y restauración, así como de gestión y manejo de los robledales, con lo que se añade una entrada mas para los Sistemas de Ayuda a la Toma de Decisiones utilizados por los responsables de la gestión de los recursos naturales. 


\subsection{Objetivos}

El objetivo principal del presente trabajo es la caracterización ambiental de los melojares nevadenses. Se pretende estudiar el comportamiento de los diferentes núcleos existentes en Sierra Nevada respecto a diferentes variables ambientales (climáticas, topográficas, etc.) y forestales. Mediante diferentes técnicas estadísticas ${ }^{3}$ se pretende: (i) caracterizar los robledales nevadenses respecto a varaiables ambientales y forestales; para por un lado, (ii) analizar si existe un patrón de comportamiento diferente entre los diferentes núcleos de robledal en Sierra Nevada; y (iii) establecer cuales son los parámetros ambientales mas importantes que definen dicho patrón de comportamiento. Mas concretamente los objetivos de este trabajo son:

- Establecer los valores de las ambientales que definen el hábitat óptimo y marginal de las poblaciones en Sierra Nevada.

- Identificar las variables ambientales que explican la distribución de los robledales en Sierra Nevada.

- Una vez identificadas las variables ambientales que concidionan la distribución de los robledales, nos interesa conocer si existen diferentes grupos de comportamiento determinados por variables ambientales. Intentaremos responder a la pregunta ¿que variables ambientales o que combinación de variables ambientales discriminan mejor entre las poblaciones de robledal de Sierra Nevada?

- Analizar si la discriminación en diferentes grupos debido a características ambientales se refleja en una discriminación basada en la composición de especies de las diferentes poblaciones

- Analizar si existen diferencias entre los grupos de comportamiento detectados respecto a las variables ambientales y forestales.

\footnotetext{
${ }^{3}$ ver apartado de metodologías
} 


\section{Capítulo 2}

\section{Metodologías}

\subsection{Zona de estudio.}

La zona de estudio elegida para el presente trabajo es el espacio natural de Sierra Nevada, situado entre las provincias de Granada y Almería (Figura 2.1). Se trata de un área montañosa con una extensión de 170.000 Has. Se considera uno de los centros de diversidad mas importantes de la Región Mediterránea (Blanca et al. 1998). Alberga mas de 2100 especies de plantas vasculares (Blanca et al. 2001), representando el $25 \%$ de la flora española y el $20 \%$ de la europea, y cuenta con cerca de 80 endemismos (Lorite et al. 2007), lo que lo convierte en uno de los hotspot de diversidad vegetal mas importantes de la cuenca Mediterránea. Es un área donde destaca el gradiente altitudinal ( $800-3482 \mathrm{~m}$ ) y el gradiente de temperatura. La temperatura media anual oscila entre 12-16 ${ }^{\circ} \mathrm{C}$ por debajo de los $1500 \mathrm{~m}$ de altitud hasta $0{ }^{\circ} \mathrm{C}$ por encima de $3000 \mathrm{~m}$. La precipitación media anual varía desde valores inferiores a $350 \mathrm{~mm}$ en algunas zonas basales, hasta más de los $700 \mathrm{~mm}$ en los picos. En verano la precipitación es casi inexistente y en invierno se produce en forma de nieve por encima de los 2000 m de altitud. El alto valor de biodiversidad y geodiversidad, así como su riquerza paisajística y cultural han hecho que Sierra Nevada presente varios reconocimientos y cuente con diversas figuras legales de protección. Además de contar con un Parque Nacional y un Parque Natural, Sierra Nevada es una Reserva de la Biosfera (MaB, Unesco). Está incluida en la red Natura 2000 como Zona de Especial Protección para las Aves y Lugar de Interes Comunitario (LIC). 


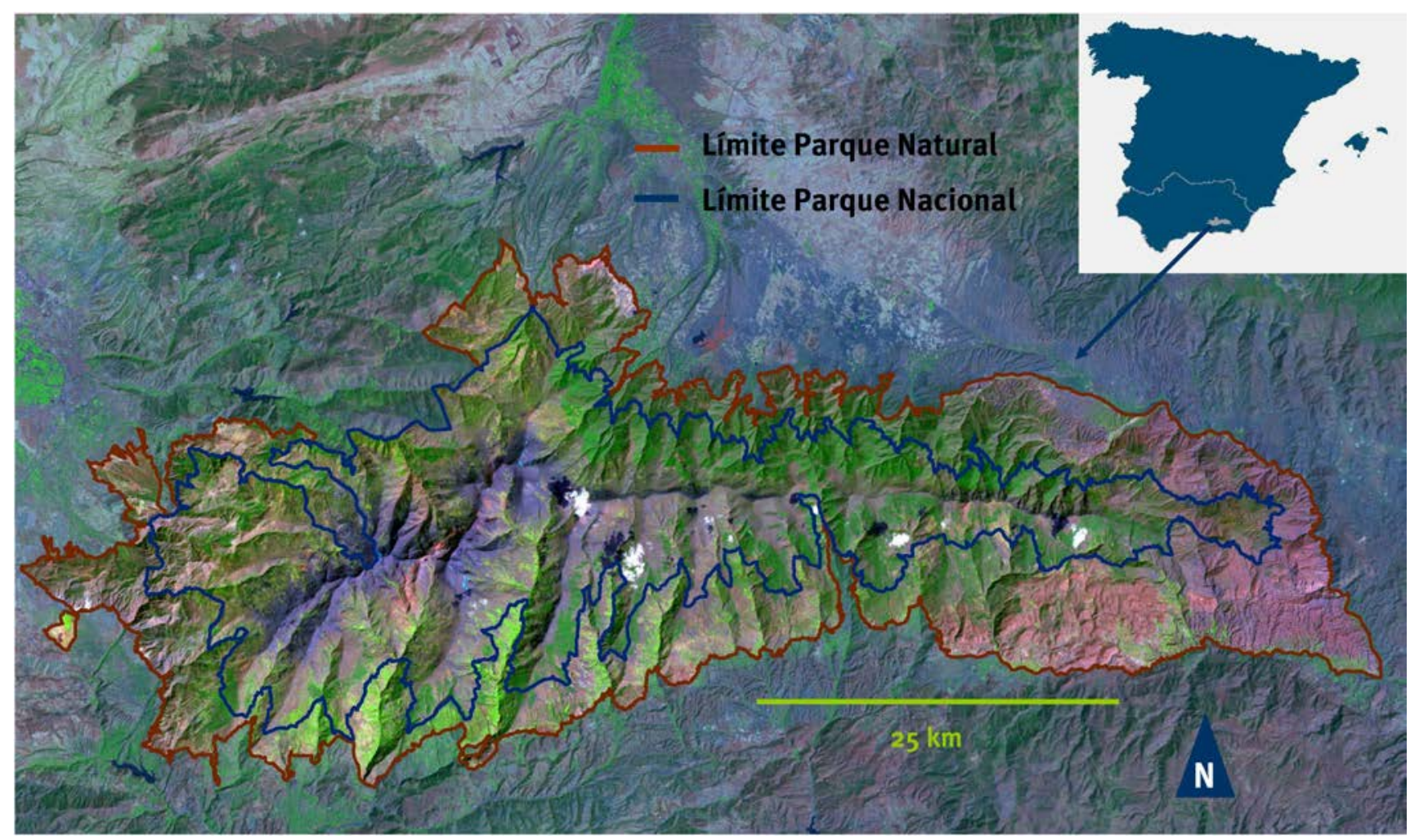

Figura 2.1. Localización de la zona de estudio.

\subsection{Robledales de Quercus pyrenaica.}

Las poblaciones objeto de estudio en este trabajo son las poblaciones de Quercus pyrenaica en el espacio natural de Sierra Nevada. Para su delimitación se ha utilizado como fuente de información básica el mapa digital de vegetación a escala de detalle 1:10.000 de Sierra Nevada (Molero Mesa et al. 2001). A partir de éste, apoyándonos en diversas fuentes bibliográficas y en el mapa digital de ecosistemas desarrollado por el Observatorio de Cambio Global en Sierra Nevada ${ }^{1}$ se han delimitado las formaciones puras de robledal. Para ello se ha integrado toda la información en un Sistema de Información Geográfica (SIG) (ArcView Gis 9.2; ESRI Inc., Redlands, California, USA) y se han realizado diferentes consultas en la base de datos espacial creada (geodatabase) agrupando aquellos polígonos que contenían la formación robledal o que presentaban como especie arbórea dominante a Quercus pyrenaica. Una vez obtenida esta primera capa, se ha comprobado la delimitación de esta formación vegetal mediante técnicas de fotointrepretación en detalle (Navarro-González, 2010; Navarro-González \& Bonet, 2010), para lo cual se ha utilizado la ortofotografía digital del año 2001 a escala 1:20.000, en Blanco/Negro y resolución espacial de 0.5 metros (Junta de Andalucía, 2004), así como la ortofotografía digital del año 2004/05, a escala 1:20.000, en falso color (IRGB) y resolución espacial de 1 metro (Junta de Andalucía, 2005b), para la corrección de errores.

\footnotetext{
${ }^{1}$ Mapa digital de Ecosistemas de Sierra Nevada. Elaborado por Pérez-Luque, A.J. \& Bonet-García, F.J. Disponible en Linaria: Sistema de Información del Observatorio de Cambio Global de Sierra Nevada. http://dev. iecolab. es/linaria/.
} 
Las poblaciones de robledales puros obtenidas se muestran en la figura 2.2. Como se puede observar, estas poblaciones $^{2}$ se sitúan rodeando la porción occidental de Sierra Nevada. Se localizan en un rango de altitud que varía entre los 1189 hasta los $2035 \mathrm{~m}$. A grandes rasgos podemos diferenciar aquellas que se presentan en la cara norte de Sierra Nevada (poblaciones 1 al 5) de las situadas en la vertiente sur (poblaciones 6 a 8).

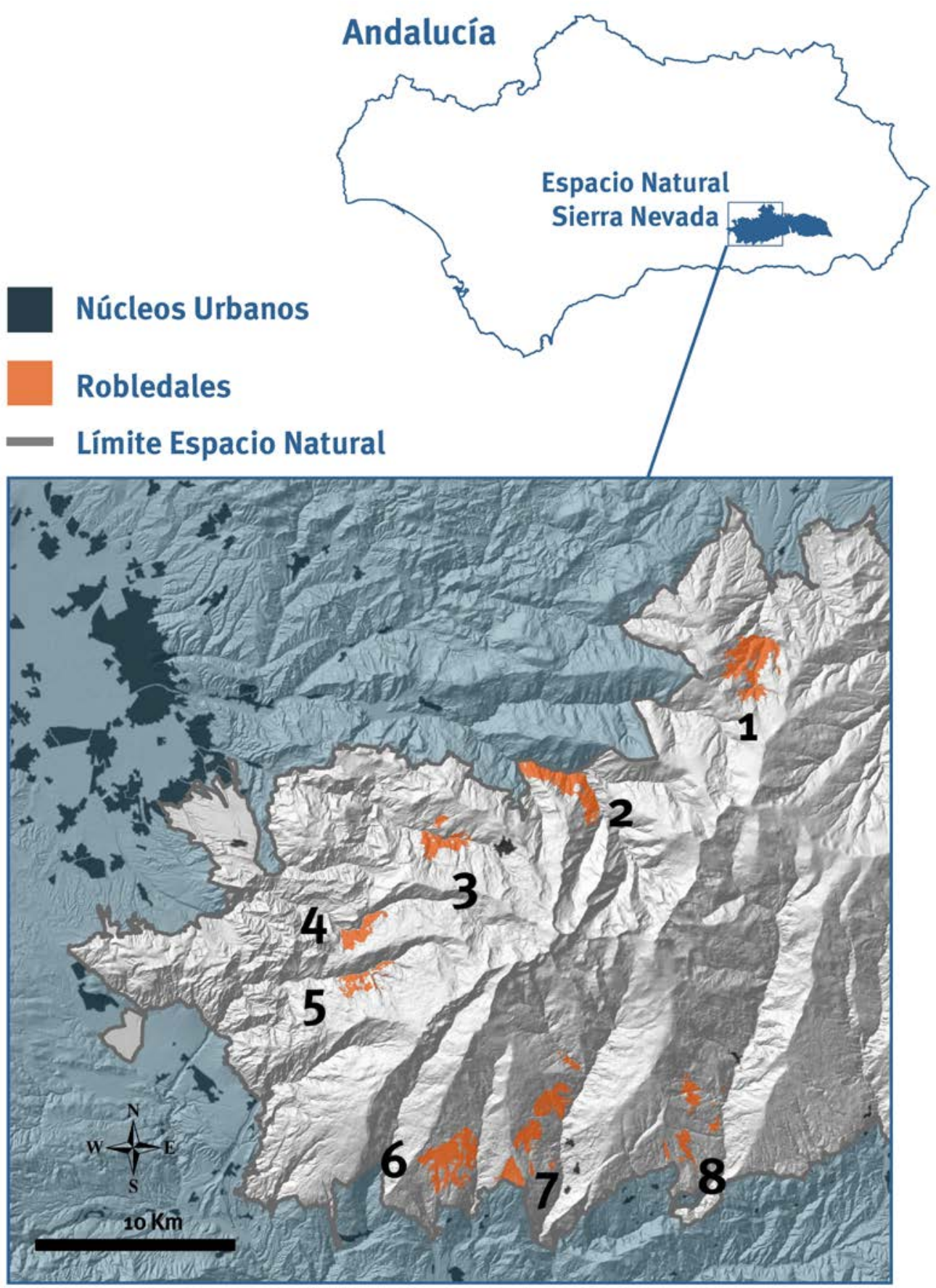

Figura 2.2. Mapa de distribución de las poblaciones de robledales en Sierra Nevada.

\footnotetext{
${ }^{2}$ Para facilitar el trabajo con ellas se ha procedido a numerarlas del 1 a 8 (ver tabla 2.1)
} 


\begin{tabular}{|c|c|c|c|c|c|c|}
\hline Población & Localidad & Coordenadas & Valle & Municipio & Área (Has) & Altitud \\
\hline \multirow[t]{2}{*}{1} & El Camarate & $3^{\circ} 15^{\prime} 24.33^{\prime \prime} \mathrm{W}$ & Río Alhama & Lugros & 457.15 & $1740(1441-2026)$ \\
\hline & & $37^{\circ} 10^{\prime} 29.49^{\prime \prime} \mathrm{N}$ & & & & \\
\hline \multirow[t]{2}{*}{2} & Loma del Muerto & $3^{\circ} 21^{\prime} 54.60^{\prime \prime} \mathrm{W}$ & Río Genil & Güejar-Sierra & 395.00 & 1519 (1189-1899) \\
\hline & & $37^{\circ} 7^{\prime} 29.63^{\prime \prime} \mathrm{N}$ & & & & \\
\hline \multirow[t]{2}{*}{3} & Loma de la Perdiz & $3^{\circ} 25^{\prime} 46.65^{\prime \prime} \mathrm{W}$ & Río Monachil & Monachil & 204.55 & $1780(1564-1990)$ \\
\hline & & $37^{\circ} 5^{\prime} 54.87^{\prime \prime} \mathrm{N}$ & & & & \\
\hline \multirow[t]{2}{*}{4} & Puntal de los Mecheros & $3^{\circ} 28^{\prime} 29.07^{\prime \prime} \mathrm{W}$ & Río Dílar & Dílar & 154.07 & $1764(1478-1960)$ \\
\hline & & $37^{\circ} 3^{\prime} 33.61^{\prime \prime} \mathrm{N}$ & & & & \\
\hline \multirow[t]{2}{*}{5} & Loma de Enmedio & $3^{\circ} 28^{\prime} 38.44^{\prime \prime} \mathrm{W}$ & Río Durcal & Dúrcal & 137.03 & $1824(1530-2035)$ \\
\hline & & $37^{\circ} 1^{\prime} 58.75^{\prime \prime} \mathrm{N}$ & & & & \\
\hline \multirow[t]{2}{*}{6} & El Robledal de Cañar & $3^{\circ} 25^{\prime} 57.10^{\prime \prime} \mathrm{W}$ & Río Chico & Cañar & 436.20 & $1687(1366-1935)$ \\
\hline & & $36^{0} 57^{\prime} 28.04^{\prime \prime} \mathrm{N}$ & & & & \\
\hline \multirow[t]{3}{*}{7} & Loma de las Matanzas y & $3^{\circ} 22^{\prime} 55.12^{\prime \prime} \mathrm{W}$ & Rio Poqueria & Soportújar, & 458.95 & $1740(1214-1981)$ \\
\hline & Loma de Ramón & $36^{\circ} 57^{\prime} 58.90^{\prime \prime} \mathrm{N}$ & & Pampaneira, & & \\
\hline & & & & Bubión, Capileira & & \\
\hline \multirow[t]{2}{*}{8} & Loma de los Lores & $3^{\circ} 17^{\prime} 25.75^{\prime \prime} \mathrm{W}$ & Río Trevelez & Pórtugos, & 197.91 & $1692(1312-1963)$ \\
\hline & & $36^{\circ} 58^{\prime} 37.38^{\prime \prime} \mathrm{N}$ & & Busquístar & & \\
\hline
\end{tabular}

Tabla 2.1. Poblaciones de roble en el espacio natural de Sierra Nevada.

Las coordenas se refieren al centroide del polígono. Para la altitud se ofrecen los valores medios (mínimo-máximo)

\subsection{Conjunto de datos.}

En el presente trabajo hemos utilizado un conjunto de datos procedentes de diversas fuentes de información. Funcionalmente agrupamos estos datos en: datos forestales procedentes del inventario forestal y datos ambientales que proceden de otras fuentes.

\subsubsection{Datos del inventario forestal.}

El subconjunto de datos forestales proceden del Inventario Forestal del Parque Nacional de Sierra Nevada ${ }^{3}$ llevado a cabo en 2004-2005 (MMA, 2005), consistente en 600 parcelas permanentes distribuidas entre las masas

\footnotetext{
${ }^{3}$ Agradezco al Dr. Francisco J. Bonet García el que me proporcionara la base de datos correspondiente al inventario forestal así como su ayuda en el cálculo de muchos de los atributos forestales utilizados para el presente trabajo.
} 
forestales mas importantes del espacio natural. En cada parcela (20 x $20 \mathrm{~m}$ ) se anotaban todas las especies arbóreas con diámetro a la altura del pecho $(d b h)^{4}$ superior a $7.5 \mathrm{~cm}$, indicándo la especie y el $d b h$. Dentro de cada parcela se establecieron además dos subparcelas, una de $5 \mathrm{~m}$ de radio $\left(78.5 \mathrm{~m}^{2}\right.$ de área) para la estimación de juveniles ${ }^{5}$ y plántulas ${ }^{6}$, y otra subparcela de $10 \mathrm{~m}$ de radio $\left(314 \mathrm{~m}^{2}\right.$ de área $)$ donde se estimaron la composición y abundancia de especies herbáceas y arbustivas utilizando la escala de cobertura-abundancia de Braun-Blanquet (Westhoff \& Van der Maarel, 1978) .

Todas las parcelas de este inventario forestal están categorizadas de acuerdo a la formación vegetal a la que pertenecían: pinares de repoblación, encinares, bosques caducifolios, y otras. Para el presente trabajo se seleccionaron aquellas pertenecientes a la categoría "bosques caducifolios" que se encontraban dentro de la distribución espacial de las formaciones de robledales utilizada en el apartado anterior. Además se incluyeron algunas parcelas, que aún no estando consideradas como pertenecientes a "bosques caducifolios", se ha observado mediante fotointerpretación que están dentro de robledales y que no pertenecen a las categorías pinares de repoblación y encinares. En total en el presente trabajo se han utilizado 32 parcelas.

La caracterización de los ecosistemas en base a su composición de especies, a pesar de ser una aproximación muy utilizada, ignora los procesos ecológicos subyacentes (Noss, 1990). Es por ello que se han llevado a cabo aproximaciones en las que para la descripción de los ecosistemas forestales se utiliza, además de la composición, otros atributos relacionados con la estructura y la función del ecosistema (McElhinny et al. 2005). En este estudio hemos seleccionado un conjunto de atributos, extraidos del inventario forestal, relacionados con tres aspectos del ecosistema: estructura, función y composición. El primero de ellos se refiere a la disposición espacial de varios de los componentes del ecosistema, y en nuestro caso está representado por variables como la cobertura de la masa forestal, la altura, densidad de pies arbóreos, entre otros (ver tabla 2.2). La función está referida a los proceos ecológicos que ocurren en el ecosistema y al ritmo o tasa a los que operan. Para el presente estudio hemos seleccionado los procesos de regeneración de la masa forestal. Por último la composición alude a la variedad de elementos, para lo cual se utilizan variables como la riqueza de especies y el índice de diversidad de Shannon-Wiener. Así se han seleccionado un total de 14 variables (tabla 2.2) que nos permitan analizar las diferencias entre las poblaciones de robledal en Sierra Nevada en términos de estructura, composición y función.

\footnotetext{
${ }^{4}$ del inglés, "diameter at breast height", diámetro del tronco de un árbol en pie a la altura de 1.30 metros sobre la superficie del terreno (SECF, 2005). Se trara de una de las principales medidas para la caracterización de las especies arbóreas en los inventarios forestales.

${ }^{5}$ Se consideran juveniles aquellos individuos con un $d b h$ entre 2.5 y $7.5 \mathrm{~cm}$

${ }^{6}$ individuos con $d b h<2.5 \mathrm{~cm}$ y altura $<1.3 \mathrm{~m}$.
} 


\begin{tabular}{|c|c|c|c|c|}
\hline & Variable & & Descripción & Unidades \\
\hline \multirow[t]{9}{*}{ Estructura } & $\begin{array}{l}\text { Fracción de Cabida Cubierta } \\
\text { (FCC) Total }\end{array}$ & $f c c T o t$ & $\begin{array}{l}\text { Superficie de la parcela cubierta por la } \\
\text { proyección vertical de todas las copas }\end{array}$ & $\begin{array}{c}\% \\
0: 0-9 \% \\
1: 10-19 \%\end{array}$ \\
\hline & FCC de especies arbóreas & fccTree & $\begin{array}{c}\text { Superficie de la parcela cubierta por la } \\
\text { proyección vertical de las copas de las especies } \\
\text { arbóreas }\end{array}$ & $\begin{array}{c}2: 20-29 \% \\
\text { 3: } 30-39 \% 4: \\
40-49 \%\end{array}$ \\
\hline & FCC de especies arbustivas & fccShr & $\begin{array}{c}\text { Superficie de la parcela cubierta por la } \\
\text { proyección vertical de las copas de las especies } \\
\text { arbustivas }\end{array}$ & $\begin{array}{c}5: 50-59 \% \\
6: 60-69 \% 7: \\
70-79 \%\end{array}$ \\
\hline & FCC de especies herbáceas & fccHer & $\begin{array}{l}\text { Superficie de la parcela cubierta por la } \\
\text { proyección vertical de especies herbáceas }\end{array}$ & $\begin{array}{l}8: 80-89 \% \\
9: 90-99 \% \\
10: 100 \%\end{array}$ \\
\hline & Diversidad estructural & shaEst & $\begin{array}{c}\text { Índice de Shannon para los estratos. } \\
H^{\prime}=-\sum_{i=1}^{n} p_{i} \cdot \ln p_{i} \text { donde } \\
p_{i}=\frac{c o b_{i}}{\sum_{\text {cubierta }} \text { ( } F C C \text { ) del estrato } i} \operatorname{cob}_{i}=\text { Fracción de cabida } \\
\sum \text { cob }=\text { Sumatorio de la FCC de todos los } \\
\text { estratos }\end{array}$ & \\
\hline & Altura media & heiTre & $\begin{array}{c}\text { Altura media de los pies mayores de las } \\
\text { especies arbóreas de la parcela }\end{array}$ & metros \\
\hline & Densidad de pies mayores & denTre & Densidad de pies mayores por hectárea & ind. $\cdot \mathrm{Ha}^{-1}$ \\
\hline & Área basal & $a b a Q p$ & $\begin{array}{c}\text { Suma del área basimétrica (superficie de la } \\
\text { sección del tronco a } 1.30 \mathrm{~m} \text {. de altura) de los } \\
\text { pies mayores de Quercus pyrenaica }\end{array}$ & $\mathrm{m}^{2} \cdot \mathrm{Ha}^{-1}$ \\
\hline & Volumen & volQp & $\begin{array}{l}\text { Suma del volumen de los pies mayores de } \\
\text { Quercus pyrenaica }\end{array}$ & $\mathrm{m}^{3} \cdot \mathrm{Ha}^{-1}$ \\
\hline \multirow[t]{2}{*}{ Composición } & Índice de Shannon-Weiner & shaSp & $\begin{array}{c}\text { Índice de diversidad de especies de } \\
\text { Shannon-Weiner } H^{\prime}=-\sum_{i=1}^{n} p_{i} \cdot \ln p_{i} \\
\text { siendo } p_{i}=\text { abundancia relativa de la especie } i\end{array}$ & \\
\hline & Riqueza & rich & Número total de especies vegetales presentes & $\mathrm{n}^{\mathrm{Q}}$ de especies \\
\hline \multirow[t]{3}{*}{ Función } & Regenerado total & regTot & Suma de las plántulas de todas las especies & $\mathrm{n}^{0}$ de plántulas \\
\hline & $\begin{array}{l}\text { Regenerado de Quercus } \\
\text { pyrenaica }\end{array}$ & $\operatorname{sed} Q p$ & Número de plántulas de Quercus pyrenaica & $\mathrm{n}^{\underline{0}}$ de plántulas \\
\hline & Regenerado de Quercus ilex & sedQi & Número de plántulas de Quercus pyrenaica & $\mathrm{n}^{0}$ de plántulas \\
\hline
\end{tabular}

Tabla 2.2. Variables forestales para las poblaciones de Quercus pyrenaica en Sierra Nevada.

Como hemos visto mas arriba, dentro de cada parcela, se analizó la composición y abundancia de especies, en subparcelas de $10 \mathrm{~m}$. de radio. De tal forma que para las parcelas seleccionadas en este trabajo hemos obtenido otra matriz de datos con las especies presentes y su abundancia. Las especies encontradas en todas las parcelas asi como la abreviatura utilizada para un mejor manejo de los datos se puede ver en la Tabla I.1 del Anexo I.

\subsubsection{Datos de variables ambientales.}

Las diferentes variables de datos ambientales ${ }^{7}$ utilizadas en el presente trabajo proceden del procesamiento de diferentes conjuntos de datos para Sierra Nevada. De forma genérica las variables ambientales se han obtenido

\footnotetext{
${ }^{7}$ La mayor parte de la información ambiental utilizada en este trabajo ha sido derivada de la información ambiental generada para Sierra Nevada por el Dr. Blas M. Benito de Pando, al cual agradezco enormemente que me los haya proporcionado, así como su disponibilidad y ayuda.
} 
procesando los datos de partida en GRASS GIS ${ }^{8}$ (Neteler \& Mitasova, 2007), mediante la aplicación de diferentes módulos de cálculo (Benito, 2009) . De esta forma se han generado mapas de variables ambientales de los cuales se han extraido los valores para las poblaciones de robledales de Sierra Nevada. Hemos utilizado un conjunto de variables (tabla 2.3) que se pueden agrupar en función del grupo temático del que informan: topográficas, hidrográficas, climáticas, de distancia e influencia antrópica.

Para la obtención de las variables relacionadas con la topografía se utilizó el modelo digital de elevaciones de 10 m de resolución espacial (Junta de Andalucía, 2005a) y mediante la utilización de los módulos r.param.scale, r.sun y r.slope.aspect en GRASS, se han obtenido las siguientes variables topográficas:

- elevación

- pendiente

- relacionadas con la orientación: orientación y gradientes de orientación Este-Oeste y Sur-Norte.

- relacionadas con la radiación: radiación solar directa anual y por estaciones; y cantidad de horas de sol anual y por estaciones

- Exposición topográfica

En la obtención de variables relacionadas con la hidrografía se ha utilizado el modelo digital de elevaciones (Junta de Andalucía, 2005a) y se ha calculado, utilizando el módulo r.terraflow de GRASS, el índice topográfico de humedad y el índice de acumulación de sedimentos, que nos informan del comportamiento hidrológico del territorio discriminando entre áreas que reciben y dan sedimentos. Están directamente relacionados con la profundidad del suelo y con la disponibilidad de agua (Moore et al. 1993)

Para el cálculo de la variable de influencia antrópica se han llevado a cabo análisis de vecindad en un radio de 2000 metros desde las poblaciones de robledal. En este análisis, mediante el módulo r.neighbors de GRASS, se ha calculado la frecuencia de diferentes infraestructuras antrópicas: carreteras, equipamientos públicos de los Espacios Naturales, núcleos de población, senderos y acequias. Para todas estas capas, obtenidas a partir de los datos publicados por la Red de Información Ambiental de Andalucía (REDIAM) ${ }^{10}$, se ha calculado su frecuencia (número de celdas ocupadas) en el radio de 2000 metros desde los robledales. Seguidamente se han agrupado creando un índice de intervención humana calculado como el valor máximo de celdas ocupadas de todas las capas anteriores, de forma que a mayor valor de dicho índice mayor influencia antrópica.

\footnotetext{
${ }^{8}$ Sistema de Información Geográfica - Geographic Resources Analysis Support System http://grass.itc.it

${ }^{9}$ Metodología detallada del procesamiento de la información en Benito (2009) o el material del mismo autor disponible en http://ide.ugr.es/blasbenito/tesis/

${ }^{10} \mathrm{http}: / /$ www.juntadeandalucia.es/medioambiente/site/rediam
} 
Se ha computado como variable de distancia, la distancia lineal al mar mediterráneo, para lo cual se ha utilizado el modelo digital de elevaciones (Junta de Andalucía, 2005a) y se han obtenido para cada punto de las poblaciones de robledal, la distancia mínima lineal en línea recta al mar mediterráneo.

En la obtención de las variables climáticas se han utilizado los mapas de clima pasado de alta resolución para Sierra Nevada, desarrollados por el Observatorio de Cambio Global de Sierra Nevada ${ }^{11}$, con una resolución de 100 metros. En su elaboración se han utilizado los datos de la serie histórica de los registros climáticos de la red de estaciones meteorológicas existentes en Sierra Nevada, y mediante aplicación de técnicas downscaling y de métodos de regresión múltiple con correción residual (Ninyerola et al. 2000) se han generado mapas climáticos de detalle. A partir de ellos se han obtenido los valores de tres variables climáticas:

- precipitación: precipitación media acumulada anual y media de las precipitaciones acumuladas de verano, otoño, invierno y primavera

- temperatura mínima: promedio histórico estacional (verano, otoño, invierno y primavera) de las medias de las temperaturas mínimas diarias

- temperatura máxima: promedio histórico estacional (verano, otoño, invierno y primavera) de las medias de las temperaturas máximas diarias

\footnotetext{
${ }^{11}$ Mapas de clima pasado. Elaborados por Benito, B.; Reyes-Muñoz, P.S \& Pérez-Pérez, R. Disponibles en Linaria: Sistema de Información del Observatorio de Cambio Global de Sierra Nevada. http://dev. iecolab. es/linaria/clima/indice_mapas_ pasados. Mas información en http://iecolab.es/node/43 y en http://iecolab.es/node/51. Agradezo a P. S. Reyes el esfuerzo en la preparación de los datos.
} 


\begin{tabular}{|c|c|c|c|c|}
\hline & Variable & & Descripción & $\begin{array}{c}\text { Tipo-Escala } \\
\text { (unidades) }\end{array}$ \\
\hline \multirow[t]{14}{*}{ Topográficas } & Elevación & tp_elev & Elevación & metros \\
\hline & Pendiente & $t p \_p e n d$ & Pendiente del terreno & grados \\
\hline & Orientación & $t p \_o r$ & Orientación & grados \\
\hline & Gradiente_ES_OE & tp_es_oe & Gradiente de orientación Este - Oeste & $\%$ \\
\hline & Gradiente_SU_NO & $t p \_s u_{-} n o$ & Gradiente de orientación Sur - Norte & $\%$ \\
\hline & Exposición topográfica & tp_expo_1000 & $\begin{array}{l}\text { Diferencia de elevación en un radio de } \\
\qquad 1000 \text { metros }\end{array}$ & metros \\
\hline & Radiación solar directa invierno & $t p \_r s d_{-} i$ & Radiación solar media de invierno & \multirow{4}{*}{$\frac{W h}{m^{2}} d i a$} \\
\hline & Radiación solar directa otoño & $t p_{-} r s d_{-} o$ & Radiación solar media de otoño & \\
\hline & Radiación solar directa primavera & $t p \_r s d_{-} p$ & Radiación solar media de primavera & \\
\hline & Radiación solar directa verano & $t p_{-} r s d_{-} v$ & Radiación solar media de verano & \\
\hline & Horas de sol invierno & $t p_{-} r s h_{-} i$ & Horas de sol medias en invierno & \multirow{4}{*}{ horas } \\
\hline & Horas de sol otoño & $t p_{-} r s h_{-} o$ & Horas de sol medias en otoño & \\
\hline & Horas de sol primavera & $t p_{-} r h_{-} p$ & Horas de sol medias en primavera & \\
\hline & Horas de sol verano & $t p_{-} r h_{-} v$ & Horas de sol medias en verano & \\
\hline \multirow[t]{2}{*}{ Hidrografícas } & Índice topográfico de humedad & hidro_tci & Índice topográfico de humedad & \\
\hline & $\begin{array}{l}\text { Índice de acumulación de } \\
\text { sedimentos }\end{array}$ & hidro_acum & Índice de acumulación de sedimentos & \\
\hline $\begin{array}{l}\text { Influencia } \\
\text { antrópica }\end{array}$ & Índice de intervención humana & hu_2000_max & $\begin{array}{l}\text { Número de celdas ocupadas por } \\
\text { infraestructuras humanas en un radio de } \\
2000 \text { m (ver texto para mas información) }\end{array}$ & $\mathrm{N}^{\mathrm{O}}$ de celdas \\
\hline Distancia & Distancia al mar & dis_mar & Distancia lineal al mar mediterráneo & kilómetros \\
\hline \multirow[t]{4}{*}{ Climáticas } & Precipitación anual & P_anual & $\begin{array}{c}\text { Precipitación media anual histórica (1960 } \\
-2010)\end{array}$ & $\mathrm{mm}$ \\
\hline & $\begin{array}{c}\text { Precipitación estacional (verano, } \\
\text { otoño, invierno y primavera) }\end{array}$ & $\begin{array}{l}\text { P_ver, } P_{-} \text {oto, } \\
\text { P_inv, } P_{-} \text {pri }\end{array}$ & $\begin{array}{c}\text { Promedio histórico (1960 - 2010) de la } \\
\text { precipitación acumulada estacional }\end{array}$ & $\mathrm{mm}$ \\
\hline & $\begin{array}{l}\text { Temperaturas medias mínimas } \\
\text { estacionales (verano, otoño, } \\
\text { invierno y primavera) }\end{array}$ & $\begin{array}{c}T \min V, \\
T \min O, T \min l \\
T \min P\end{array}$ & $\begin{array}{l}\text { Promedio histórico (1960 - 2010) para } \\
\text { cada estación de la media de las } \\
\text { temperaturas mínimas diarias }\end{array}$ & decígrados \\
\hline & $\begin{array}{l}\text { Temperaturas medias máximas } \\
\text { (verano, otoño, invierno y primavera }\end{array}$ & $\begin{array}{l}T \max V, T \max O \\
T \max , T \max P\end{array}$ & $\begin{array}{l}\text { Promedio histórico (1960 - 2010) para } \\
\text { cada estación de la media de las } \\
\text { temperaturas máximas diarias }\end{array}$ & decígrados \\
\hline
\end{tabular}

Tabla 2.3. Variables ambientales para las poblaciones de Quercus pyrenaica en Sierra Nevada. Se indica la categoría a la que pertenecen. Se incluye el nombre de la variable, un acrónimo, su descripción y las unidades en las que se mide.

\subsection{Análisis estadístico.}

Para llevar a cabo los diferentes análisis estadísticos partimos de diferentes matrices de datos. En cuanto a los datos bióticos-forestales tenemos por un lado, una matriz de atributos forestales $(32 \times 14)$ que contiene 
los valores de las variables forestales en las parcelas seleccionadas ${ }^{12}$, y por otro lado, una matriz de especies $(32 \times 110)$ relativa a la abundancia de diferentes especies en cada una de las parcelas ${ }^{13}$. Con respecto a los datos de variables ambientales contamos por un lado una matriz de datos ambientales $(2451 \times 31)$ referidos a las poblaciones de robledal y una matriz de datos ambientales para cada una de las parcelas en las que hemos medido atributos forestales, matriz ambiental puntual $(32 \times 31)^{14}$.

En primer lugar hemos realizado un análisis descriptivo univariante de las diferentes variables (ambientales y forestales) con objeto de aportar los valores mínimos, máximos y media (con el error estándar). Asimismo se ha calculado los percentiles 10 y 90 para cada una de éstas variables. Con estos valores hemos determinado las siguientes características: límite inferior (LI) como el valor mínimo del parámetro en todos los puntos de muestreo; umbral inferior (UI) como el percentil 10; valor medio (media \pm error estándar); umbral superior (US) correspondiente al percentil 90; y el límite superior $(L S)$, valor máximo. Esta aproximación, realizada en otros estudios similares (Díaz-Maroto et al. 2005; 2006; 2007) nos permite calcular los límites ecológicos (climáticos, topográficos, fisiográficos, forestales, etc.) y definir el hábitat de Quercus pyrenaica en Sierra Nevada atendiendo a los siguientes criterios (Gaines \& Denny, 1993): se considera hábitat óptimo, para un parámetro, el intervalo definido por los umbrales $(U S)$ e inferior $(U I)$; mientras que consideraremos los rangos que van desde el límite inferior $(L I)$ hasta el umbral inferior $(U I)$, y desde el umbral superior $(U S)$ hasta el límite superior $(L S)$ como el hábital marginal. El hábitat óptimo define las condiciones ambientales y forestales consideradas mas aptas para esta especie en Sierra Nevada, mientras que el hábitat marginal nos informa de los valores de los parámetros menos óptimos para la presencia de esta la misma. ${ }^{15}$

Con objeto de identificar las principales variables ambientales que explican la variabilidad de los robledales de Sierra Nevada realizamos un análisis de componentes principales (ACP) (Hotelling, 1933). Este método estadístico, que permite obtener patrones de las diferentes variables ambientales (Legendre \& Legendre, 2000) que explican la variabilidad de un conjunto de datos, ha sido ampliamente utilizado en estudios ecológicos. Permite reducir la dimensión de un conjunto de datos generando un reducido número de factores (componentes) que son combinaciones lineales de las variables originales. Se realizó un análisis exploratorio de los datos comprobó la idoneidad de los datos para la aplicación de este método multivariante. Debido a que las variables ambientales estaban en diferentes escalas de medida (figura II.1 Anexo 2) se llevó a cabo un escalamiento de los datos. Se analizó la matriz de correlaciones entre las variables ambientales, y aunque los valores de éstas no eran elevados (tabla II.1 Anexo 2; Figura II.3 Anexo 2) se comprobó que mas del $75 \%$ de las correlaciones eran significativas (r de Sperman ${ }^{16}$, p-valor < 0.01). Por otro lado se estudió la adecuación muestral de los datos mediante el estadístico de Kaiser-Meyer-Olkin, resultando en una adecuación muestral aceptable (KMO = 0.713831). Se realizaron diferentes análisis para determinar el número de comoponentes a retener (Peres-Neto et al 2003;

\footnotetext{
1214 variables forestales en 32 parcelas (pertenecientes a las ocho poblaciones de robledal)

${ }^{13}$ En total hemos encontrado 110 especies diferentes en las 32 parcelas (pertenecientes a las ocho poblaciones de robledal)

${ }^{14}$ Se trata de un subconjunto de la matriz anterior. Para ello se han asignado a cada parcela de muestreo forestal el dato ambiental más cercano

${ }^{15}$ Para una revisión de esta aproximación ver los trabjos de Díaz-Maroto et al. (2005; 2006; 2007) así como la biblografía referida en ellos.

${ }^{16}$ No se muestran los valores de la $r$ de Sperman.
} 
2005; Raiche \& Magis 2010) (figura II.2 Anexo II). Finalmente se fijaron valores mínimos de correlación entre las variables y las componentes seleccionadas $(>|0.7|)$.

Complementariamente se realizó un análisis discriminante, técnica multivariante frecuentemente utilizada en ecología (Legrende \& Legrende, 2000) con el objetivo de determinar las variables ambientales que mejor discriminen las poblaciones establecidas a priori, y para identificar diferentes grupos de poblaciones en función de las variables (o combinación de éstas) ambientales.

Una vez identificados los diferentes grupos de poblaciones se compararon las diferencias para cada variable ambiental y forestal entre estos grupos. Para ello, en primer lugar se asignó a cada población de robledal el grupo de pertenencia mostrado por el análisis discriminante. Posteriormente se analizó para cada variable y grupo si se cumplía la hipótesis de normalidad, para lo cual se utilizó es test de Shapiro-Wilk o el test de KolmogorovSmirnov (en función del tamaño de muestra). Asimismo la hipótesis de homocedasticidad fue comprobada mediante el test de Levene. Para aquellos casos que cumplían normalidad y homocedasticidad se evaluaron las diferencias mediante Análisis de la varianza de una vía (ANOVA). En estos casos y cuando se encontraban diferencias significativas entre los grupos $(\mathrm{p}<0.05)$ se utilizó la prueba de minima diferencia significativa de Tukey. Para los casos donde no se cumplian las hipótesis de normalidad y homocedasticidad utilizamos el test no paramétrico de Kruskal-Wallis (test $H$ ) para comparar entre grupos. Si resultaban diferencias significativas, realizamos comparaciones grupo a grupo mediante el test de suma de rangos de Wilcoxon (o también conocida como $U$ de Mann-Whitney) para comprobar si podían considerarse diferentes.

Con objeto de explorar los patrones de composición de especies en las diferentes parcelas de las poblaciones de robledal, se realizó un escalamiento multidimensional no métrico (NMDS) utilizando la matriz de especies. Este método de ordenación multivariante, basado en las proximidades (similaridad o disimilaridad) entre objetos, nos permite reducir la dimensionalidad de los datos sin una transformación a priori. Se utilizó la distancia de Sorensen (Bray-Curtis) para calcular la matriz de similitud entre parcelas (Legrende \& Legrende, 2000). Posteriormente representamos las puntuaciones de los sitios (parcelas) sobre los dos primeras dimensiones. Sobre ellas generamos superficies de respuesta de las variables ambientales (Oksanen et al. 2010). Esta técnica utiliza modelos generalizados aditivos $\left(\mathrm{gam}^{17}\right)$ para ajustar superficie de respuesta. Para ello utilizamos la matriz de datos ambientales de las parcelas forestales (matriz ambiental puntual) y realizamos una interpolación de los valores ajustados sobre el diagrama de ordenación obtenido con el NMDS. Se realizó una interpretación de la ordenación respecto de las principales variables ambientales identificadas en el Análisis de Componentes Principales.

Todos los análisis se llevaron a cabo el software estadístico R (R Development Core Team, 2011). Para ello se utilizaron los siguientes paquetes o librerías: agricolae (de Mendiburu 2010), BiodiversityR (Kindt \& Coe 2005), bpca (Faria \& Demetrio 2011), car (Fox \& Weisberg 2011), ellipse (Murdoch \& Chow 2007), ggplot2 (Wickham, 2009), Hmisc (Harrel et al 2010), lattice (Sarkar, 208), MASS (Venables \& Ripley 2002), multcomp

\footnotetext{
${ }^{17}$ Del inglés, generalized additive models
} 
(Hothorn et al 2008), nFactors (Raiche \& Magis 2010), nortest (Gross 2006), pastecs (Ibanez et al 2009), rgl (Adler \& Murdoch 2011), scatterplot3d (Ligges \& Mächler 2003), vegan (Oksanen et al 2010), xtable (Dahl, 2009). También se utilizó el software S.P.S.S (v.15 SPSS Inc., Chicago, IL, U.S.A). 


\section{Capítulo 3}

\section{Resultados}

Con la información de partida hemos caracterizado los melojares de Sierra Nevada mediante las estadísticas descriptivas univariantes de diferentes atributos forestales (tabla 3.1) y de las varariables ambientales (tabla 3.2). Se han determinado el hábitar óptimo y marginal de los robledales de Sierra Nevada respecto de las variables ambientales (figura III.1 Anexo 3) y de los atributos forestales (figura III.2 Anexo 3). Para estas representaciones gráficas se han escalado a una distancia fija los valores del límite inferior $(L I)$, umbral inferior $(U I)$, la media \pm error estándar, el umbral superior $(U S)$ y el límite superior $(L S)$, con objeto de visualizar mejor la cantidad de hábitat óptimo y marginal de cada parámetro. Se incluyen los valores de las diferentes características. Los atributos forestales que mostraron una alta heterogeneidad (coeficientes de variación superiores al $80 \%$ ) son: regeneración total, fracción de cabida cubierta total, densidad arbórea, altura media, área basal y volumen. La regeneración media fue de $37.72 \pm 9.74$ plántulas/parcela $\left(0.48 \mathrm{ind} / \mathrm{m}^{2}\right)$, correspondiendo la mayor parte a plántulas de Q. pyrenaica (33.47 \pm 9.88 plántulas/parcela ; 0.42 ind $\left./ m^{2}\right)$, tal y como era de esperar. El índice de diversidad de estructuras arrojó un valor medio de $0.91 \pm 0.03$, no mostrando un coeficiente de variación muy alto. Respecto a la composición de especies en los robledales, el número total de especies varió entre 1 y 25 especies con un valor medio de $13.41 \pm 0.90\left(0.04\right.$ especies $\left./ m^{2}\right)$, mientras que el índice de diversidad de Shannon-Weiner mostró un valor medio de $1.79 \pm 0.10$.

Respecto a las variables ambientales las características hidrográficas son las que presentan una mayor heterogeneidad en los datos, sobre todo el índice de acumulación hídrica $(\mathrm{CV}=580 \%)$. Por otro lado las variables topográficas presentan mayores valores de heterogeneidad que el resto de características (climáticas, distancia e influencia humana; ver tabla 3.2). 


\begin{tabular}{ccccccc} 
& LI & UI & media \pm SE & US & LS & CV (\%) \\
\hline regTot & 0 & 0 & $37.72 \pm 9.74$ & 98.30 & 200.00 & 150 \\
sedQp & 0 & 0 & $33.47 \pm 9.88$ & 97.40 & 200.00 & 17 \\
sedQi & 0 & 0 & $2.19 \pm 0.98$ & 9.00 & 27.00 & 25 \\
fccTot & 1.00 & 6.10 & $8.28 \pm 0.38$ & 10.00 & 10.00 & 26 \\
fccTre & 0 & 0 & $2.81 \pm 0.40$ & 5.90 & 7.00 & 80 \\
fccShr & 0 & 1.00 & $4.22 \pm 0.47$ & 7.90 & 10.00 & 63 \\
fccHer & 1.00 & 1.00 & $4.03 \pm 0.46$ & 8.00 & 9.00 & 65 \\
denTre & 0 & 0 & $196.03 \pm 42.39$ & 519.93 & 849.85 & 120 \\
heiTre & 0 & 0 & $6.36 \pm 1.15$ & 13.19 & 25.11 & 100 \\
abaQp & 0 & 0 & $5.63 \pm 1.32$ & 16.70 & 23.12 & 130 \\
volQp & 0 & 0 & $66.90 \pm 18.42$ & 225.81 & 436.88 & 160 \\
shaSp & 0 & 1.25 & $1.79 \pm 0.10$ & 2.46 & 2.85 & 32 \\
shaEst & 0.56 & 0.64 & $0.91 \pm 0.03$ & 1.07 & 1.10 & 18 \\
rich & 1.00 & 9.00 & $13.41 \pm 0.90$ & 19.90 & 25.00 & 38
\end{tabular}

Tabla 3.1 Estadísticas descriptivas de los atributos forestales. Se muestra el valor mínimo (Límite

Inferior, LI), máximo (Límite Superior, LS), los percentiles 10 y 90 (umbrales Inferior y Superior, UI y US) y la media con el error estándar. Además se incluye el coeficiente de variación.

\begin{tabular}{|c|c|c|c|c|c|c|}
\hline & LI & UI & $\operatorname{media} \pm \mathrm{SE}$ & US & LS & $\mathrm{CV}(\%)$ \\
\hline hidro_tci & 1.07 & 3.45 & $5.19 \pm 0.03$ & 7.17 & 16.26 & 32 \\
\hline hidro_acum & 1.00 & 5.86 & $204.60 \pm 24.00$ & 208.58 & 18692.13 & 580 \\
\hline tp_elev & 1189.00 & 1471.00 & $1701.07 \pm 3.23$ & 1887.00 & 2035.00 & 9.4 \\
\hline tp_pend & 2.70 & 12.90 & $24.91 \pm 0.19$ & 37.10 & 57.20 & 37 \\
\hline tp_expo_1000 & -170.90 & -67.40 & $-12.97 \pm 0.79$ & 28.70 & 110.50 & - \\
\hline tp_or & 0 & 29.00 & $188.71 \pm 2.38$ & 338.00 & 360.00 & 62 \\
\hline tp_es_oe & 1.00 & 8.00 & $40.09 \pm 0.54$ & 80.00 & 100.00 & 67 \\
\hline tp_su_no & 0 & 12.00 & $51.01 \pm 0.58$ & 89.00 & 100.00 & 56 \\
\hline tp_rsd_i & 0 & 0 & $1909.51 \pm 28.01$ & 3623.00 & 5238.00 & 73 \\
\hline tp_rsd_p & 0 & 1148.00 & $3421.72 \pm 31.84$ & 5257.00 & 6395.00 & 46 \\
\hline tp_rsd_v & 2923.00 & 5753.00 & $6920.74 \pm 15.92$ & 7778.00 & 7909.00 & 11 \\
\hline tp_rsd_o & 2000.00 & 4421.00 & $6044.64 \pm 21.48$ & 7214.00 & 7368.00 & 18 \\
\hline tp_rsh_i & 0 & 0 & $5.61 \pm 0.06$ & 9.20 & 9.50 & 55 \\
\hline tp_rsh_p & 0 & 5.50 & $7.84 \pm 0.04$ & 10.50 & 10.90 & 24 \\
\hline tp_rsh_v & 5.50 & 10.00 & $11.48 \pm 0.02$ & 12.60 & 14.20 & 9.9 \\
\hline tp_rsh_o & 5.00 & 9.00 & $10.67 \pm 0.02$ & 12.00 & 13.00 & 11 \\
\hline hu_2000_max & 0 & 0 & $11.29 \pm 0.29$ & 32.96 & 58.00 & 13 \\
\hline dis_mar & 22.04 & 24.08 & $34.54 \pm 0.18$ & 47.18 & 48.49 & 26 \\
\hline P_inv & 214.50 & 231.83 & $247.36 \pm 0.23$ & 262.08 & 272.89 & 4.7 \\
\hline P_pri & 118.12 & 131.53 & $145.88 \pm 0.19$ & 157.39 & 166.10 & 6.6 \\
\hline P_ver & 50.90 & 64.04 & $80.03 \pm 0.21$ & 91.86 & 98.48 & 13 \\
\hline P_oto & 234.18 & 251.64 & $275.08 \pm 0.36$ & 301.08 & 316.13 & 6.5 \\
\hline P_anual & 617.69 & 682.58 & $748.34 \pm 0.93$ & 803.38 & 843.84 & 6.2 \\
\hline tminl & -1.53 & -0.54 & $0.41 \pm 0.02$ & 1.41 & 2.53 & 19 \\
\hline $\operatorname{tmin} P$ & 2.58 & 3.42 & $4.39 \pm 0.02$ & 5.44 & 6.71 & 18 \\
\hline $\operatorname{tmin} V$ & 11.00 & 11.72 & $12.77 \pm 0.02$ & 13.99 & 15.40 & 6.8 \\
\hline $\operatorname{tmin} O$ & 5.24 & 5.99 & $6.95 \pm 0.02$ & 7.99 & 9.30 & 11 \\
\hline tmaxl & 5.80 & 7.09 & $9.07 \pm 0.03$ & 11.10 & 13.49 & 17 \\
\hline tmaxP & 11.20 & 12.68 & $14.21 \pm 0.02$ & 15.65 & 17.38 & 8.1 \\
\hline $\operatorname{tmax} V$ & 22.62 & 23.97 & $25.29 \pm 0.02$ & 26.55 & 28.84 & 3.9 \\
\hline $\operatorname{tmax} 0$ & 13.78 & 15.14 & $16.91 \pm 0.03$ & 18.66 & 21.02 & 7.9 \\
\hline
\end{tabular}

Tabla 3.2 Estadísticas descriptivas de las variables ambientales. Se muestra el valor mínimo (Límite Inferior, LI), máximo (Límite

Superior, LS), los percentiles 10 y 90 (umbrales Inferior y Superior, UI y US) y la media con el error estándar. Además se incluye el coeficiente de variación. 
Los resultados del análisis de componentes principales muestran que los cuatro primeros ejes (componentes) explican el $71.8 \%$ del total de la varianza (tabla 3.3). Si atendemos a las diferentes reglas disponibles para la retención de componentes (Peres-Neto et al 2003; 2005; Raiche \& Magis 2010) (ver Figura II.2 Anexo 2) deberiamos elegir entre los 6 componentes que ofrecen tres de las reglas (criterio de Kaiser-Guttman, criterio del bastón-roto y criterio de Coordenadas óptimas) y un único componente retenido de acuerdo al criterio de Factor de Aceleración (Raiche \& Magis 2010). Sin embargo, para datos ecológicos la elección de un elevado número de componentes dificulta la interpretación de los mismos (Legrende \& Legrende 2000), y por otro lado la elección de ún unico componente nos explicaría muy poca varianza de los datos (32.7\%, tabla 3.3). Algunos autores (Peres Neto et al 2003; 2005) han apuntado no existen unas reglas de retención de componentes que sean mejores que otras, porque la elección va a depender de la estructura de correlación de los datos. En nuestro caso, debido a que tenemos unas correlaciones bajas (aunque significativas) vamos a optar por la elección de cuatro componentes que explican cerca de un $72 \%$ de la varianza.

\begin{tabular}{lccc} 
& $\begin{array}{c}\text { Desviación } \\
\text { estándar }\end{array}$ & $\begin{array}{c}\text { \% Varianza } \\
\text { explicada }\end{array}$ & $\begin{array}{c}\text { \% Varianza } \\
\text { acumulada }\end{array}$ \\
\cline { 2 - 4 } PC1 & 3.18601 & 0.327 & 0.327 \\
PC2 & 2.27134 & 0.166 & 0.494 \\
PC3 & 1.97925 & 0.126 & 0.620 \\
PC4 & 1.73861 & 0.098 & 0.718 \\
PC5 & 1.50619 & 0.073 & 0.791 \\
PC6 & 1.20453 & 0.047 & 0.838 \\
PC7 & 0.99375 & 0.032 & 0.870 \\
PC8 & 0.90761 & 0.027 & 0.896 \\
PC9 & 0.78189 & 0.020 & 0.916 \\
PC10 & 0.74958 & 0.018 & 0.934
\end{tabular}

Tabla 3.3 Importancia de cada uno de los ejes extraidos del análisis PCA. Se muestran solamente los 10 primeros ejes.

La tabla de las cargas (loadings) (tabla 3.4) de las variables sobre cada uno de los ejes muestra que el primer componente se encuentra fuerte y negativamente correlacionado con todas las variables topográficas de radiación (> -0.8) y algo menos con algunas de precipitación (P_oto; P_ver y P_anual; > -0.7). Por otro lado este primer eje tambien se encuentra fuertemente correlacionado en sentido positivo con la distancia al mar (0.75) y con el gradiente de exposición Sur-Norte (0.745). Las temperaturas máximas muestran una fuerte correlación negativa con el segundo componente $(>-0.8)$ y mas débil con las temperaturas mínimas, que aunque solamente la temperatura mínima de invierno presenta una correlación mayor a $|0.7|$, el resto de temperaturas mínimas son las siguientes variables que muestran una mayor correlación con este eje (tabla 3.4). El tercer componente presenta de nuevo, aunque de forma más debil, las mayores correlaciones con: por un lado, las temperaturas mínimas en sentido negativo, y por otro lado, algo más debil y en sentido positivo, con la precipitaciones. Es destacable que en este caso la única variable que supera el umbral de correlación que fijamos $(|0.7|)$ es la temperatura mínima de verano, cuya correlación con el eje anterior no superaba dicho umbral. Por último el 
cuarto componente presenta una correlación positiva con la elevación (0.61) y mas débil y en sentido negativo con variables topográficas (radiación solar directa en invierno y orientación).

\begin{tabular}{|c|c|c|c|c|c|c|c|c|c|c|c|c|}
\hline \multirow[b]{2}{*}{ hidro_tci } & \multicolumn{3}{|c|}{$\begin{array}{l}\text { PC1 } \\
\text { correlación varianza }\end{array}$} & \multicolumn{3}{|c|}{ PC2 } & \multicolumn{3}{|c|}{ PC3 } & loading & \multicolumn{2}{|l|}{ PC4 } \\
\hline & -0.024 & -0.076 & 0.006 & -0.012 & -0.027 & 0.001 & 0.026 & 0.051 & 0.003 & -0.062 & -0.107 & 0.011 \\
\hline hidro_acum & 0.022 & 0.071 & 0.005 & 0.010 & 0.022 & 0.000 & -0.004 & -0.008 & 0.000 & -0.044 & -0.076 & 0.006 \\
\hline tp_elev & -0.147 & -0.469 & 0.220 & -0.006 & -0.014 & 0.000 & 0.121 & 0.240 & 0.058 & 0.350 & 0.609 & 0.371 \\
\hline tp_pend & 0.213 & 0.678 & 0.460 & -0.080 & -0.181 & 0.033 & 0.163 & 0.323 & 0.104 & -0.042 & -0.074 & 0.005 \\
\hline tp_expo_1000 & -0.156 & -0.496 & 0.246 & -0.009 & -0.021 & 0.000 & -0.054 & -0.108 & 0.012 & 0.090 & 0.157 & 0.025 \\
\hline tp_or & -0.205 & -0.652 & 0.425 & -0.004 & -0.009 & 0.000 & -0.089 & -0.176 & 0.031 & -0.210 & -0.364 & 0.132 \\
\hline tp_es_oe & 0.083 & 0.265 & 0.070 & 0.091 & 0.206 & 0.042 & -0.015 & -0.030 & 0.001 & 0.150 & 0.262 & 0.069 \\
\hline tp_su_no & 0.234 & 0.745 & 0.555 & 0.023 & 0.053 & 0.003 & 0.093 & 0.185 & 0.034 & 0.217 & 0.377 & 0.142 \\
\hline tp_rsd_i & -0.263 & -0.837 & 0.701 & -0.019 & -0.044 & 0.002 & -0.105 & -0.207 & 0.043 & -0.220 & -0.382 & 0.146 \\
\hline tp_rsd_p & -0.268 & -0.854 & 0.729 & -0.011 & -0.025 & 0.001 & -0.125 & -0.247 & 0.061 & -0.202 & -0.352 & 0.124 \\
\hline tp_rsd_v & -0.274 & -0.874 & 0.764 & 0.046 & 0.105 & 0.011 & -0.161 & -0.319 & 0.102 & -0.034 & -0.059 & 0.003 \\
\hline tp_rsd_o & -0.281 & -0.896 & 0.803 & 0.019 & 0.042 & 0.002 & -0.149 & -0.295 & 0.087 & -0.125 & -0.217 & 0.047 \\
\hline tp_rsh_i & -0.278 & -0.886 & 0.785 & -0.002 & -0.005 & 0.000 & -0.133 & -0.264 & 0.070 & -0.133 & -0.232 & 0.054 \\
\hline tp_rsh_p & -0.272 & -0.868 & 0.753 & 0.038 & 0.086 & 0.007 & -0.159 & -0.314 & 0.099 & -0.014 & -0.025 & 0.001 \\
\hline tp_rsh_v & -0.127 & -0.405 & 0.164 & 0.122 & 0.276 & 0.076 & -0.115 & -0.228 & 0.052 & 0.251 & 0.436 & 0.190 \\
\hline tp_rsh_o & -0.180 & -0.572 & 0.327 & 0.107 & 0.244 & 0.060 & -0.121 & -0.240 & 0.058 & 0.201 & 0.350 & 0.122 \\
\hline hu_2000_m & -0.146 & -0.466 & 0.217 & -0.070 & -0.159 & 0.025 & 0.164 & 0.325 & 0.106 & -0.098 & -0.171 & 0.029 \\
\hline dis_mar & 0.235 & 0.750 & 0.562 & 0.075 & 0.170 & 0.029 & -0.091 & -0.180 & 0.032 & 0.081 & 0.141 & 0.020 \\
\hline P_inv & -0.192 & -0.612 & 0.375 & -0.176 & -0.400 & 0.160 & 0.285 & 0.564 & 0.318 & 0.151 & 0.262 & 0.069 \\
\hline P_pri & -0.174 & -0.555 & 0.308 & -0.063 & -0.144 & 0.021 & 0.246 & 0.487 & 0.237 & 0.337 & 0.586 & 0.343 \\
\hline P_ver & -0.224 & -0.715 & 0.511 & -0.079 & -0.180 & 0.032 & 0.228 & 0.451 & 0.203 & 0.264 & 0.459 & 0.211 \\
\hline P_oto & -0.226 & -0.721 & 0.520 & -0.171 & -0.388 & 0.151 & 0.215 & 0.426 & 0.181 & 0.025 & 0.043 & 0.002 \\
\hline P_anual & -0.224 & -0.712 & 0.507 & -0.142 & -0.322 & 0.104 & 0.259 & 0.512 & 0.262 & 0.178 & 0.309 & 0.095 \\
\hline tminl & 0.039 & 0.123 & 0.015 & -0.336 & -0.764 & 0.584 & -0.276 & -0.546 & 0.298 & 0.151 & 0.263 & 0.069 \\
\hline $\operatorname{tmin} P$ & 0.034 & 0.107 & 0.011 & -0.286 & -0.650 & 0.423 & -0.319 & -0.632 & 0.399 & 0.197 & 0.342 & 0.117 \\
\hline $\operatorname{tmin} V$ & 0.023 & 0.074 & 0.005 & -0.181 & -0.412 & 0.170 & -0.364 & -0.720 & 0.518 & 0.257 & 0.447 & 0.200 \\
\hline $\operatorname{tmin} 0$ & 0.034 & 0.108 & 0.012 & -0.269 & -0.610 & 0.372 & -0.329 & -0.652 & 0.425 & 0.211 & 0.367 & 0.135 \\
\hline tmaxl & 0.042 & 0.134 & 0.018 & -0.356 & -0.810 & 0.656 & 0.126 & 0.248 & 0.062 & -0.182 & -0.316 & 0.100 \\
\hline tmaxP & 0.055 & 0.176 & 0.031 & -0.357 & -0.811 & 0.658 & 0.083 & 0.164 & 0.027 & -0.161 & -0.280 & 0.078 \\
\hline $\operatorname{tmax} V$ & 0.048 & 0.153 & 0.023 & -0.397 & -0.901 & 0.812 & 0.006 & 0.011 & 0.000 & -0.097 & -0.168 & 0.028 \\
\hline tmaxO & 0.044 & 0.142 & 0.020 & -0.375 & -0.851 & 0.724 & 0.092 & 0.181 & 0.033 & -0.160 & -0.279 & 0.078 \\
\hline
\end{tabular}

Tabla 3.4. Cargas de las diferentes variables sobre los 4 primeros componentes. Se muestra la correlación de las variables con los ejes (en negrita aquellas que superan el valor $>|.7|$ ) y el porcentaje de varianza explicado para cada variable por cada eje.

Hemos realizado una representación tridimensional de los tres primeros ejes con respecto a los puntos de muestreo y a las variables ambientales (Figura 3.1), donde podemos observar la importancia de cada variable en cada uno de los ejes. De este modo, como hemos comentado anteriormente, el primer eje esta positivamente correlacionado con la distancia al mar y el gradiente de orientación Sur-Norte; mientras que se encuentra negativamente correlacionado con la precipitación y la radiación solar. Por otro lado el segundo eje puede ser interpretado como una variable relacionada con la temperatura, y mas concretamente con las temperaturas máximas (alta correlación negativa). El tercer eje puede interpretarse relacionándolo con la precipitación (positivamente) y con las temperaturas mínimas. Por último el cuarto eje (no mostrado en la figura 3.1) lo intepretamos relacionado mas débilmente con la elevación. 


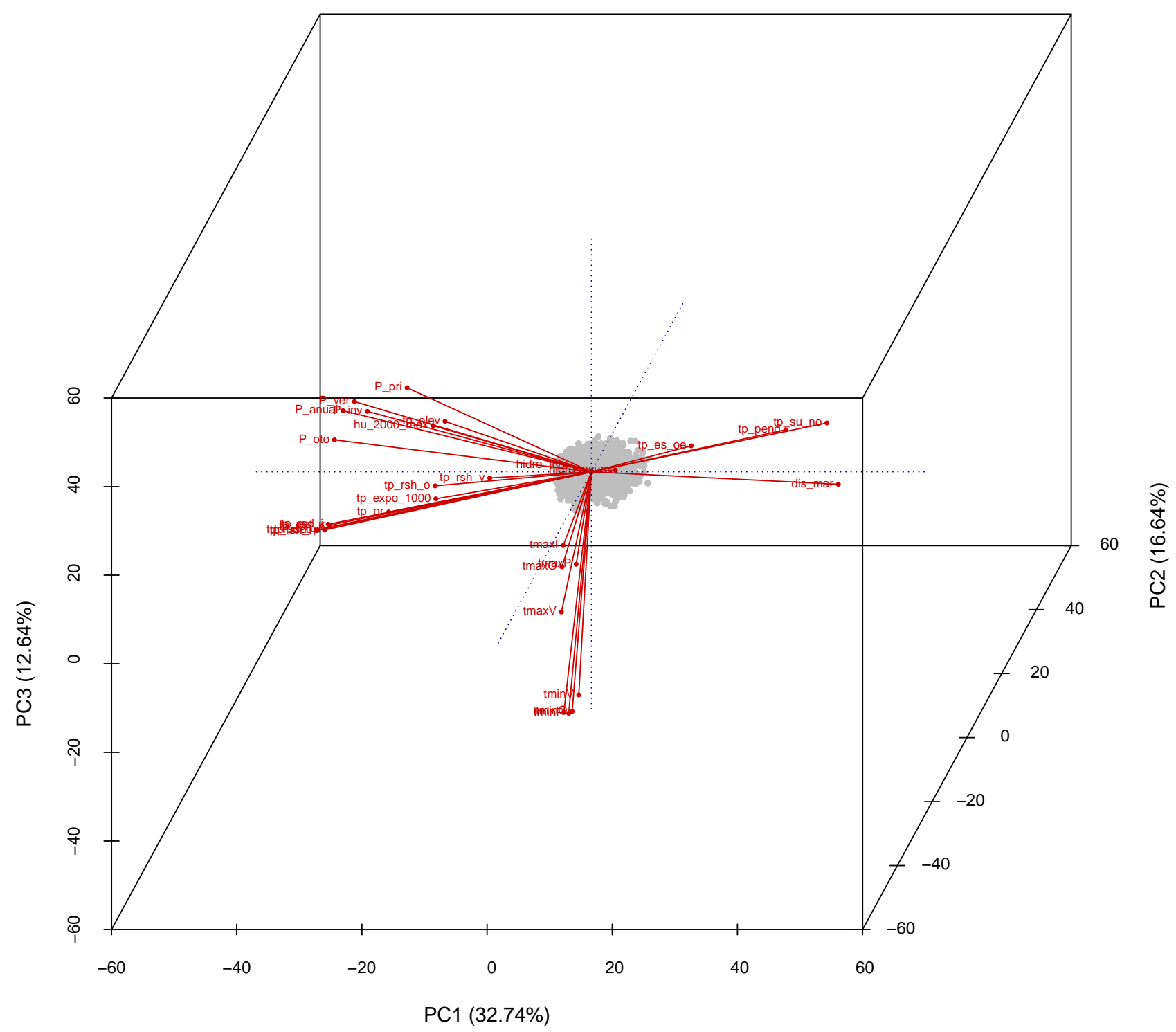

Figura 3.1. Representación tridimensional de los tres primeros componentes del ACP. Se indica para cada eje el porcentaje de varianza explicado.

Respecto a la localización de las diferentes poblaciones de robledal respecto a los tres primeros ejes (Figura 3.2 ), podemos observar como se disponen las diferentes poblaciones respecto a estas variables. Existen algunas poblaciones mas estrechamente agrupadas que otras. En general observamos como la población 8 (color negro en figura 3.2) se encuentra algo mas dispersa y separada del resto de poblaciones que forman un agrupamiento central. No obstante dentro de ese agrupamiento central podemos vislumbrar como las poblaciones 2, 6 y 7 (rojo, rosa y amarillo respectivamente) se encuentran formando grupos mas o menos homogéneos; mientras que el resto de población no podemos diferenciarlas bien, mediante esta representación. 

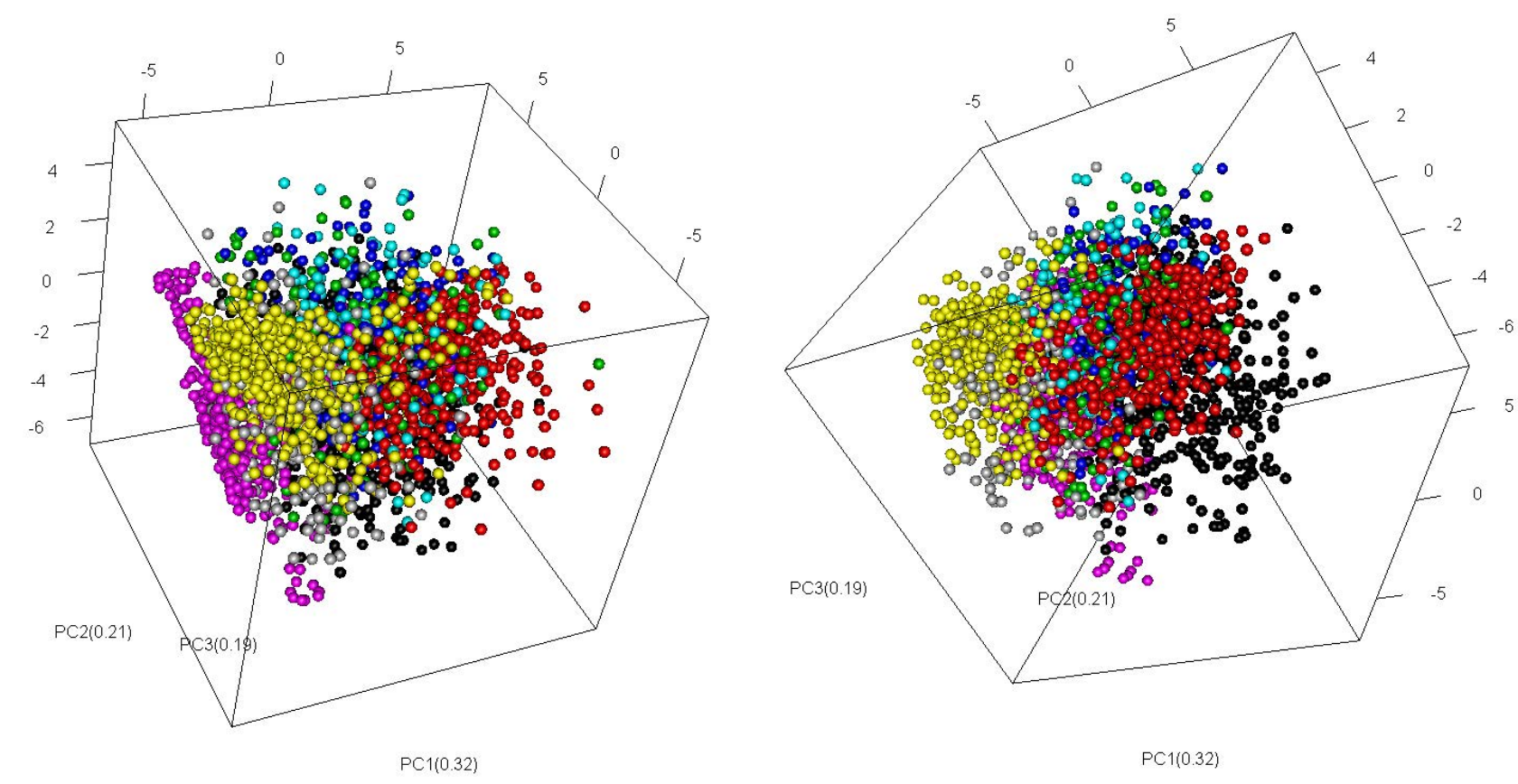

Figura 3.2. Representación tridimensional de los tres primeros componentes del ACP. Se incluyen solamente los sitios (puntos de muestreo de variables ambientales). Se ofrecen diferentes perspectivas de la ordenación. Los colores indican las diferentes poblaciones: 1 negro; 2 rojo; 3 verde; 4 azul; 5 cian; 6 rosa; 7 amarillo y 8 gris.

Por esta razón y con el objeto de discriminar entre las diferentes poblaciones realizamos complementariamente un análisis discriminante de las poblaciones. El análisis previo de igualdad de medias entre los grupos mostró que la variable menos importante a priori en la discriminación ha sido el índice de acumulación de sedimentos (mayor valor de $\lambda$ Wilkis $=.993$; y menor valor de $F=2.306$ ) (tabla IV. 1 Anexo 4), frente a la distancia al mar y la precipitación de otoño como variables mas significativas $(\lambda$ Wilkis $=.013, F=27432.36$ y $\lambda$ Wilkis $=.197$, $F=1425.61$, respectivamente). La prueba de Box para igualdad de las covarianzas de las matrices mostró un determinante logarítmico de 61.90. Se obtuvo una $M$ de Box de 33151.76 y una $F$ de 17.96, con una significación de $\mathrm{p}=0.000$. De tal forma rechazamos la hipótesis nula de igualdad de la covarianzas de las matrices de los grupos, es decir que existieron diferencias significativas en los comportamientos de las variables estudiadas entre las poblaciones, a partir del resultado de las covarianzas de sus matrices respectivas.

Los resultados de este análisis muestran que las dos primeras funciones discriminantes recogen el $89.2 \%$ de la varianza (tabla 3.5), mostrando éstas funciones unos altos valores de correlación canónica (0.997 y 0.989, respectivamente), de forma que la dispersión observada se debe a las diferencias entre las poblaciones. Estas funciones discrimiantes obtenidas presentan autovalores grandes, indicando que discriminan bien entre los grupos, ya que la variabilidad existente es debida a la diferencia entre éstos (García et al. 2007).

Las pruebas para determinar la significación de la diferencia entre los grupos a partir de las funciones calculadas, arrojaron valores de $\lambda$ de Wilkis muy bajos para las dos primeras funciones discriminantes ( $\lambda$ de Wilkis de 4.28 $\cdot \mathrm{e}^{-07}$ y $6.33 \cdot \mathrm{e}^{-05}$, respectivamente; Tabla 3.6) y de mayor magnitud para las siguentes cinco funciones. Las siete primeras funciones discriminantes resultaron significativas (p-valor $<0.00001$ ) para la discriminación entre 
las poblaciones de robledal a partir del comportamiento de las variables incluidas en el análisis y evaluadas con estas funciones.

\begin{tabular}{ccccc} 
Función & Autovalor & \% de Varianza & $\begin{array}{c}\text { \% Varianza } \\
\text { acumulado }\end{array}$ & $\begin{array}{c}\text { Correlación } \\
\text { Canónica }\end{array}$ \\
\hline $\mathbf{1}$ & 149.59 & 68.2 & 68.2 & .997 \\
$\mathbf{2}$ & 46.05 & 21.0 & 89.2 & .989 \\
$\mathbf{3}$ & 18.35 & 8.4 & 97.6 & .974 \\
$\mathbf{4}$ & 3.58 & 1.6 & 99.2 & .884 \\
$\mathbf{5}$ & 1.01 & 0.5 & 99.7 & .709 \\
$\mathbf{6}$ & 0.552 & 0.3 & 99.9 & .596 \\
$\mathbf{7}$ & 0.212 & 0.1 & 100.0 & .418
\end{tabular}

Tabla 3.5 Autovalores y porcentaje de varianza explicado por cada función discriminante. Se incluye el valor de la correlación canónica

La interpretación de la discriminación entre grupos se va a realizar en base a las primeras tres funciones discriminantes (97.6\% de la varianza explicada) para lo cual utilizaremos representaciones gráficas en dos (figura 3.3) y tres dimensiones (figura IV.1 Anexo 4). El comportamiento de los coeficientes canónicos (Tabla IV.1 Anexo 4) de estas tres funciones discriminantes así como el análisis de la matriz de estructuras (Tabla 3.7) muestra que para el primer eje la variable con mayor peso fue la distancia al mar, con una fuerte correlación positiva (0.703). De forma más débil y con una correlación negativa variables de precipitación (precipitación de otoño, anual y de invierno). Respecto a la segunda función discrimiante las variables con mayor peso han sido, las variables de radiación solar (en sentido negativo) y la precipitación de primavera en sentido positivo. Es interesante indicar que el valor de correlación de estas variables con la segunda función discriminante es muy débil. Por otro lado, respecto de la tercera función discriminante obtenemos de nuevo como variable con mayor peso, la distancia al mar (en sentido negativo), y destaca el hecho de que la influencia humana se encuentra como la variable con mayor peso en esta función en sentido positivo.

Como podemos observar en la representaciones gráficas de las funciones discriminantes, la separación entre grupos es clara y podemos diferenciar tres agrupamientos de poblaciones. Por un lado observamos la población 1 (ver tabla 2.1 para información de las poblaciones de robledal) que presenta un comportamiento claramente diferenciado del resto de poblaciones. Por otro lado observamos que las poblaciones 2 a la 5 conforman un grupo mas o menos homogéneo y que las poblaciones 6 a la 8 conforman otro grupo homogéneo.

\begin{tabular}{ccccc} 
Contraste de las Funciones & $\lambda$ de Wilkis & $\chi^{2}$ & gl. & p-valor \\
\hline 1 a la 7 & $4.28 \cdot \mathrm{e}^{-07}$ & 35719.12 & 182 & 0 \\
$\mathbf{2}$ a la 7 & $6.33 \cdot \mathrm{e}^{-05}$ & 23518.70 & 150 & 0 \\
$\mathbf{3}$ a la 7 & .003 & 14148.80 & 120 & 0 \\
$\mathbf{4}$ a la 7 & .058 & 6940.78 & 92 & 0 \\
$\mathbf{5}$ a la 7 & .264 & 3236.94 & 66 & 0 \\
$\mathbf{6}$ a la 7 & .532 & 1537.32 & 42 & $<0.00001$ \\
$\mathbf{7}$ & .825 & 468.15 & 20 & $<0.00001$ \\
\hline
\end{tabular}

Tabla 3.6 Contraste de Lambda de Wilkis de las funciones discriminantes 


\begin{tabular}{|c|c|c|c|c|c|c|c|c|c|c|c|}
\hline & 1 & & 2 & 3 & 4 & 5 & & 6 & & 7 & \\
\hline dismar & 0.703 & $*$ & 0.042 & -0.493 & 0.100 & 0.159 & & 0.172 & & 0.333 & \\
\hline tpsuno & 0.076 & & 0.070 & -0.070 & 0.178 & 0.518 & $*$ & -0.110 & & -0.145 & \\
\hline tprshi & -0.073 & & -0.083 & 0.098 & -0.100 & -0.433 & $*$ & 0.219 & & 0.061 & \\
\hline tprsdi & -0.071 & & -0.076 & 0.081 & -0.162 & -0.404 & $*$ & 0.246 & & 0.089 & \\
\hline tprsdp & -0.067 & & -0.077 & 0.084 & -0.132 & -0.384 & $*$ & 0.254 & & 0.053 & \\
\hline tprsdo & -0.056 & & -0.069 & 0.090 & -0.093 & -0.364 & $*$ & 0.264 & & 0.030 & \\
\hline tprshp & -0.051 & & -0.054 & 0.101 & -0.049 & -0.350 & $*$ & 0.163 & & -0.012 & \\
\hline tppend & 0.032 & & 0.034 & -0.073 & 0.015 & 0.312 & $*$ & -0.091 & & -0.018 & \\
\hline tprsdv & -0.045 & & -0.059 & 0.090 & -0.052 & -0.306 & $*$ & 0.233 & & 0.020 & \\
\hline tpor & -0.044 & & -0.043 & 0.075 & -0.136 & -0.269 & $*$ & 0.084 & & 0.082 & \\
\hline $\operatorname{tmin} V$ & 0.014 & & -0.011 & 0.045 & 0.202 & -0.233 & $*$ & 0.096 & & 0.062 & \\
\hline tprsho & -0.018 & & -0.003 & 0.074 & 0.020 & -0.161 & $*$ & 0.083 & & -0.028 & \\
\hline $\operatorname{tmin} O$ & 0.009 & & -0.009 & 0.008 & 0.145 & -0.160 & $*$ & 0.008 & & 0.051 & \\
\hline $\operatorname{tmin} P$ & 0.007 & & -0.008 & 0.001 & 0.128 & -0.147 & $*$ & -0.010 & & 0.051 & \\
\hline tpesoe & 0.029 & & 0.065 & 0.044 & 0.000 & 0.141 & $*$ & 0.092 & & 0.001 & \\
\hline tprshv & -0.003 & & 0.003 & 0.061 & 0.030 & -0.094 & $*$ & 0.035 & & -0.017 & \\
\hline tpexpo1000 & -0.021 & & -0.013 & 0.006 & -0.025 & -0.093 & $*$ & -0.072 & & 0.035 & \\
\hline tminl & 0.003 & & -0.001 & -0.024 & 0.080 & -0.091 & $*$ & -0.071 & & 0.044 & \\
\hline Pinv & -0.081 & & 0.024 & -0.076 & -0.036 & 0.219 & & 0.558 & $*$ & -0.260 & \\
\hline Panual & -0.092 & & 0.032 & -0.001 & -0.014 & 0.206 & & 0.545 & * & -0.293 & \\
\hline Poto & -0.157 & & -0.043 & -0.074 & -0.001 & 0.232 & & 0.536 & $*$ & -0.254 & \\
\hline Ppri & -0.044 & & 0.087 & 0.074 & -0.007 & 0.184 & & 0.535 & $*$ & -0.321 & \\
\hline Pver & -0.073 & & 0.069 & 0.092 & -0.013 & 0.177 & & 0.525 & $*$ & -0.335 & \\
\hline tpelev & 0.000 & & -0.014 & 0.105 & 0.001 & 0.190 & & 0.522 & $*$ & -0.303 & \\
\hline tmaxl & -0.021 & & 0.014 & -0.176 & -0.236 & 0.368 & & -0.417 & $*$ & -0.025 & \\
\hline $\operatorname{tmaxO}$ & -0.018 & & 0.011 & -0.160 & -0.199 & 0.321 & & -0.385 & $*$ & -0.012 & \\
\hline tmaxP & -0.009 & & -0.014 & -0.155 & -0.144 & 0.346 & & -0.360 & $*$ & -0.006 & \\
\hline $\operatorname{tmax} V$ & -0.010 & & 0.004 & -0.120 & -0.111 & 0.237 & & -0.285 & $*$ & 0.005 & \\
\hline hidroacum & 0.004 & & -0.003 & 0.005 & 0.009 & -0.032 & & 0.060 & $*$ & -0.009 & \\
\hline hu2000max & -0.067 & & 0.013 & 0.107 & -0.317 & 0.325 & & 0.292 & & 0.759 & * \\
\hline hidrotci & -0.009 & & 0.005 & 0.018 & -0.022 & -0.090 & & -0.082 & & 0.107 & * \\
\hline
\end{tabular}

Tabla 3.7. Correlaciones intra-grupo combinadas entre las variables discriminante y las funciones discriminantes canónicas. Se indica con asterístico la mayor correlación absoluta entre cada variable y cualquier función

En función de los resultados obtenidos del análisis discriminante hemos llevado a cabo una agrupación (Tabla 3.8) de las poblaciones para realizar comparaciones entre las diferentes variables ambientales y los atributos forestales.

\begin{tabular}{clc} 
Población & Localidad & GRUPO \\
\hline 1 & El Camarate & A \\
\hline 2 & Loma del Muerto & \\
3 & Loma de la Perdiz & $B$ \\
4 & Puntal de los Mecheros & \\
5 & Loma de Enmedio & \\
\hline 6 & El Robledal de Cañar & C \\
7 & Loma de las Matanzas y & \\
& Loma de Ramón & \\
\hline
\end{tabular}

Tabla 3.8. Agrupación de las poblaciones en función de los resultados del análisis discriminante 


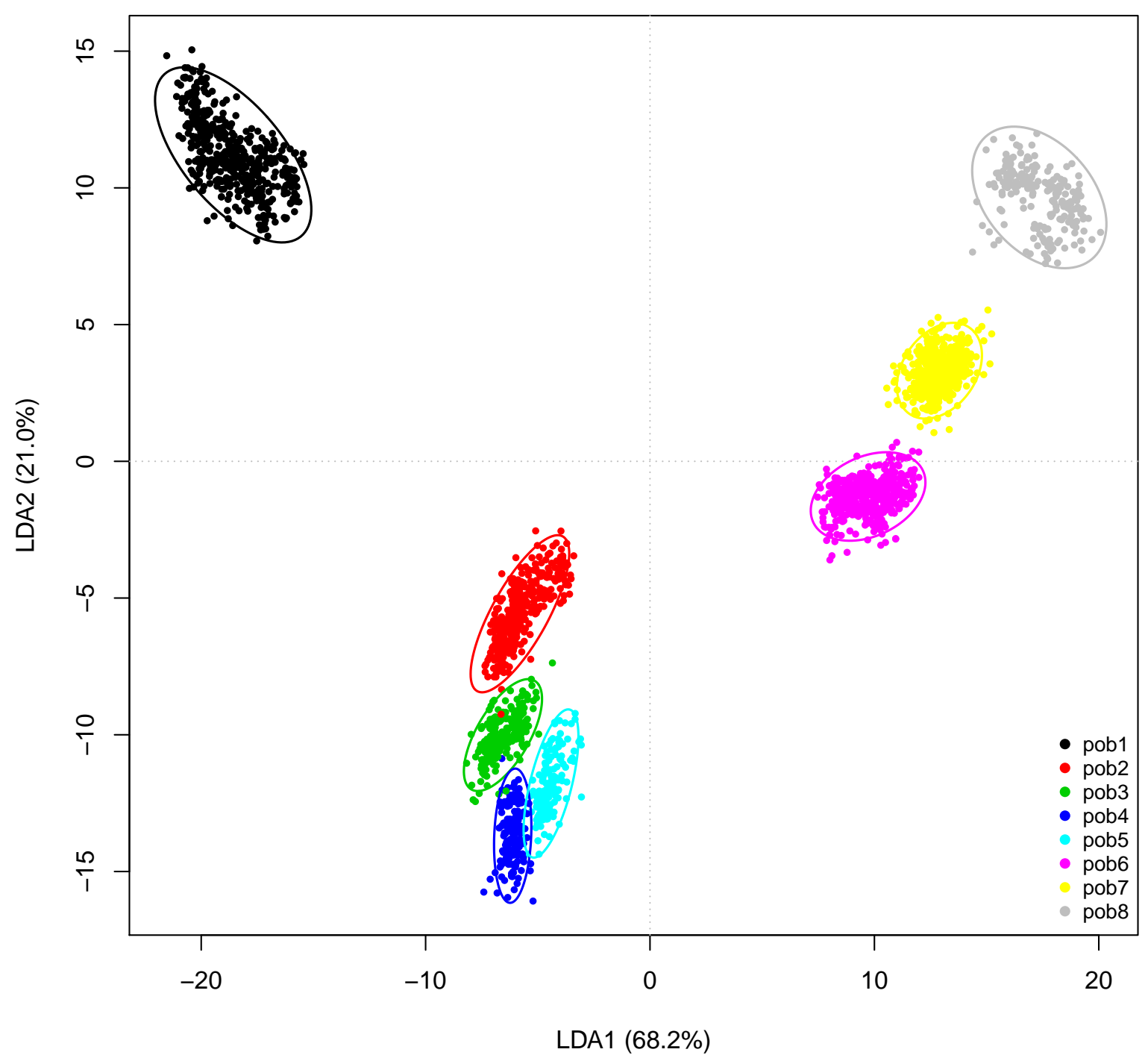

Figura 3.3. Representación de las diferentes poblaciones respecto de las dos funciones discriminantes.

Los resultados de las comparaciones de los atributos forestales entre los grupos derivados del análisis discriminante se muestran en la tabla 3.9. No hemos encontrado diferencias significativas en la regeneración entre los diferentes grupos $\left(\chi^{2}=.183 ; \mathrm{p}\right.$-valor $\left.=.913\right)$ aunque se observa que la cantidad de regenerado de Quercus pyrenaica es menor en el grupo A, aunque no es significativa con respecto a los otros dos grupos $\left(\chi^{2}=.389\right.$; p-valor $=.823$ ) (figura 3.4). También es interesante el hecho de que, aun no siendo significativas las diferencias entre los grupos $\left(\chi^{2}=3.389\right.$; p-valor $=.143$ ), la cantidad de regereado de encina (sedQi) mostró unos valores inferiores en el grupo B. Con respecto a los atributos relacionados con la estructura de la masa forestal no hemos encontrado diferencias significativas en ninguno de ellos, excepto en la fracción de cabida cubierta de herbáceas (fcc; $\chi^{2}=11.183 ; \mathrm{p}$-valor $\left.<0.01\right)$ siendo esta significativamente diferente $(U$ de Mann-Whitney=15.0; p-valor $<0.01)$ en el grupo A $(6.50 \pm 0.60)$ y B $(2.83 \pm 0.51)$ (figura 3.5$)$. 


\begin{tabular}{|c|c|c|c|c|c|c|c|c|c|}
\hline & \multirow[b]{2}{*}{ estadístico } & \multirow[b]{2}{*}{ g.l. } & \multirow[b]{2}{*}{$\mathbf{p}$} & \multicolumn{6}{|c|}{ Grupos (media \pm SD) } \\
\hline & & & & $\mathbf{A}$ & & B & & $\mathrm{C}$ & \\
\hline regTot & $\chi^{2}=.183$ & 2 & .913 & $19.38 \pm 6.25$ & & $47.56 \pm 16.16$ & & $32.67 \pm 15.82$ & \\
\hline sedQp & $\chi^{2}=.389$ & 2 & .823 & $7.62 \pm 3.21$ & & $46.39 \pm 16.16$ & & $29.17 \pm 16.30$ & \\
\hline sedQi & $\chi^{2}=3.389$ & 2 & .143 & $5.75 \pm 3.40$ & & $0.17 \pm 0.09$ & & $3.50 \pm 2.08$ & \\
\hline fccTot & $\chi^{2}=4.447$ & 2 & .108 & $7.50 \pm 0.57$ & & $8.50 \pm 0.54$ & & $8.67 \pm 0.99$ & \\
\hline fccTre & $F_{2,29}=1.406$ & 2,29 & .261 & $1.75 \pm 0.62$ & & $3.33 \pm 0.58$ & & $2.67 \pm 0.80$ & \\
\hline fccShr & $F_{2,29}=1.960$ & 2,29 & .159 & $2.75 \pm 0.86$ & & $4.50 \pm 0.51$ & & $5.33 \pm 1.54$ & \\
\hline fccHer & $\chi^{2}=11.183$ & 2 & .004 & $6.50 \pm 0.60$ & $a$ & $2.83 \pm 0.51$ & $b * *$ & $4.33 \pm 1.12$ & $a b$ \\
\hline denTre & $\chi^{2}=3.175$ & 2 & .204 & $61.57 \pm 31.95$ & & $226.97 \pm 65.10$ & & $282.47 \pm 86.03$ & \\
\hline heiTre & $\chi^{2}=1.148$ & 2 & .563 & $4.19 \pm 1.67$ & & $6.96 \pm 1.83$ & & $7.45 \pm 1.76$ & \\
\hline abaQp & $\chi^{2}=4.434$ & 2 & .109 & $0.71 \pm 0.47$ & & $7.11 \pm 2.00$ & & $7.71 \pm 2.78$ & \\
\hline volQp & $\chi^{2}=3.632$ & 2 & .163 & $7.50 \pm 4.92$ & & $90.05 \pm 29.24$ & & $76.66 \pm 34.22$ & \\
\hline shaEst & $\chi^{2}=2.088$ & 2 & .352 & $0.85 \pm 0.06$ & & $0.92 \pm 0.04$ & & $0.93 \pm 0.04$ & \\
\hline rich & $F_{2,29}=2.955$ & 2,29 & .068 & $16.62 \pm 1.95$ & & $11.72 \pm 1.21$ & & $14.17 \pm 0.70$ & \\
\hline shaSp & $\chi^{2}=8.670$ & 2 & .013 & $2.27 \pm 0.17$ & $a$ & $1.57 \pm 0.13$ & $b * *$ & $1.83 \pm 0.09$ & $a b$ \\
\hline
\end{tabular}

Tabla 3.9. Diferencias entre las medias de los grupos para las diferentes atributos forestales. Se muesta el valor del éstadistico (ANOVA o Kruskal-Wallis). Letras diferentes indican diferencias entre las medias de los grupos. ${ }^{* *}<0.01$

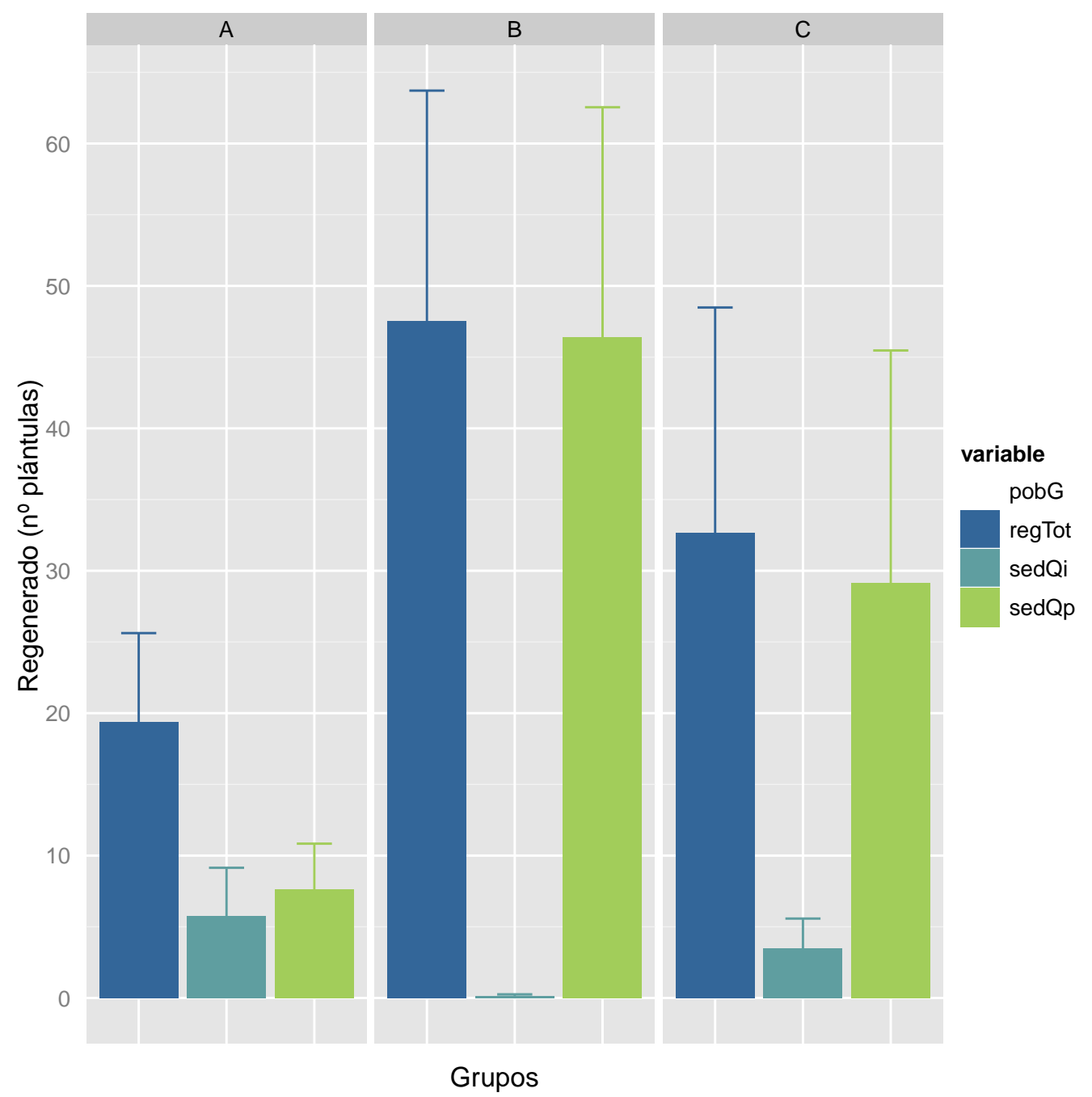

Figura 3.4. Diferencias entre los grupos de poblaciones respecto al regenerado 
Destaca tambien el hecho de que aún no existiendo diferencias significativas entre los atributos forestales estructurales (excepto para fccHer, como hemos comentado) el grupo A presenta unos valores inferiores respecto a los otros dos grupos para él área basal $\left(0.71 \pm 0.47 \mathrm{~m}^{2} \cdot \mathrm{Ha}^{-1}\right)$, la densidad de pies mayores $(61.57 \pm 31.95$ ind $\left.\cdot \mathrm{Ha}^{-1}\right)$ y el volumen de los pies mayores $\left(7.50 \pm 4.92 \mathrm{~m}^{3} \cdot \mathrm{Ha}^{-1}\right)$ (tabla 3.9 ; figura 3.7 ).

La diversidad de especies fue significativamente diferente $\left(\chi^{2}=8.670\right.$; p-valor $<0.05$; tabla 3.9), observando que el grupo A presentaba un valor mayor $(2.27 \pm 0.17)$ que el resto de grupos, siendo significativamente $(U$ de Mann-Whitney=22.0; p-valor < 0.01) diferente al grupo B (1.57 \pm 0.13$)$ (figura 3.8). Sin embargo en la riqueza de especies no se apreciaron diferencias significativas entre los grupos (tabla 3.9)(figura 3.8).

\begin{tabular}{|c|c|c|c|c|c|c|c|c|}
\hline & \multirow[b]{2}{*}{$\chi^{2}$} & \multirow[b]{2}{*}{$\mathbf{p}$} & \multicolumn{6}{|c|}{ Grupos (media \pm SD) } \\
\hline & & & A & & B & & $\mathrm{C}$ & \\
\hline hidro_tci & 60.738 & $<0.001$ & $4.90 \pm 0.08$ & $a$ & $5.08 \pm 0.05$ & $b$ & $5.40 \pm 0.05$ & c \\
\hline hidro_acum & 66.219 & $<0.001$ & $345.35 \pm 97.91$ & $a$ & $175.73 \pm 32.95$ & $b$ & $169.57 \pm 21.93$ & $c$ \\
\hline tp_elev & 32.383 & $<0.001$ & $1740.05 \pm 6.52$ & $a$ & $1669.84 \pm 6.22$ & $b$ & $1710.33 \pm 4.20$ & $c$ \\
\hline tp_pend & 568.135 & $<0.001$ & $26.10 \pm 0.33$ & $a$ & $29.93 \pm 0.28$ & $b$ & $20.32 \pm 0.25$ & $c$ \\
\hline tp_expo_1000 & 201.903 & $<0.001$ & $-22.52 \pm 1.73$ & & $-22.46 \pm 1.64$ & & $-1.25 \pm 0.75$ & $a$ \\
\hline tp_or & 656.798 & $<0.001$ & $160.25 \pm 5.50$ & $a$ & $113.33 \pm 2.33$ & $b$ & $262.06 \pm 3.14$ & $c$ \\
\hline tp_es_oe & 442.277 & $<0.001$ & $40.37 \pm 1.47$ & $a$ & $54.36 \pm 0.84$ & $b$ & $28.34 \pm 0.58$ & $c$ \\
\hline tp_su_no & 1363.014 & $<0.001$ & $62.33 \pm 0.93$ & $a$ & $73.73 \pm 0.66$ & $b$ & $27.76 \pm 0.54$ & $c$ \\
\hline tp_rsd_i & 1301.216 & $<0.001$ & $1489.98 \pm 50.78$ & $a$ & $770.18 \pm 31.99$ & $b$ & $3013.85 \pm 25.28$ & $c$ \\
\hline tp_rsd_p & 1242.793 & $<0.001$ & $3056.60 \pm 59.95$ & $a$ & $2140.28 \pm 41.68$ & $b$ & $4619.39 \pm 26.39$ & $c$ \\
\hline tp_rsd_v & 1064.834 & $<0.001$ & $6835.85 \pm 29.69$ & $a$ & $6352.91 \pm 25.49$ & $b$ & $7419.43 \pm 14.46$ & $c$ \\
\hline tp_rsd_o & 1238.903 & $<0.001$ & $5854.49 \pm 40.75$ & $a$ & $5205.08 \pm 30.85$ & $b$ & $6808.90 \pm 17.59$ & $c$ \\
\hline tp_rsh_i & 1565.276 & 0 & $4.77 \pm 0.10$ & $a$ & $2.98 \pm 0.08$ & $b$ & $8.10 \pm 0.05$ & $c$ \\
\hline tp_rsh_p & 125.570 & $<0.001$ & $7.42 \pm 0.06$ & $a$ & $6.47 \pm 0.06$ & $b$ & $9.13 \pm 0.04$ & $c$ \\
\hline tp_rsh_v & 2.364 & .306 & $11.49 \pm 0.05$ & & $11.37 \pm 0.04$ & & $11.58 \pm 0.03$ & \\
\hline tp_rsh_o & 117.907 & $<0.001$ & $10.44 \pm 0.05$ & & $10.37 \pm 0.04$ & & $11.01 \pm 0.03$ & $a$ \\
\hline hu_2000_max & 983.670 & $<0.001$ & $0.00 \pm 0.00$ & $a$ & $6.95 \pm 0.38$ & $b$ & $19.53 \pm 0.45$ & $c$ \\
\hline dis_mar & 2094.165 & 0 & $47.10 \pm 0.04$ & $a$ & $39.52 \pm 0.11$ & $b$ & $25.26 \pm 0.04$ & $c$ \\
\hline P_inv & 926.558 & $<0.001$ & $233.38 \pm 0.43$ & $a$ & $246.53 \pm 0.27$ & $b$ & $253.85 \pm 0.28$ & $c$ \\
\hline P_pri & 576.535 & $<0.001$ & $135.36 \pm 0.39$ & $a$ & $148.30 \pm 0.32$ & $b$ & $148.28 \pm 0.21$ & $c$ \\
\hline P_ver & 847.350 & $<0.001$ & $67.76 \pm 0.39$ & $a$ & $79.57 \pm 0.32$ & $b$ & $85.51 \pm 0.20$ & $c$ \\
\hline P_oto & 1703.161 & 0 & $253.82 \pm 0.45$ & $a$ & $267.02 \pm 0.29$ & $b$ & $290.49 \pm 0.35$ & $c$ \\
\hline P_anual & 1142.997 & $<0.001$ & $690.32 \pm 1.66$ & $a$ & $741.43 \pm 1.10$ & $b$ & $778.13 \pm 0.95$ & $c$ \\
\hline tminl & 5.351 & .069 & $0.45 \pm 0.04$ & & $0.42 \pm 0.02$ & & $0.37 \pm 0.02$ & \\
\hline $\operatorname{tmin} P$ & 18.446 & $<0.001$ & $4.55 \pm 0.04$ & $a$ & $4.37 \pm 0.02$ & & $4.35 \pm 0.02$ & \\
\hline $\operatorname{tmin} V$ & 80.106 & $<0.001$ & $13.13 \pm 0.04$ & $a$ & $12.68 \pm 0.03$ & & $12.68 \pm 0.03$ & \\
\hline $\operatorname{tmin} O$ & 28.557 & $<0.001$ & $7.15 \pm 0.04$ & $a$ & $6.93 \pm 0.02$ & & $6.89 \pm 0.02$ & \\
\hline tmaxl & 184.761 & $<0.001$ & $8.22 \pm 0.05$ & $a$ & $9.40 \pm 0.05$ & $b$ & $9.16 \pm 0.04$ & $c$ \\
\hline $\operatorname{tmax} P$ & 46.598 & $<0.001$ & $13.95 \pm 0.04$ & $a$ & $14.35 \pm 0.04$ & $b$ & $14.21 \pm 0.03$ & $c$ \\
\hline $\operatorname{tmax} V$ & 87.498 & $<0.001$ & $24.93 \pm 0.04$ & $a$ & $25.46 \pm 0.04$ & $b$ & $25.29 \pm 0.03$ & $c$ \\
\hline $\operatorname{tmax} 0$ & 170.760 & $<0.001$ & $16.22 \pm 0.05$ & $a$ & $17.19 \pm 0.05$ & $b$ & $16.97 \pm 0.04$ & $c$ \\
\hline
\end{tabular}

Tabla 3.10. Diferencias entre las medias de los grupos para las diferentes variables ambientales. Se muesta el valor del éstadistico de la prueba no paramétrica de Kruskal-Wallis. Se ha omitido los grados de libertad que se correponden con $g . l .=2$. Letras diferentes indican diferencias entre las medias de los grupos. Todas las diferencias entre grupos a un nivel $\alpha<0.05$ 


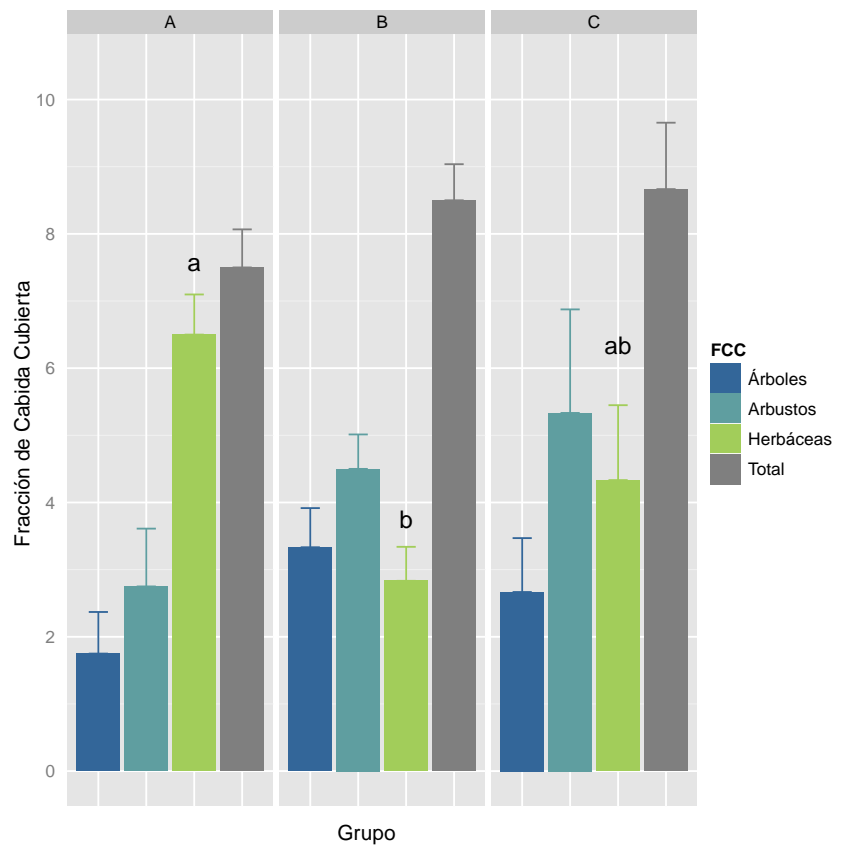

Figura 3.5 Diferencias entre los grupos de poblaciones respecto a las variables de Fracción de Cabida Cubierta. Diferentes letras indican diferencias significativas. Ver tabla 3.9

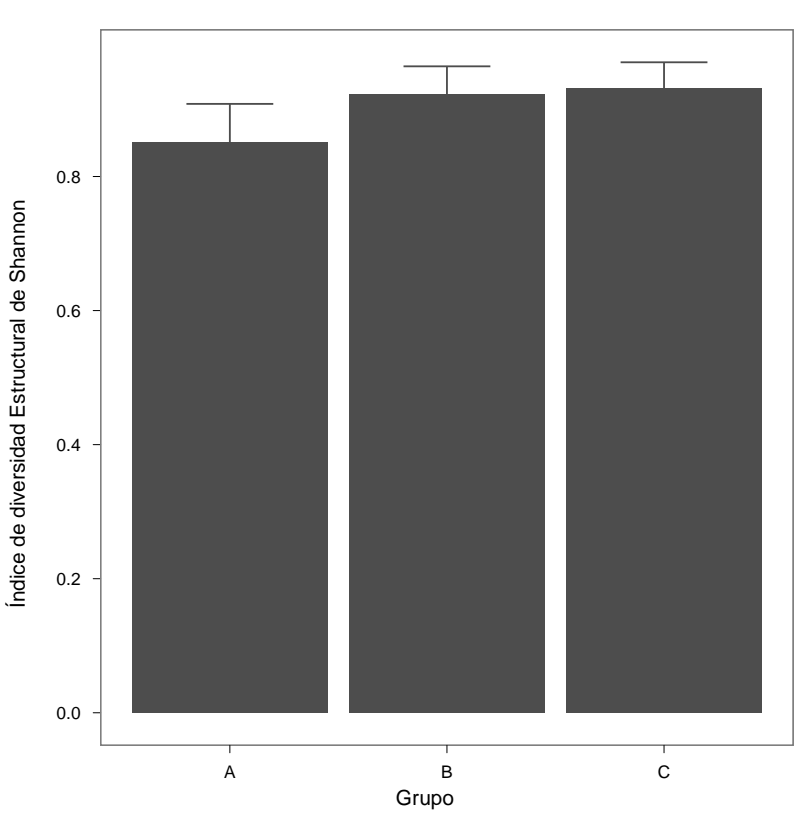

Figura 3.6 Diferencias entre los grupos de poblaciones respecto al índice de diversidad de estructuras
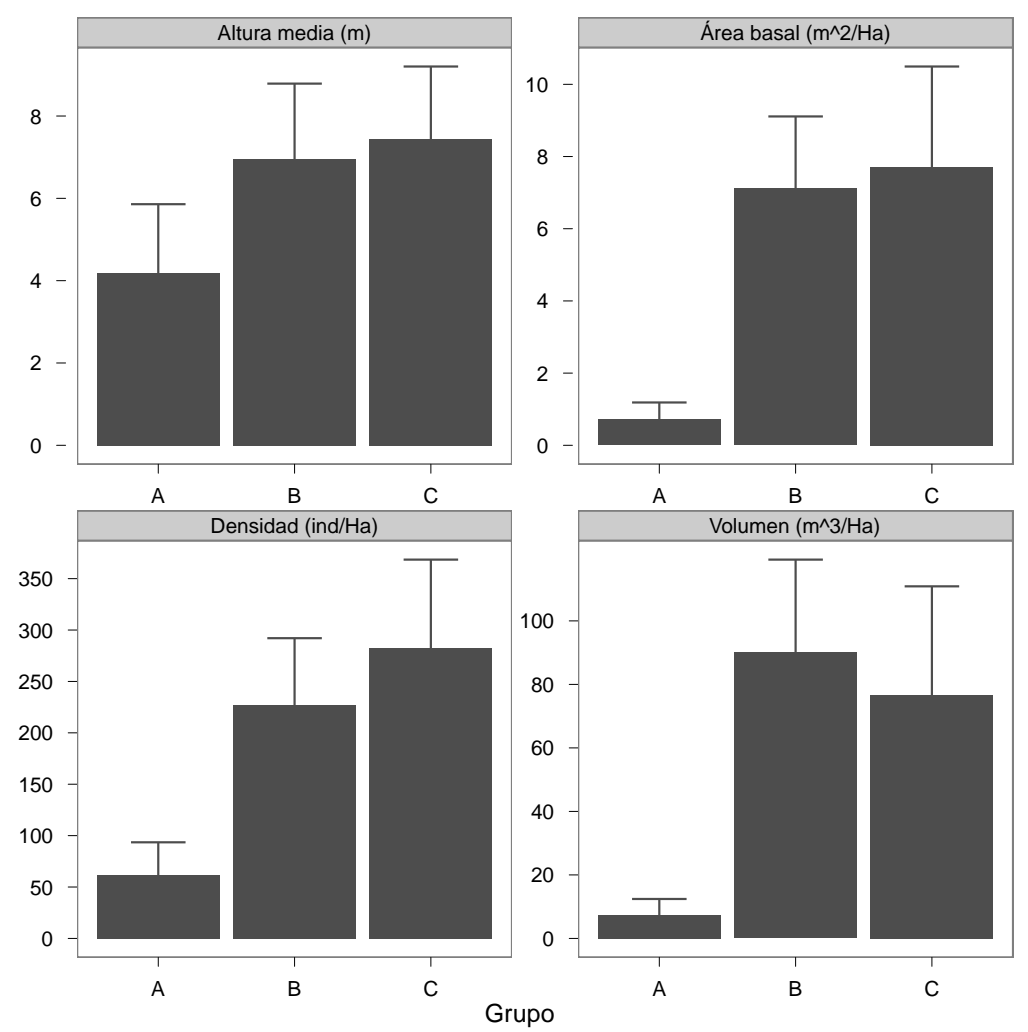

Figura 3.7 Diferencias entre los grupos de poblaciones respecto diferentes atributos estrucruales. 


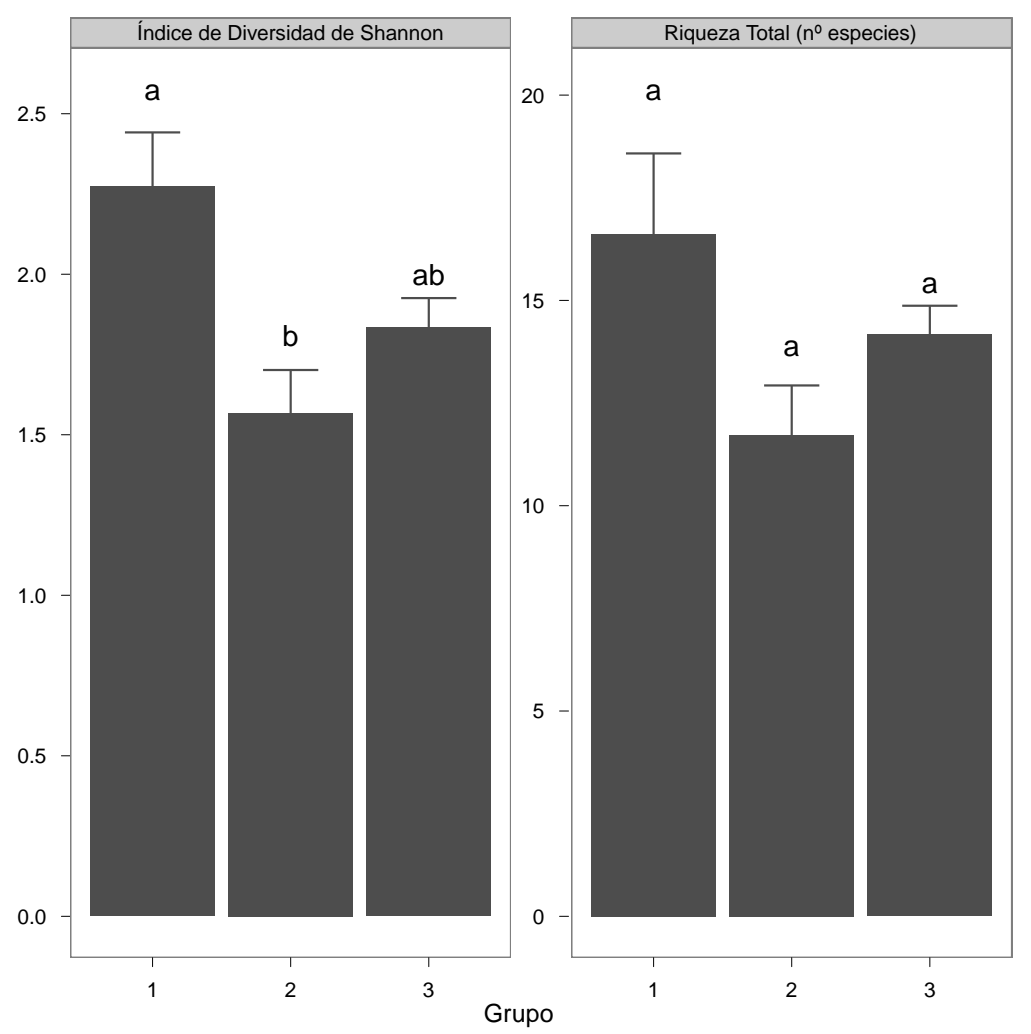

Figura 3.8 Diferencias entre los grupos de poblaciones respecto a la riqueza e índice de diversidad de Shanon-Weinner. Diferentes letras indican diferencias significativas. Ver tabla 3.9.

Las variables ambientales climáticas presentaron diferencias significativas (temperaturas mínimas, máximas y precipitación) a excepción de la tempertura mínima de invierno que no mostró diferencias entre los grupos $\left(\chi^{2}=5.351 ;\right.$ p-valor $=0.069 ;$ tabla 3.10) (tabla 3.10; figuras 3.10 y 3.11). Encontramos que los grupos diferen unos de otros (par a par) para las variables de temperaturas máximas (figura 3.11) y de precipitación (figura 3.10). El grupo de población A se diferencia del resto de grupos respecto a las temperaturas mínimas de primavera, verano y otoño, no existiendo diferencias entre los grupos B y C para estas variables (figura 3.11).

Igualmente para las variables de distancia al mar, influencia humana, hidrográficas (índice de acumulación de sedimentos e índice topográfico de humedad) (figura 3.14), elevación, pendiente, orientación, gradientes de orientación este-oeste y norte-sur (figura 3.13), observamos como los grupos de poblaciones se pueden considerar significativamente diferentes unos de otros. Con las variables de radiación ocurre igual para la cantidad de radiación recibida en las diferentes estaciones del año (figura 3.12) y la cantidad de horas de sol en invierno y en primavera (figura 3.11). Sin embargo hemos encontrado que no existen diferencias en la cantidad de horas de sol en verano entre los grupos de poblaciones $\left(\chi^{2}=2.364\right.$; p-valor $=0.306$; tabla 3.10$)$ y que las horas de sol recibidas en otoño en el grupo de poblaciones $\mathrm{C}$ es diferente respecto a grupo de poblaciones A ( $U$ de MannWhitney=179801.5; p-valor < 0.001) y B ( $U$ de Mann-Whitney=369119.0; p-valor < 0.001) (figura 3.11). Un comportamiento similar se ha observado en relación al gradiente de exposición, siendo éste significativamente diferente en el grupo C, con respecto al grupoa A ( $U$ de Mann-Whitney=145927.5; p-valor $<0.001$ ) y B ( $U$ de Mann-Whitney=3529996.0; p-valor < 0.001)(figura 3.11). 


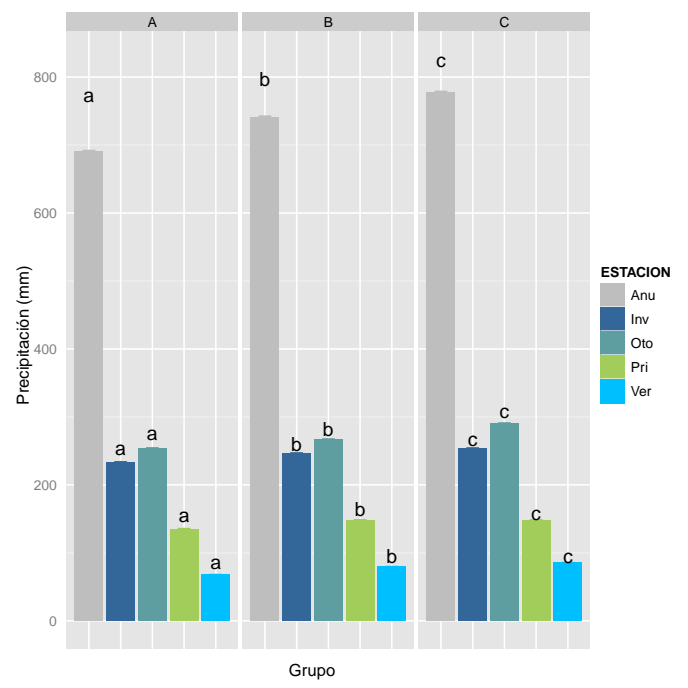

Figura 3.10 Diferencias entre los grupos de poblaciones respecto a precipitación. Diferentes letras indican diferencias significativas. Ver tabla 3.10

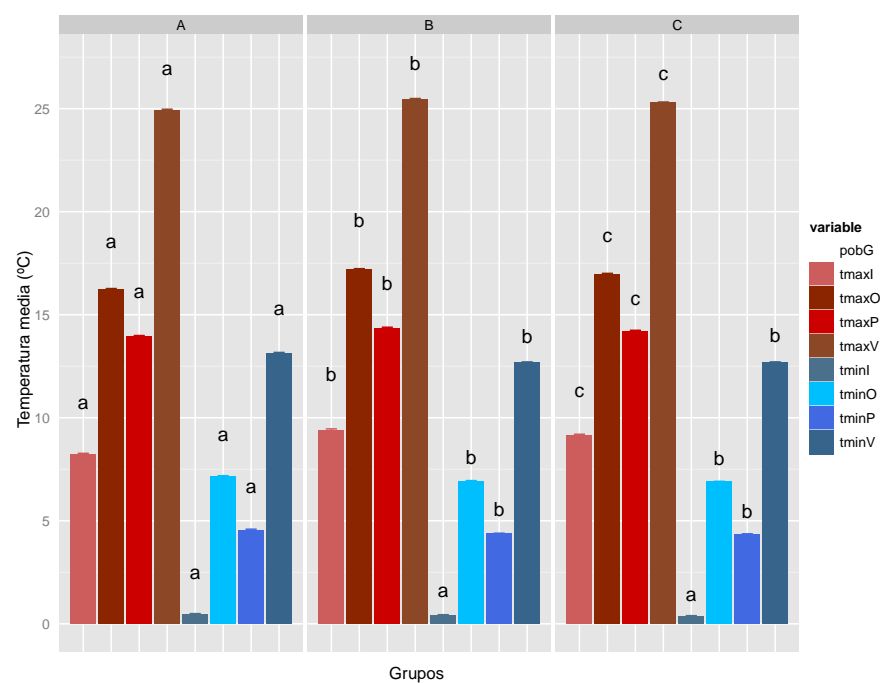

Figura 3.11 Diferencias entre los grupos de poblaciones respecto a las temperaturas medias de las míminas y de las máximas. Diferentes letras indican diferencias significativas. Ver tabla 3.10

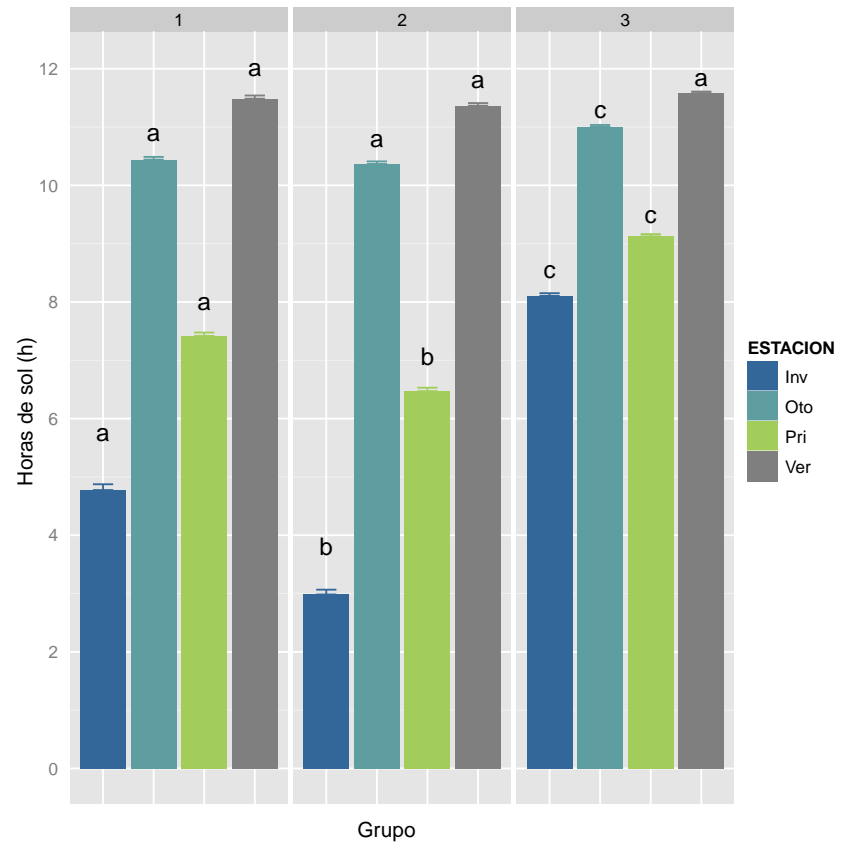

Figura 3.11 Diferencias entre los grupos de poblaciones respecto a la cantidad de horas de sol recibidas. Diferentes letras indican diferencias significativas. Ver tabla 3.10

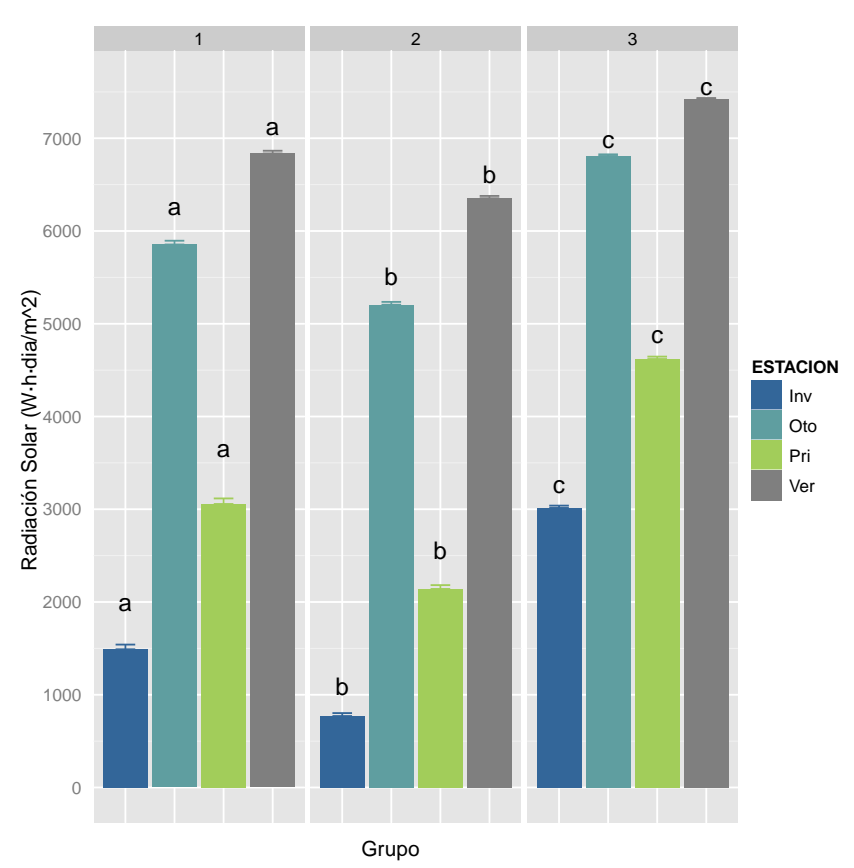

Figura 3.12 Diferencias entre los grupos de poblaciones respecto a la cantidad de radiación solar recibida. Diferentes letras indican diferencias significativas. Ver tabla 3.10 

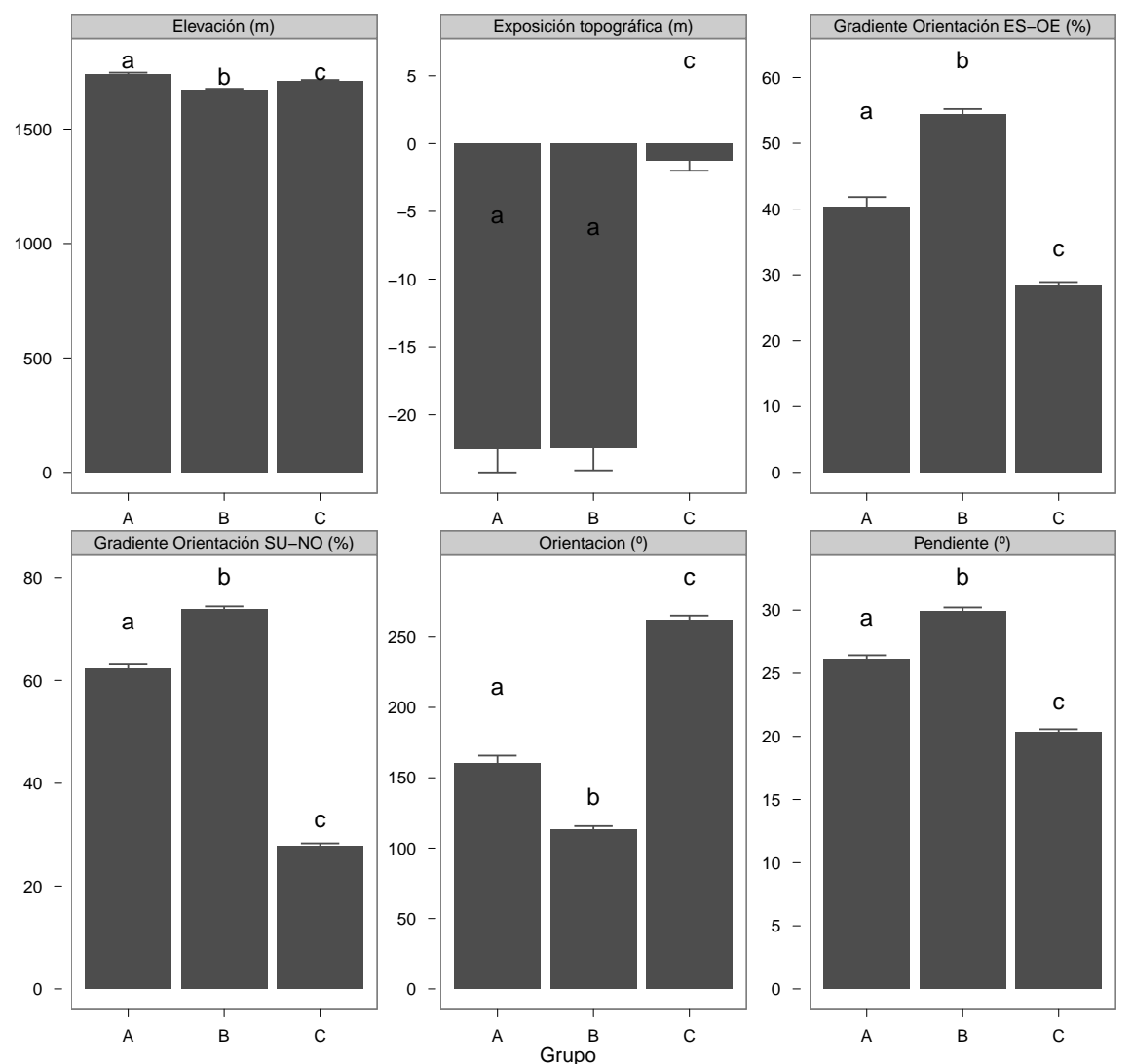

Figura 3.13 Diferencias entre los grupos de poblaciones respecto a diferentes variables topográficas. Diferentes letras indican diferencias significativas. Ver tabla 3.10

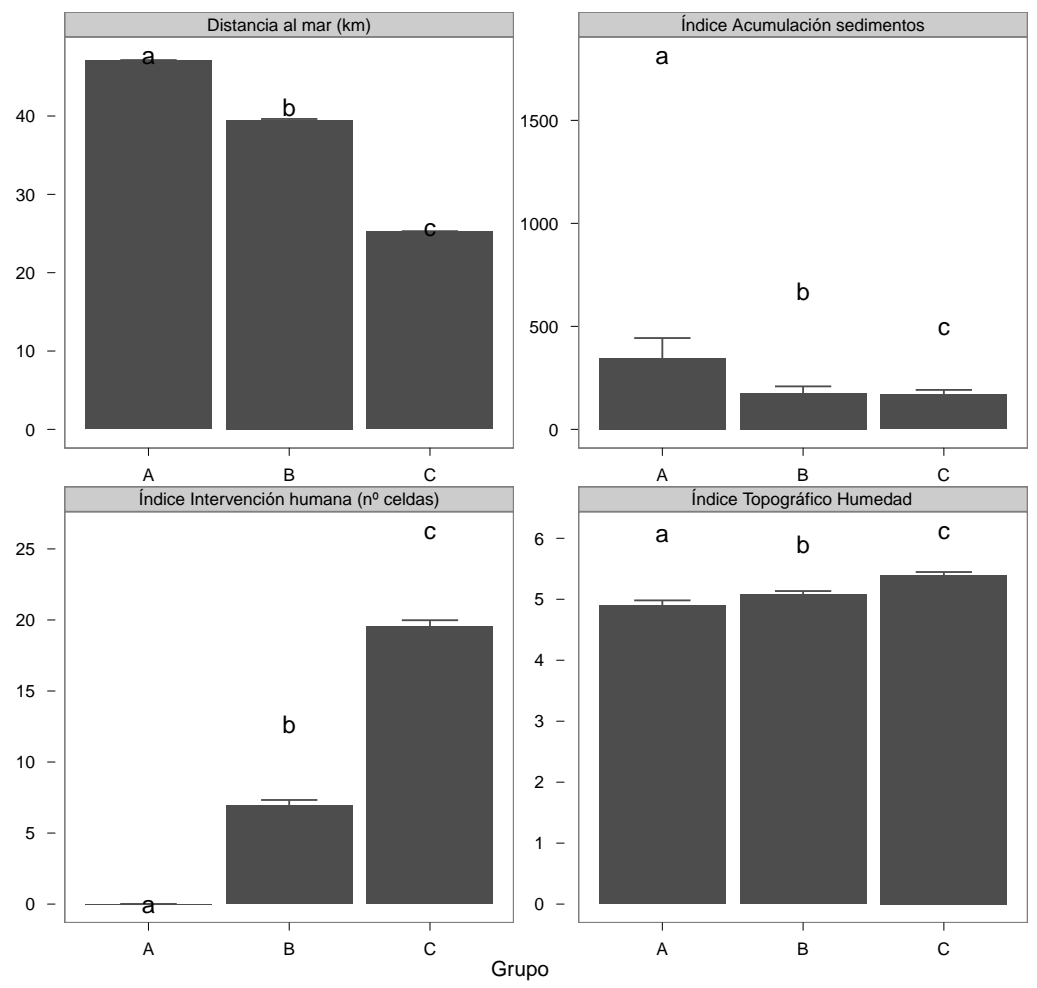

Figura 3.14 Diferencias entre los grupos de poblaciones respecto a variables hidrográficas, de distancia al mar y de influencia humana. Diferentes letras indican diferencias significativas. Ver tabla 3.10 
El análisis de ordenación realizado con el escalamiento multidimensional no métrico (NMDS) ha mostrado agrupados a los puntos de muestreo en función de su composición florística (figura 3.15). Observamos como las parcelas pertenecientes a la misma población se sitúan, en general, mas próximas entre sí, indicando mas similtud de especies entre las parcelas de una misma población que del resto de poblaciones. Esta ordenación obtuvo un valor de Stress de 0.216 y se evaluó su ajuste mediante el diagrama de Sherpard, que aportó una buena medida de ajuste (non-metric $R^{2}=.953$, figura V.1 Anexo 1). Igualmente se analizaron que parcelas fueron las que peor se ajustaban a esta ordenación (figura V.1 Anexo 1).

Sobre la representación gráfica (3.15) de la ordenación resultante del NMDS se ajustaron las variables ambientales de cada una de las parcelas (matriz ambiental puntual) observando de nuevo que las variables mas importantes fueron, por un lado la distancia al mar frente a las precipitaciones, y por otro lado la elevación frente a las temperturas máximas (figura 3.16). Posteriormente y sobre la ordenación obtenida hemos ajustado superficies de respuesta para las variables ambientales mas importantes arrojadas tanto por el ACP como por el análisis discriminante. Los resultados se pueden observar en las figuras 3.17 y 3.18 . 


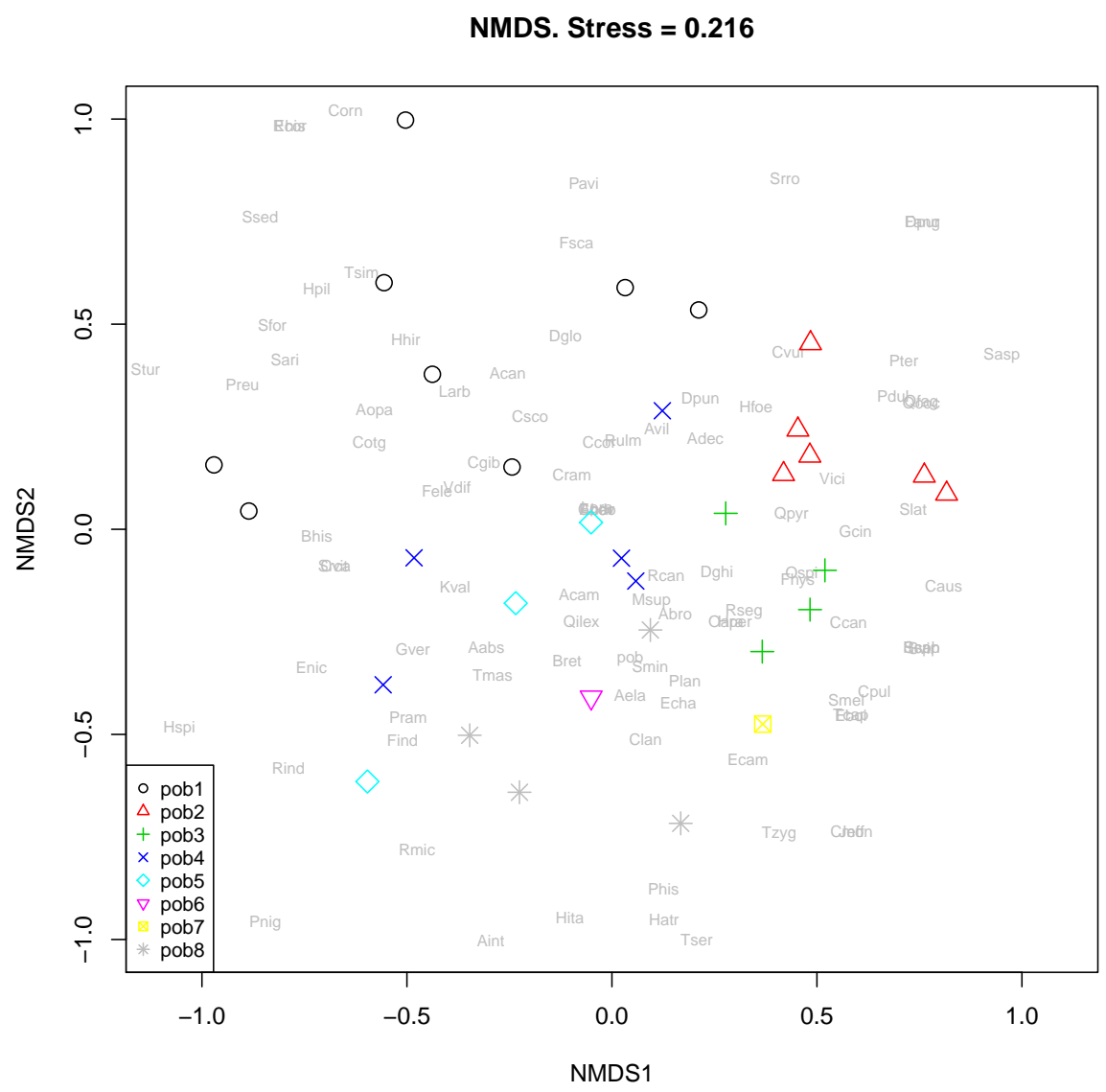

Figura 3.15 Ordenación de las parcelas de las diferentes poblaciones en función de su composición específica.

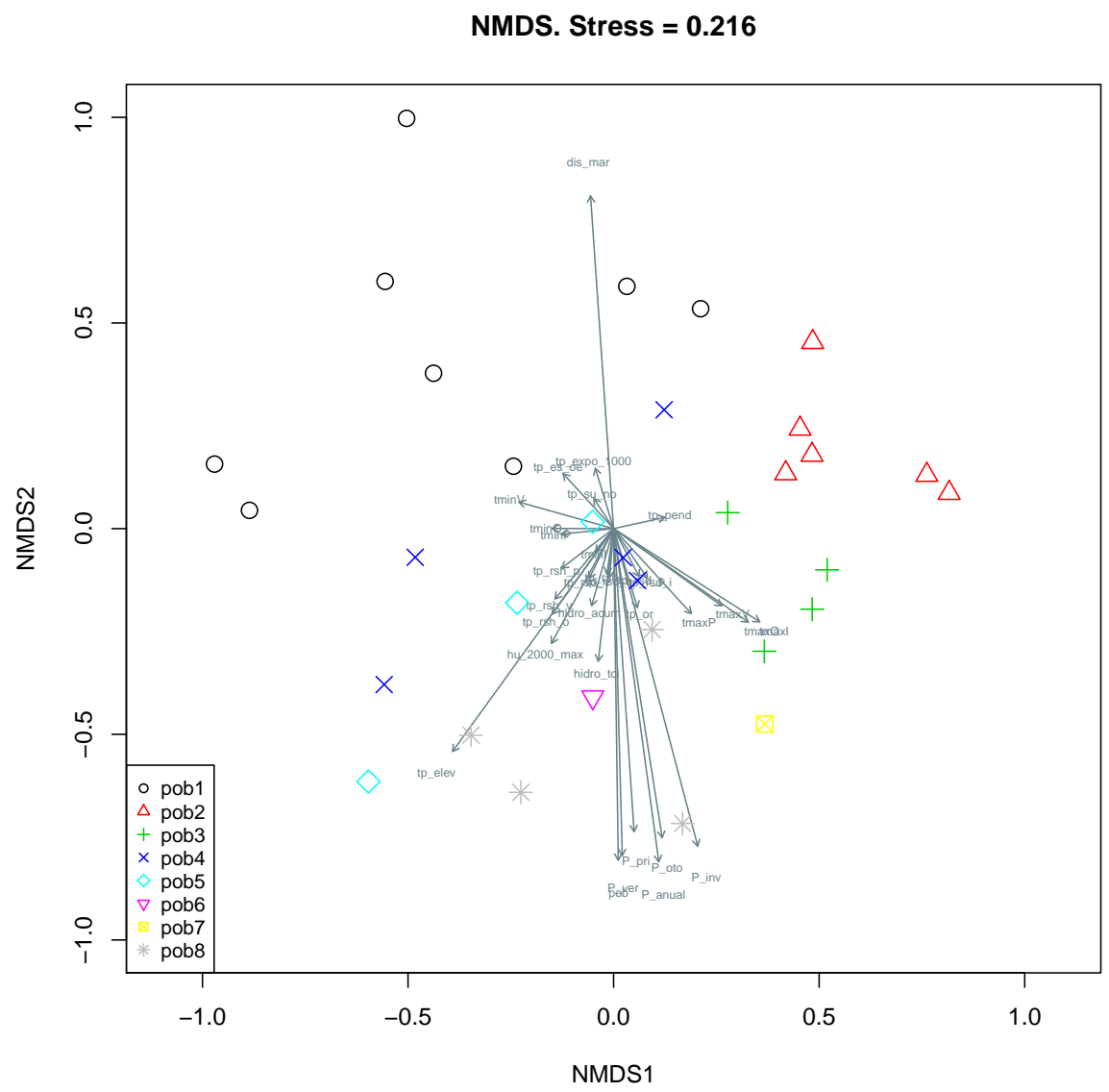

Figura 3.16 Ajuste de las variables ambientales de las parcelas (matriz ambiental puntual) sobre la ordenación de éstas obtenida en el escalamiento multidimensional no-metrico 

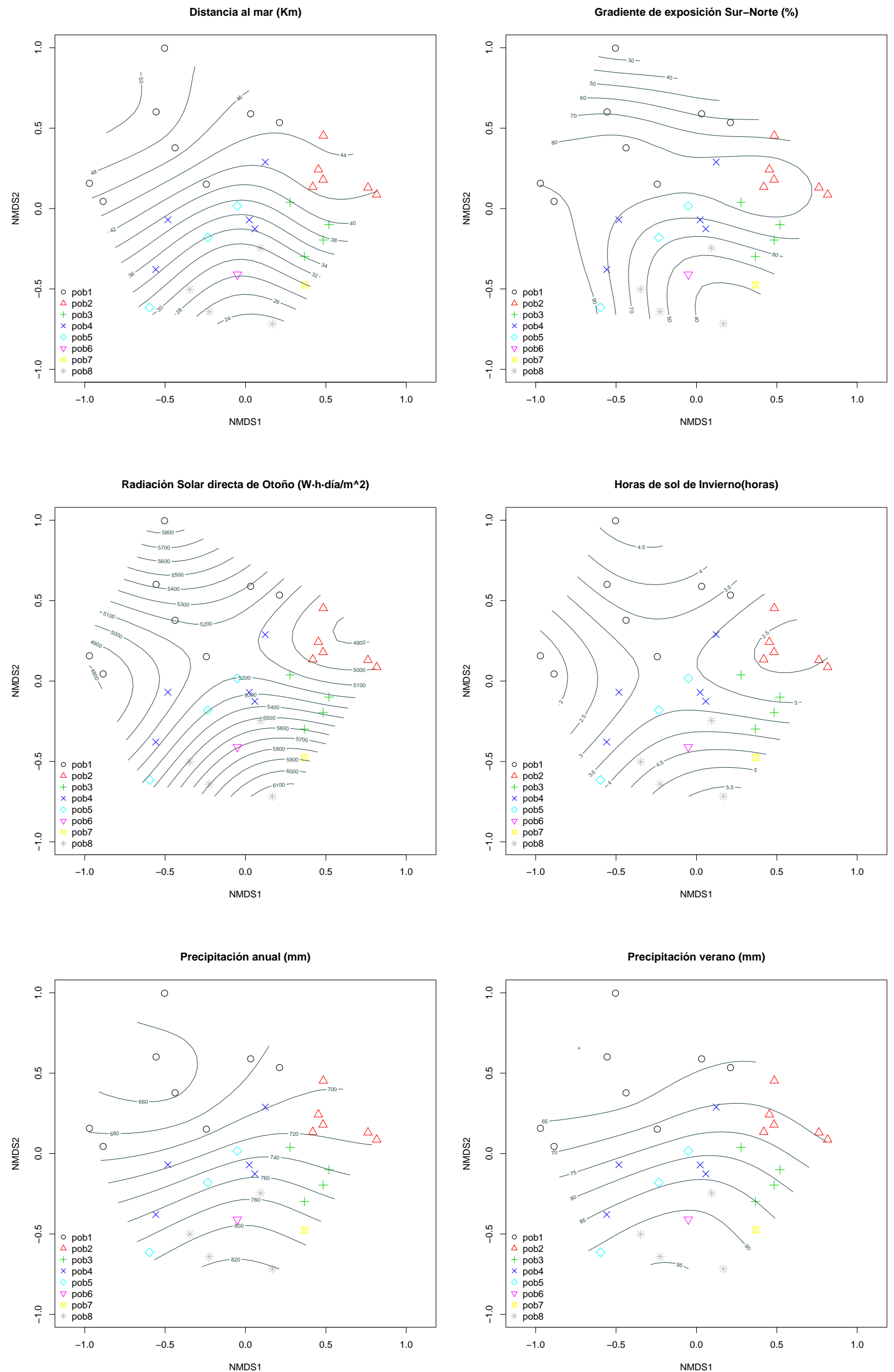

Figura 3.17 Superficies de ajuste de diferentes variables ambientales de las parcelas (matriz ambiental puntual) sobre la ordenación obtenida 
Temperatura media de las mínimas de Invierno $\left({ }^{\circ} \mathrm{C}\right)$

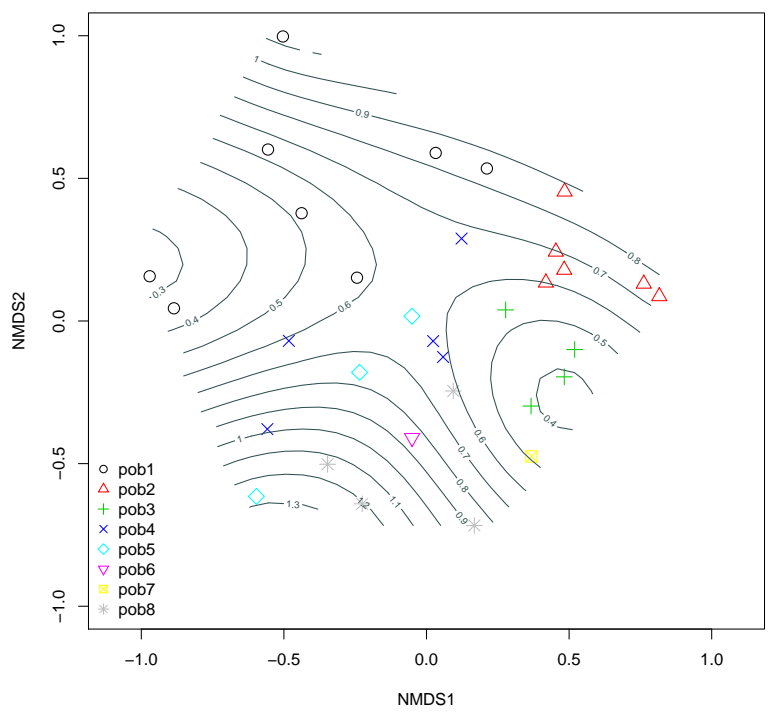

Temperatura media de las máximas de Invierno $\left({ }^{\circ} \mathrm{C}\right)$

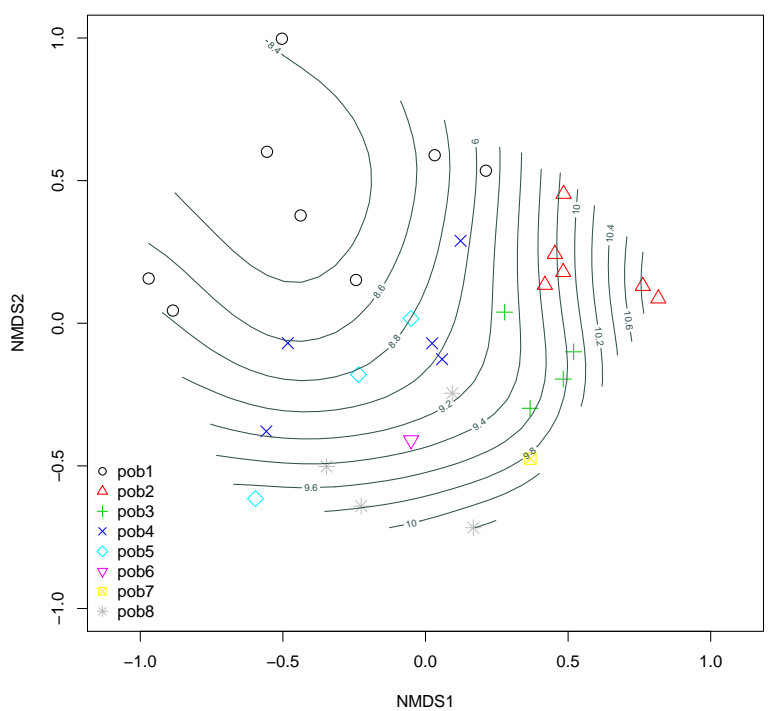

Elevacion (m)

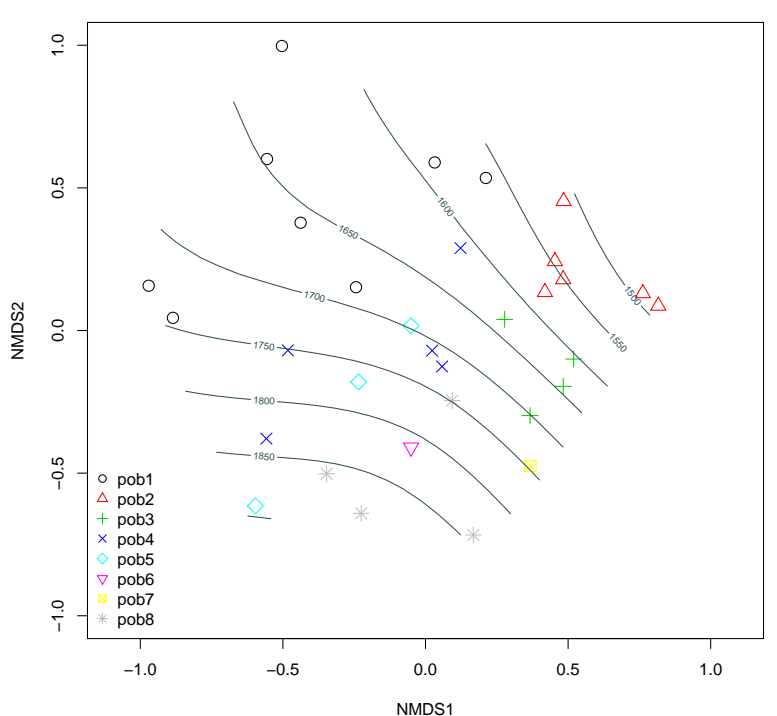

Temperatura media de las mínimas de Verano $\left({ }^{\circ} \mathrm{C}\right)$

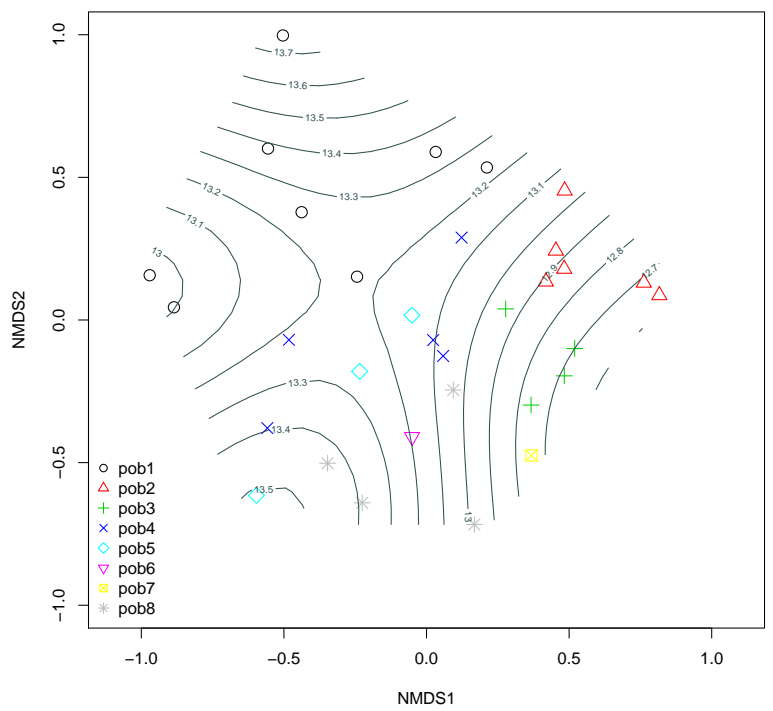

Temperatura media de las máximas de Verano (ํㅜ)

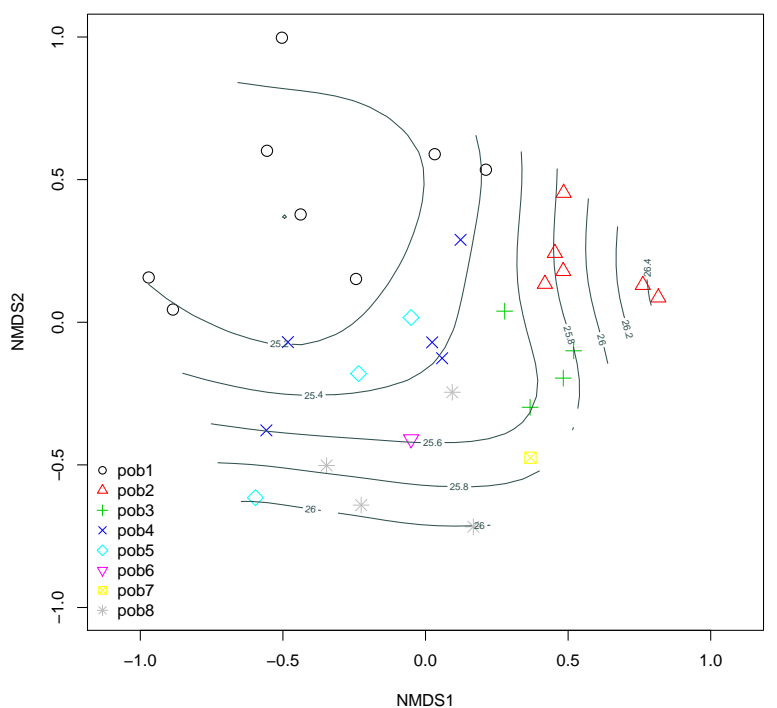

Precipitación primavera (mm)

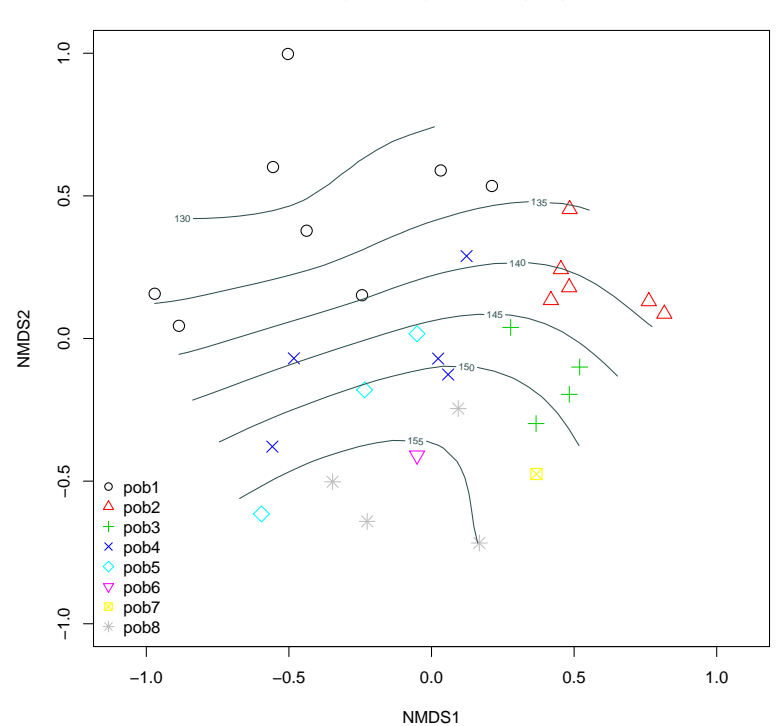

Figura 3.18 Superficies de ajuste de diferentes variables ambientales de las parcelas (matriz ambiental puntual) sobre la ordenación obtenida 


\section{Capítulo 4}

\section{Discusión}

\subsection{Discusión y conclusiones}

Respecto a la caracterización del hábtiat óptimo y marginal de los robledales de Sierra Nevada que hemos realizado cabe destacar que para las variables ambientales el coeficiente de variación ha sido en general bajo excepto para el índice de acumulación hídrica. No ha ocurrido lo mismo para los atributos forestales donde hemos apreciado que tanto los relacionados con la estructura (densidad de pies mayores, área basal de Quercus pyrenaica, altura media de los pies mayores y volumen) como la cantidad de regeneración observada han presentado un alto coeficiente de variación, indicando la heterogeneidad respecto a dichos atributos forestales. El hecho de esta heterogeniedad en la estructura de los robledales puede ser consecuencia del diferente impacto antrópico que presentan las ocho poblaciones de robledal en Sierra Nevada. Algunos trabajos han apuntado que estos ecosistemas han estado sometidos a diferentes presiones en Sierra Nevada (Jiménez-Olivencia, 1991; CamachoOlmedo et al 2001), lo que concuerda con lo observado en otros robledales de la Península Ibérica (Gavilán et al 2000; 2007) y que queda evidenciado con los resultados obtenidos en este trabajo: alta heterogeneidad mostrada por las diferentes poblaciones respecto a la estructura vertical forestal. Con respecto a la regeneración de los robledales la heterogeneidad obsevada puede tener relación con las diferencias en la estructura forestal en las poblaciones de robledal. Plieninger et al (2010) han apuntado que la regeneración de Quercus pyrenaica está gobernada principalmente por las actuaciones de gestión forestal y por la estructura forestal, estándo negativamente correlacionada con la presencia de grandes árboles. En este sentido, aunque en este trabajo solamente hemos realizado una exploración de los patrones de regeneración, los resultados observados parecen apuntar en esa dirección, indicando que el diferente uso antrópico condiciona la estructura forestal y la regeneración, hecho este último que ha sido puesto de manifiesto en otros trabajos sobre regeneración en ecosistemas forestales de Sierra Nevada (Navarro et al 2011; Navarro et al in prep). aunque sería necesario realizar un estudio específico de los factores que condicionan la regeneración en los robledales de Sierra Nevada, para lo cual sería básico contar con un tamaño de muestra mayor (mas parcelas de inventario forestal).

Como era de esperar, los valores medios del que definen el hábitat óptimo de las variables ambientales coinciden en general con los datos obtenidos por Benito (2009) ya que parte del conjunto de datos utilizados en el presente 
trabajo derivan de un mismo conjunto de datos. No ocurre igual para los datos climáticos, ya que por un lado, en nuestro trabajo hemos utilizado una serie temporal histórica de todos los datos climáticos disponibles en Sierra Nevada, y por otro lado, la escala utilizada en este trabajo es mayor gracias a los mapas climáticos del pasado de alta resolucion desarrollados por el Observatorio de Cambio Global de Sierra Nevada ${ }^{1}$. Este hecho pone de manifiesto la necesidad de la utilización de datos de alta resolución para realizar la simulaciones del comportamiento de las especies frente a los escenarios de cambio global, para lo cual, la existencia de programas de investigación a largo sobre cambio global es imprescindible.

Con respecto a las variables ambientales que condicionan la distribución de los robledales en Sierra Nevada, la distancia al mar y la precipitación son unas de las principales variables mas importantes en la distribución de los robledales de Sierra Nevada, como muestran los resultados obtenidos tanto en el análisis de componentes principales como en el análisis discriminante. El siguiente grupo de variables en importancia son las temperaturas, en mayor medida las temperaturas máximas y mas debilmente las temperaturas mínimas. Es conocido que los robledales necesistan unas condiciones de humedad mínimas durante el periodo vegetativo (Martinez-Parras \& Molero, 1982) y en Sierra Nevada los robledales, que se corresponden con su límite mas meridional de distribución, consiguen este aporte situándose en lugares donde las condiciones microclimáticas les permitan conseguir este aporte hídrico. La distancia al mar juega un papel muy importante en este sentido. Aquellas poblaciones mas cercanas al mar reciben el aporte extra necesario por la influencia del aire húmedo mediterráneo.

La discriminación entre las diferentes poblaciones de Sierra Nevada (figura 3.3) nos ha aportado una diferenciación en tres grupos de poblaciones: el grupo A, situado mas al norte y representado únicamente por la población de la Dehesa del Camarate (población 1); el grupo B, compuesto por las poblaciones de los valles del río Genil, río Monachil, río Dílar y río Durcal (poblaciones 2 a 5), que se sitúan en la zona norte-nordeste de Sierra Nevada; y por último el grupo $C$, compuesto por las poblaciones situadas al sur de Sierra Nevada (valles de los ríos Chico, Poqueira y Trevelez; poblaciones 6 a 8). Al igual que en el análisis de componentes principales, las principales variables que discriminan entre estos grupos de poblaciones son, por un lado y en primer lugar, la distancia al mar, estándo el grupo A mas alejado del mar mediterráneo que los robledales del grupo B y C; en segundo lugar, tanto las precipitaciones de primeravera como las radiación solar. Destaca por último con importancia mas débil el índice de influencia humana, siendo el grupo C, es decir las poblaciones situadas mas al sur las que presentan un mayor índice de influencia humana.

La comparación de las diferentes variables ambientales y atributos forestales entre estos grupos de poblaciones ha puesto de manifiesto, que por un lado respecto a las características forestales, el grupo A presenta menores valores de atributos estructurales (altura media, área basal, densidad de pies mayores, volumen) y una menor regeneración. Cabría esperar que en este grupo existiera una mayor influencia humana, pero la variable utilizada en este trabajo no revela que presente este grupo un mayor índice de intervención humana. No obstante se

\footnotetext{
${ }^{1}$ Mapas de clima pasado. Elaborados por Benito, B.; Reyes-Muñoz, P.S \& Perez-Perez, R. Disponibles en Linaria: Sistema de Informacion del Observatorio de Cambio Global de Sierra Nevada. http: // dev. iecolab. es/ linaria/ clima/ indice_ mapas_ pasados . Mas informacion en http://iecolab.es/node/43 y en http://iecolab.es/node/51.
} 
evidencia la necesidad de realizar estudios de las variables forestales en estos grupos relacionándolos con variables que midan el uso humano o la influencia antrópica de forma mas explícita para estudiar si el comportamiento en los atributos forestales de estos grupos de poblaciones están condicionados por el diferente uso humano de dichas poblaciones. Por otro lado el grupo A presenta un mayor número de especies y difiere en cuanto a la diversidad de las mismas con el grupo de población B. Asimismo ocurre igual para la fracción de cabida cubierta de herbáceas.

Para las variables ambientales se han encontrado que los tres grupos de poblaciones quedan significativamente diferenciados para la mayoría de las diferentes variables ambientales estudiadas. No ha ocurrido lo mismo para los atributos forestales, como hemos comentado. Este hecho refleja que las condiciones ambientales en las que se situan los grupos de poblaciones son diferentes y que el comportamiento forestal de las poblaciones no está influenciado tanto por las condiciones ambientales sino por el uso humano que se ha realizado de los ecosistemas naturales, de forma que pone de manifiesto la importancia del impacto humano como motor principal motor de cambio en los ecosistemas meditarráneos (Dale, 1997) que puede actuar de forma sinérgica con el cambio climático (Matesanz et al. 2009).

Además, y como resultado interesante, es destacable el hecho de que los diferentes grupos discriminados por medio de las variables ambientales se corresponden igualmente con la ordenación de las poblaciones en función de su similitud florística (figura 3.15). Observamos en esta última que los diferentes grupos de poblaciones se sitúan agrupados: el grupo A (población 8) en la parte superior del gráfico; el grupo B (poblaciones 2 a 5 ) en la parte central, y el grupo C (poblaciones 6 a 8 ) en la parte inferior del gráfico. Cuando relacionamos esta ordenación con las diferentes variables ambientales obtenemos resultados concordantes con la discriminación entre grupos realizada por el análisis discrimiante en base exclusivamente a variables ambientales (figura 3.16), siendo la distancia al mar, la precipitación, las temperaturas, y en menor medida la elevación, las variables mas importantes que condicionan la composición específica de estos grupos de poblaciones. Es decir, existe un acoplamiento entre la separación de grupos de poblaciones de robledal realizado basándonos en variables abióticas y aquella realizada en base a la composición florística.

Por último el presente trabajo supone un análisis preliminar que ha permitdo realizar una caracterización de los diferentes grupos de poblaciones de robledal existentes en Sierra Nevada. En este sentido se considera una aportación útil ya que: por un lado, a la hora de llevar a cabo estudios concretos de la evaluación de los efectos del cambio global (cambios de uso y cambio climático) podemos utilizar esta separación de grupos para elegir los sistemas en los que realizar dichas investigaciones y no necesariamente se han de realizar en todas las poblaciones de robledal, ya que como hemos mostrado, se diferencian claramente tres grupos de comportamiento, tanto ambiental como de composición florística. En este sentido y en un caso mas concreto, el proyecto Cambio Global, Migración altitudinal y colonización de hábitats degradados en montañas Mediterráneas (MIGRAME) ${ }^{2}$,

Proyecto de Investigación de Excelencia de la Junta de Andalucía. IP: Regino Zamora Rodríguez, catedrático de Ecología. Departamento de Ecología, Universidad de Granada. Mas información en http://www.iecolab.es/node/54 
cuyo objetivo principal es reconstruir el pasado de las formaciones de robledal y enebral en Sierra Nevada, conocer la dinámica demográfica y dispersiva actual, y calibrar simulaciones de distribución futura; necesita definir unas zonas de trabajo previas para la realización de los trabajos de campo, para lo cual la discriminación entre poblaciones de robledal aportada por este trabajo ayuda a la hora de seleccionar aquellas zonas de muestreo. Por otro lado a la hora de realizar actuaciones de gestión de los recursos naturales y mas concretamente, sobre la conservación y restauración de los robledales, los resultados aportados en este trabajo añaden información útil a los responsables del espacio Natural de Sierra Nevada para los Sistemas de Ayuda a la Toma de Decisiones.

Finalmente la existencia de programas de seguimiento sobre los efectos del cambio global en las regiones de montaña, como el Observatorio de Cambio Global de Sierra Nevada (Bonet et al, 2007; 2010; 2011), es imprescindible para generar información de detalle, como la utilizada en este tabajo, que nos permita conocer el funcionamiento de los ecosistemas frente a los impactos del cambio global para realizar tareas de gestión adaptativa.

\subsection{Futuras líneas de investigación}

- Estudios de la influencia del impacto humano en las poblaciones de robledal de Sierra Nevada.

- Análisis del acoplamiento entre la composición de especies y las variables ambientales en diferentes ecosistemas forestales de Sierra Nevada

- Caracterización ambiental de los principales ecosistemas de Sierra Nevada. 


\section{Capítulo 5}

\section{Bibliografía}

Adler, D. \& Murdoch, D. (2011). rgl: 3D visualization device system (OpenGL). R package version 0.92.798. http: //CRAN . R-project . org/package=rgl

Atil, H. \& Unver, Y. (2001). Multiple comparisons. Online Journal of Biological Sciences, 1 (8): 723-727.

Baraza, E., Gómez, J.M., Hódar, J.A. \& Zamora, R. (2004) Herbivory has a greater impact in shade than in sun : response of Quercus pyrenaica seedlings to multifactorial environmental variation. Canadian Journal of Botany, 364, 357-364.

Baraza, E., Zamora, R. \& Hódar, J.A. (2010) Species-specific responses of tree saplings to herbivory in contrasting lighte environments: an experimental approach. Ecoscience, 17, 156-165.

Benito, B. (2008). El calentamiento global en Sierra Nevada. Modelos de distribución potencial de formaciones vegetales sobre distintos escenarios de cambio climático. Trabajo Defensa Diploma de Estudios Avanzados. Disponible en http://dl.dropbox.com/u/4948740/DEA_TESIS/2008_DEA_BLAS_BENITO.pdf

Benito, B. (2009). Ecoinformática aplicada a la conservación: simulación de efectos del cambio global en la distribución de la flora de Andalucía. Tesis Doctoral. Departamento de Botánica. Universidad de Granada. Disponible en http://ide.ugr.es/blasbenito/tesis/PDF/TESIS_BLAS_BENITO.pdf

Benito, B., Lorite, J. \& Peñas, J. (2011) Simulating potential effects of climatic warming on altitudinal patterns of key species in Mediterranean-alpine ecosystems. Climatic Change, 108(3): 471-483.

Blanca, G.; Cueto, M.; Martínez-Lirola, M.J. \& Molero-Mesa, J. (1998). Threatened vascular flora of Sierra Nevada (Southern Spain). Biological Conservation, 85 (3): 269-285.

Blanca, G.; López, M.R.; Lorite, J.; Martínez-Lirola, M.J.; Molero-Mesa, J.; Quintas, S.; Ruíz Girela, M.; Varo, M.A. \& Vidal, S. (2001). Flora amenazada y endémica de Sierra Nevada. Universidad de Granada. Consejería de Medio Ambiente. Junta de Andalucía.

Bonet García, F.J.; Aspizua Cantón, R.; Cano Manuel-León, F.J.; Zamora Rodríguez, R. \& Sánchez Gutiérrez, J. (2007). El obseratorio de seguimiento del cambio global de Sierra Nevada (España). In I Congreso Nacional sobre Cambio Global Ambiental. Abril 2007. Madrid.

Bonet, F.J.; Pérez-Luque, A.J.; Moreno, R. \& Zamora, R. (2010). Observatorio de Cambio Global en Sierra Nevada. Estructura y contenidos básicos. Consejería de Medio Ambiente, Junta de Andalucía - Universidad de Granada.http://es.scribd.com/doc/32239398/Observatorio-Sierra-Nevada-Datos-basicos

Bonet García, F.J.; Aspizua Cantón, R.; Zamora Rodríguez, R.; Sánchez Gutiérrez, F.J.; Cano-Manuel León, F.J. \& Henares-Civantos, I. (2011). Sierra Nevada Observatory for monitoring global change: Towards the adaptive management of natural resources. In Austrian MaB Comitee, (Ed.). Austrian Academy of Sciences Press, 48-52.

Borsdorf, A. \& Braun, V. (2008). The European and Global dimension of mountain research. An overview. Journal of Alpine Research, 96 (4): 117-129 
Butchart, S.M.; Walpole, M.; Collen, B.; van Strien, A. Scharlemann, J.P.W.; Almond, R.; Baillie, J.E.M.; Bomhard, B.; Brown, C.; Bruno, J.; Carpenter, K.E.; Carr, G.M.; Chanson, J.; Chenery, A.M.; Csirke, J.; Davidson, N.C.; Dentener, F.; Foster, M.; Galli, A.; Galloway, J.N.; Genovesi, P.; Gregory, R.D.; Hockings, M.; Kapos, V.; Lamarque, J.F.; Leverington, F.; Loh, J.; McGeoch, M.A.; McRae, L.; Minasyan, A.; Hernández Morcillo, M.; Oldfield, T.E.E.; Pauly, D.; Quader, S.; Revenga, C.; Sauer, J.R.; Skolnik, B.; Spear, D.; Stanwell-Smith, D.; Stuart, S.N.; Symes, A.; Tierney, M.; Tyrrell, T.D.; Vié, J.C.; \& Watson, R. (2010). Global Biodiversity: Indicators of Recent Declines. Science, 328: 1164-1168.

Camacho-Olmedo, M.T., Jiménez-Olivencia, Y., García-Martínez, P., Mentor, J. \& Paniza, A. (2002). La alta alpujarra granadina en la segunda mitad del siglo XX a través de la cartografía evolutiva de su paisaje: dinámica vegetal y repoblación forestal. Cuadernos Geograficos, 32, 25-42.

Castillo-Marín, P.A. \& Castillo-Marín, C. (2010). Situación y caracterización del roble melojo ( Quercus pyrenaica Willd.) en el parque natural de la Sierra de Aracena y picos de Aroche (Huelva). Forestra, 50: 92-100.

Castillo-Marín, P. A. \& Castillo-Marín, A. (2006). Determinación del área potencial del rebollo (Quercus Pyrenaica Willd) en el Parque Natural de la Sierra Norte de Sevilla. En: Camacho, M.T.; Cañete, J.A. \& Lara Valle, J.J. (eds). XII CONGRESO NACIONAL DE TECNOLOGÍAS DE LA INFORMACIÓN GEOGRÁFI$C A$. El acceso a la información espacial y las nuevas tecnologías geográficas, Granada, Editorial Universidad de Granada, 1831 pp.

Castro, J., Zamora, R. \& Hódar, J.A. (2006). Restoring Quercus pyrenaica forests using pioneer shrubs as nurse plants. Applied Vegetation Science, 9, 137-142.

Costa, M., Morla, C., y Sainz, H. (Eds) (2005). Los bosques ibéricos: una interpretación geobotánica. Ed. Planeta. 572 pp. $4^{\text {a }}$ Edición.

Dahl, D.B. (2009). xtable: Export tables to LAEX or HTML. R package version 1.5-6. http: //CRAN . R-project. org/package=xtable

Dale, V.H. (1997). The relationship between land-use change and climate change. Ecological Applications, 7 : $753-769$.

de Mendiburu, F. (2010). agricolae: Statistical Procedures for Agricultural Research. R package version 1.0-9. http://CRAN.R-project.org/package=agricolae

del Río, S. del, Herrero, L. \& Penas, Á. (2007) Bioclimatic analysis of the Quercus pyrenaica forests in Spain. Phytocoenologia, 37, 541-560.

Díaz-Maroto, I.J.; Fernández-Parajes, J. \& Vila-Lameiro, P. (2006). Autécologie du chêne tauzin (Quercus pyrenaica Willd.) en Galice (Espagne). Ann. For. Sci. 63: 157-167

Díaz-Maroto, I.J.; Vila-Lameiro, P.; Guchu, E. \& Díaz-Maroto, M.C. (2007). A comparison of the autecology of Quercus robur L. and Q. pyrenaica Wild.: present habitat in Galicia, NW Spain. Forestry, 80 (3): $223-239$.

Entrocassi, G., Gavilán, R. \& Sánchez Mata, D. (2004) Aplicación de análisis multivariables a los bosques ibéricos de Quercus pyrenaica. Fitosociologia, 41, 143-154.

EPA (Environmental Protection Agency, US). (2010). Climate Change and Ecosystems. Disponible en http: //www.epa.gov/climatechange/downloads/Climate_Change_Ecosystems.pdf

Falk, D.A., Millar, C.I. \& Olwell, M. (Eds.). (1996) Restoring Diversity: Strategies for reintroduction of endangered plants. Island Press, Washington, D.C.

Faria, J.C \& Demetrio, C. G. B (2011).bpca: Biplot of multivariate data based on Principal Components Analysis. ESALQ, USP, Brasil.

Fox, J. \& Weisberg F. (2011). An R Companion to Applied Regression. Second Edition. Thousand Oaks CA: Sage. http://socserv.socsci.mcmaster.ca/jfox/Books/Companion

Gaines, S.D. \& Denny, M.W. (1993) The largest, smallest, highest, lowest, longest and shortest: extremes in ecology. Ecology 74: 1677-1692. 
García Leal, J.; Lara Porras, A.M.; Navarrete, E.; Rico Castro, N; Román Montoya, Y.; Ruiz-Castro, J.E. \& Sánchez-Borrego, I.R. (2007). Técnicas estadísticas aplicadas en Biología con SPSS. Proyecto Sur Ediciones

García, I. \& Jiménez, P., (2009). 9230 Robledales de Quercus pyrenaica y robledales de Quercus robur y Quercus pyrenaica del Noroeste ibérico. En: VV.AA., Bases ecológicas preliminares para la conservación de los tipos de hábitat de interés comunitario en España. Madrid: Ministerio de Medio Ambiente, y Medio Rural y Marino. 66 p.

Gavilán, R., Escudero, A. \& Rubio, A. (2000) Effects of disturbance on floristic patterns of Quercus pyrenaica forests in central Spain. Proceedings IAVS Symposium. pp. 226-229.

Gavilán, R., Sánchez Mata, D., Vilches, B. \& Entrocassi, G. (2007) Modeling current distribution of Spanish Quercus pyrenaica forests using climatic parameters. Phytocoenologia, 37, 561-581.

Gavilán, R. \& Fernández-González, F. (1997). Climatic discrimination of mediterranean broad-leaved sclerophyllous and deciduous forests in central Spain. Journal of Vegetation Science, 8 (3): 377-386.

Gómez-Aparicio, L., Pérez-Ramos, I.M., Mendoza, I., Matías, L., Quero, J.L., Castro, J., Zamora, R. \& Marañón, T. (2008) Oak seedling survival and growth along resource gradients in Mediterranean forests: implications for regeneration in current and future environmental scenarios. Oikos, 117, 1683-1699.

Gómez-Aparicio, L., Valladares, F., Zamora, R. \& Quero, J.L. (2005). Response of tree seedlings to the abiotic heterogeneity generated by nurse shrubs: an experimental approach at different scales. Ecography, 28, 757-768.

Gómez, J.M., Garcia, D. \& Zamora, R. (2003) Impact of vertebrate acorn- and seedling-predators on a Mediterranean Quercus pyrenaica forest. Forest Ecology and Management, 180, 125-134.

González-Rodríguez, M.V. (2010). Establecimiento de cuatro especies de Quercus en el sur de la Península Ibérica. Factores condicionantes. Tesis Doctoral, Universidad de Córdoba.

Gordo, O. \& Sanz, J.J.É. (2010). Impact of climate change on plant phenology in Mediterranean ecosystems. Global Change Biology, 16 (3): 1082-1106

Grandas, J.A. (1997). Estudio ecológico y recomendaciones selvícolas para el manejo de las masas gallegas de Quercus pyrenaica Willd. Proyecto Fin de Carrera. E. I. T. Explotaciones Forestales. E. P. S. Lugo. Universidad de Santiago de Compostela.

Grandas, J.A.; Díaz-Maroto, I.J. \& Silva-Pando, F.J. (1997). Indicadores selvícolas de la calidad de estación de los bosques gallegos de Quercus pyrenaica Willd. (Reboleiras). I Congreso Forestal Hispano-Luso. II Congreso Forestal Español. Pamplona (España). Junio, 1997. Ed.: Gobierno de Navarra.

Gross, J (2006). nortest: Tests for Normality. R package version 1.0.

Harrell, F.E.; and with contributions from many other users (2010). Hmisc: Harrell Miscellaneous. R package version 3.7-0. http://CRAN.R-project . org/package=Hmisc

Hotelling, H. (1933). Analysis of a complex of statistical variables into principal components. J. Educ. Psychol. 24: $417-441$.

Hothorn, T.; Bretz, F. \& Westfall, P. (2008). Simultaneous Inference in General Parametric Models. Biometrical Journal 50 (3): 346-363.

Hughes, L. (2000). Biological consequences of global warming: Is the signal already apparent? Trends in Ecology and Evolution, 15: 56-61.

Ibanez, F.; Grosjean, P. \& Etienne, M. (2009). pastecs: Package for Analysis of Space-Time Ecological Series. $\mathrm{R}$ package version 1.3-11. http://CRAN. R-project.org/package=pastecs

IPCC (2007). Climate Change 200\%: Impacts, Adaptation and Vulnerability. Contribution of Working Group II to the Fourth Assessment Report of the Intergovernmental Panel on Climate Change. Cambridge University Press, Cambridge, UK. 976 pp. 
James, F.C. \& McCulloch, C.E. (1990). Multivariate analysis in ecology and systematics: Panacea or Pandora's box?. Annu. Rev. Ecol. Syst., 21:129-166.

Jiménez-Olivencia, Y. (1991). Los paisajes de Sierra Nevada. Cartografía de los sistemas naturales de una montaña mediterránea. Universidad de Granada.

Jiménez, M.P.; Díaz-Fernández, P.M.; Martín-Albertos, S. \& Gil-Sánchez, L. (1998). Las regiones de procedencia de Quercus pyrenaica Willd., Quercus faginea Lam. y Quercus canariensis Willd. MMA. Organismo autónomo de Parques Nacionales. Madrid. 91 pp.

Junta de Andalucía (2004). Ortofotografía digital de Andalucía, provincia de Granada. Consejería de Obras Públicas y Transportes. Consejería de Agricultura y Pesca. Consejería de Medio Ambiente. Junta de Andalucía.

Junta de Andalucía (2005a). Modelo digital del terreno de Andalucía. Relieve y Orografía. Consejería de Obras Públicas y Transportes. Consejería de Agricultura y Pesca. Consejería de Medio Ambiente. Junta de Andalucía.

Junta de Andalucía (2005b). Ortofotografía digital en color, provincia de Granada. Consejería de Obras Públicas y Transportes. Consejería de Agricultura y Pesca. Consejería de Medio Ambiente. Junta de Andalucía.

Kohler, T. \& Maselli, D. (2009). Mountains and climate changing. From understanding to action. Geographica Bernensia; Swiss Agency for Development and Cooperation (SDC). Bern. 76 pp.

Kindt, R. \& Coe, R. (2005). Tree diversity analysis. A manual and software for common statistical methods for ecological and biodiversity studies. World Agroforestry Centre (ICRAF), Nairobi.

Lawler, J.J.; Tear, T.H.; Pyke, C.; Shaw, M.R.; Gonzalez, P.; Kareiva, P.; Hansen, L.; Hannah, L.; Klausmeyer, K.; Aldous, A.; Bienz, C. \& Pearsall, S. (2010). Resource management in a changing and uncertain climate. Frontiers in Ecology and the Environment, 8 (1): 35 - 43.

Legendre, P. \& Legendre, L. (2000). Numerical Ecology. Elsevier. The Netherlands. 853 pp.

Ligges, U. \& Mächler, M. (2003). Scatterplot3d - an R Package for Visualizing Multivariate Data. Journal of Statistical Software 8(11): 1-20.

López de Hierro, L.; Martín-Molero, J.C.; Serrano Bernardo, F.A. \& Sánchez-Lara, A. (2001). Quercus pyrenaica Willd. En: Rosúa, J.L.; López de Hierro, L.; Martín-Molero, J.C.; Serrano Bernardo, F.A. \& Sánchez-Lara, A. (eds).: Procedencia de las especies vegetales autóctonas de Ándalucía utilizadas en restauración de la cubierta vegetal. Tomo II. Consejería de Medio Ambiente, Junta de Andalucía. pp: 185-195.

Lorite, J.; Gómez, F.; Mota, J.F. \& Valle F. (2007). Orophilous plant communities of Baetic range in Andalusia (southeastern Spain): Priority altitudinal-island for conservation. Phytocoenologia, 37(3-4): 625-644.

Lorite, J., Salazar, C., Peñas, J. \& Valle, F. (2008). Phytosociological review on the forests of Quercus pyrenaica Willd. Acta Botanica Gallica, 155, 219-233.

Macchi, M. \& ICIMOD (2010). Mountains of the world - Ecosystem services in a time of global and climate change: seizing opportunities - meeting challenges. International Center for Integrated Mountain Development, Kathmandu.

Martín-Albertos, S.; Díaz-Fernández, P.M. \& de Miguel, J. (1998). Regiones de procedencia de especies forestales españolas. Descripción y principales características. Géneros Abies, Fagus, Pinus y Quercus. Organismo Autónomo de Parques Nacionales. Madrid

Martínez-Parras, J.M. \& Molero, J. (1982) Ecología y fitosociología de Quercus pyrenaica Willd. en la provincia Bética. Los melojares béticos y sus etapas de sustitución. Lazaroa, 4, 91-104.

Matesanz, S., Escudero, A. \& Valladares, F. (2009). Impact of three global change drivers on a Mediterranean shrub. Ecology, 90 (9): 2609-2621.

McCarthy, J.J.; Canziani, O.F.; Leary, N.A.; Dokken, D.J. \& White, K.S. (Eds.). (2001) Climate Change 2001: Impacts, Adaptation \& Vulnerability. Contribution of Working Group II to the Third Assessment Report of the Intergovernmental Panel on Climate Change (GIEC). Cambridge University Press, Royaume-Uni, 1000p. 
McElhinny, C., Gibbons, P., Brack, C. \& Bauhus, J. (2005). Forest and woodland stand structural complexity: its definition and measurement. Forest Ecology and Management, 218: 1-24.

Melendo, M. \& Valle, F. (1996). Estudio comparativo de los melojares nevadenses. $1^{\text {a }}$ Conferencia Internacional Sierra Nevada, Conservación y Desarrollo Sostenible. (eds J. Chacón \& J.L. Rosúa), pp. vol. 2. 463-479.

Mendoza, I., Zamora, R. \& Castro, J. (2009). A seeding experiment for testing tree-community recruitment under variable environments: Implications for forest regeneration and conservation in Mediterranean habitats. Biological Conservation, 142, 1491-1499.

MMA, (2005). Inventario para la caracterización de las masas arboladas del Parque Nacional de Sierra Nevada. "Asistencia Técnica para la naturalización y diversificación de las masas arboladas del Parque Nacional de Sierra Nevada". TRAGSA - Ministerio de Medio Ambiente

Molero Mesa, J.; Pérez Raya, F.; López Nieto, J.M.; El Aallali, A. \& Hita Fernández, J.A. (2001). Cartografía y evaluación de la vegetación del Parque Natural de Sierra Nevada. Consejería de Medio Ambiente-Universidad de Granada.

Montgomery, D. (2002). Diseño y análisis de Experimentos. Ed. Limusa-Wiley. 686. pp.

Moore I.D., Norton, T.W., \& Williams J.E., (1993). Modelling environmental heterogeneity in forested landscapes. Journal of Hydrology, 150(2-4): 717-747.

Murdoch, D. \& Chow, E. D. (2007). ellipse: Functions for drawing ellipses and ellipse-like confidence regions. R package version $0.3-5$.

Navarro-Cerrillo, R.M.; Lora-González, A. \& Blanco Oyonarte, P. (2003). Ecosistemas forestales de Andalucía. Mapa forestal de Andalucía. In: Curso Estado del Medio Físico. Universidad de Cordoba. Departamento de Ingeniería Forestal. Disponible en http://www.uco.es/organiza/departamentos/ingforestal/extension/ mediofisico/html/programa.htm

Navarro González, I. (2010). Evolución de la cubierta vegetal: delimitación detallada de formaciones vegetales y gradientes altitudinales. Programa de seguimiento del Cambio Global en Sierra Nevada. Consultoría y asistencia técnica para la delimitación detallada de la distribución de formaciones vegetales de especial interés en Sierra Nevada y caracterización de gradientes altitudinales, mediante fotointerpretación de la ortofoto de 1956 (NET622009/1). EGMASA-CEAMA. (informe inédito).

Navarro González, I. \& Bonet García, F.J. (2010). Vegetation cover changes in Sierra Nevada mountains (Spain) during the past 50 years and relation to land use and climate change. In $2^{\mathrm{a}}$ International GMBA-DIVERSITAS Conference "Functional significance of mountain biodiversity". Chandolin, Switzerland. 27 - 30 Julio. Conference abstracts, p. 53 .

Navarro-González, I.; Pérez-Luque, A.J.; Bonet-García, F.J.; Zamora, R. (2011). Current Mediterranean forest regeneration depends on land use in the recent past. En: $12^{\text {th }}$ European Ecologial Federation Congres. Responding to rapid environmental change. Ávila, 25-29 Sep.

Navarro-González, I.; Pérez-Luque, A.J.; Bonet-García, F.J.; Zamora, R. (in prep). Current Mediterranean forest regeneration depends on land use in the recent past.

Neteler, M. \& Mitasova, H. (2007). Open Source GIS: A GRASS GIS Approach. Springer. 406 pp.

Ninyerola, M., Pons, X. y Roure, J. M. (2000). A methodological approach of climatological modelling of air temperature and precipitation through GIS techniques. International Journal of Climatology, 20: 1823-1841

Noss, R.F. (1990). Indicators for monitoring biodiversity: a hierarchical approach. Conserv. Biol. 4, 355-364.

Oksanen, J.; Blanchet, G.; Kindt, R.; Legendre, P.; Minchin, P.R.; O’Hara, B.; Simpson, G.L.; Solymos, P.; Stevens, M.H.H. \& Wagner, H. (2010). Vegan: community ecology package version 2.0.0. http: //CRAN.R-project. org $/$ package=vegan

Peres-Neto, P.R.; Jackson, D.A. \& Somers, K.M. (2003). Giving meaningful interpretation to ordination axes: assessing loading significance in principal component analysis. Ecology 84: 2347-2363. 
Peres-Neto, P.R.; Jackson, D.A. \& Somers, K.M. (2005). How many principal components? Stopping rules for determining the number of non-trivial axes revisited. Computat. Stat. Data Analysis, 49: 974-997

Plieninger, T.; Rolo, V. \& Moreno, G. (2010). Large-scale patterns of Quercus ilex, Quercus suber, and Quercus pyrenaica regeneration in Central-Western Spain. Ecosystems, 13, 644-660.

Quero, J.L., Villar, R., Marañon, T., Zamora, R. \& Poorter, L. (2007) Seed-mass effects in four mediterranean Quercus species (Fagaceae) growing in contrastring light environments. American Journal of Botany, 94, 17951803.

R Development Core Team (2011). R: A language and environment for statistical computing. R Foundation for Statistical Computing, Vienna, Austria. ISBN 3-900051-07-0. http://www.R-project.org/

Regato, P. (2008). Adapting to Global Change: Mediterranean Forests. Malaga, Spain: IUCN Centre for Mediterranean Cooperation. $254 \mathrm{pp}$.

Raiche, G. \& Magis, D. (2010). nFactors: Parallel Analysis and Non Graphical Solutions to the Cattell Scree Test. R package version 2.3.2. http://CRAN.R-project.org/package=nFactors

Rockström, J.; Steffen, W.; Noone, K.; Persson, A.; Chapin, F.S.; Lambin, E.F.; Lenton, T.M.; Scheffer, M.; Folke, C.; Schellnhuber, H.J.; Nykvist, B.; de Wit, C.A.; Hughes, T.; van der Leeuw, S.; Rodhe, H.; Sörlin, S.; Snyder, P.K.; Costanza, R.; Svedin, U.; Falkenmark, M.; Karlberg, L.; Corell, R.W.; Fabry, V.J.; Hansen, J.; Walker, B.H.; Liverman, D.; Richardson, K.; Crutzen, P. \&. Foley. J.A. (2009). A safe operating space for humanity. Nature 461: 472-475.

Sala, O.E., Chapin III, F.S., Armesto, J.J., Berlow, E., Bloomfield, J., Dirzo, R., Huber-Sanwald, E., Huenneke, L.F., Jackson, R.B., Kinzig, A., Leemans, R., Lodge, D.M., Mooney, H.A., Oesterheld, M., Poff, N.L., Sykes, M.T., Walker, B.H., Walker, M., Wall, D.H. 2000. Global Biodiversity Scenarios for the Year 2100. Science 287: 1770 - 1774 .

Sarkar, D. (2008) Lattice: Multivariate Data Visualization with R. Springer, New York.

SECF (2005). Diccionario Forestal. Sociedad Española de Ciencias Forestales. Mundi-Prensa. Madrid

Spehn, E. \& Körner, C. (2009). Biodiversity in Mountains: a natural heritage threatened by climate change. In: Kohler \& Maselli (eds.) Mountains and climate changing. From understanding to action. Geographica Bernensia; Swiss Agency for Development and Cooperation (SDC). Bern. $40-47$ pp.

Tausch, R.J. (2008). Invasive Plants and Climate Change. (May 20, 2008). U.S. Department of Agriculture, Forest Service, Climate Change Resource Center. Disponible en http://www.fs.fed.us/ccrc/topics/ invasive-plants.shtml

Thuiller, W.; Lavorel, S.; Araújo, M.B.; Sykes, M.T. \& Prentice, I.C. (2005). Climate change threats plant diversity in Europe. Proceedings of the National Academy of Sciences, 102: 8245-8250.

Venables, W. N. \& Ripley, B. D. (2002) Modern Applied Statistics with S. Fourth Edition. Springer, New York.

Westhoff, V., \& van der Maarel, E. (1978). The Braun-Blanquet approach. In R. H.Whittaker, editor. Classification of plant communities. Dr. W. Junk, Den Haag. 287-399.

Wickham, H. (2009). ggplot2: elegant graphics for data analysis. Springer New York, 2009.

Zamora, R. (2010). Las áreas protegidas como Observatorios del Cambio Global. Ecosistemas, 19 (2): 1 - 4. Disponible en http://www.revistaecosistemas.net/articulo.asp?Id=646

Zavala, M.A.; Zamora, R.; Pulido, F.; Blanco, J.A.; Imbert, J.B.; Marañón, T.; Castillo, F.J. \& Valladares, F. (2004). Nuevas perspectivas en la conservación, restauración y gestión sostenible del bosque mediterráneo. En: Ecología del bosque mediterráneo en un mundo cambiante. Madrid. Ministerio de Medio Ambiente, pp: 509-529. 
Capítulo 6

\section{Anexos}




\subsection{Anexo I: Listado de especies presentes en los inventarios florís- ticos}

\begin{tabular}{|c|c|c|c|}
\hline Nombre científico & abrev. & Nombre científico & abrev. \\
\hline Acer opalus subsp. granatense & Aopa & Hieracium pilosella subsp. tricholepium & Hpil \\
\hline Adenocarpus decorticans & Adec & Hormatophylla spinosa & Hspi \\
\hline Agrostis canina & Acan & Hypericum perforatum & Hper \\
\hline Andryala integrifolia & Aint & Juncus effusus & Jeff \\
\hline Arenaria armerina subsp. armerina & Aarm & Juniperus communis & Jcom \\
\hline Armeria villosa subsp. bernisii & Avil & Juniperus sabina & Jsab \\
\hline Arrhenatherum elatius subsp. bulbosum & Aela & Koeleria vallesiana & Kval \\
\hline Artemisia absinthium & Aabs & Lathyrus pratensis & Lpra \\
\hline Artemisia barrelieri & Abar & Lonicera arborea & Larb \\
\hline Artemisia campestris subsp. glutinosa & Acam & Marrubium supinum & Msup \\
\hline Avenula bromoides subsp. pauneroi & Abro & Ononis aragonensis & Oara \\
\hline Berberis hispanica & Bhis & Ononis spinosa & Ospi \\
\hline Brachypodium retusum & Bret & Phlomis crinita & Pcri \\
\hline Carlina corymbosa & Ccor & Pistacia terebinthus & Pter \\
\hline Carthamus lanatus & Clan & Plantago lanceolata & Plan \\
\hline Celtis australis & Caus & Plantago radicata subsp. granatensis & Prad \\
\hline Centaurea monticola & Cmon & Populus nigra & Pnig \\
\hline Centaurea ornata & Corn & Potentilla reuteri & Preu \\
\hline Centaurea pulvinata & Cpul & Prunus avium & Pavi \\
\hline Cerastium gibraltaricum & Cgib & Prunus dulcis & Pdul \\
\hline Chondrilla juncea & Cjun & Prunus mahaleb & Pmah \\
\hline Cirsium odontolepis & Codo & Prunus ramburii & Pram \\
\hline Cirsium pyrenaicum & Cpyr & Ptilostemon hispanicus & Phis \\
\hline Clematis vitalba & Cvit & Quercus coccifera & Qcoc \\
\hline Clinopodium vulgare subsp. arundanum & Cvul & Quercus faginea & Qfag \\
\hline Corynephorus canescens & Ccan & Quercus ilex subsp. ballota & Qilex \\
\hline Cotoneaster granatensis & Cotg & Quercus pyrenaica & Qpyr \\
\hline Crataegus granatensis & Crag & Retama sphaerocarpa & Rsph \\
\hline Crataegus monogyna subsp. brevispina & Cram & Ridolfia segetum & Rseg \\
\hline Crocus nevadensis & Cnev & Rosa canina & Rcan \\
\hline Cytisus galianoi & Cgal & Rosa corymbifera & Rcor \\
\hline Cytisus scoparius subsp. reverchonii & Csco & Rosa micrantha & Rmic \\
\hline Dactylis glomerata & Dglo & Rosa pouzinii & Rpou \\
\hline Dactylis glomerata subsp. hispanica & Dghi & Rosa sicula & Rsic \\
\hline Daphne gnidium & Dgni & Rubus ulmifolius & Rulm \\
\hline Dianthus pungens subsp. brachyanthus & Dpun & Rumex induratus & Rind \\
\hline Digitalis purpurea & Dpur & Salix caprea & Scap \\
\hline Echinospartum boissieri & Eboi & Sanguisorba minor & Smin \\
\hline Elymus hispanicus & Ehis & Santolina rosmarinifolia subsp. canescens & Srca \\
\hline Erinacea anthyllis & Eant & Santolina rosmarinifolia subsp. rosmarinifolia & Srro \\
\hline Eryngium campestre & Ecam & Scabiosa turolensis & Stur \\
\hline Euphorbia characias & Echa & Sedum forsteranum & Sfor \\
\hline Euphorbia nevadensis & Enev & Sedum sediforme & Ssed \\
\hline Euphorbia nicaeensis & Enic & Silene latifolia & Slat \\
\hline Festuca elegans & Fele & Silene mellifera & Smel \\
\hline Festuca hystrix & Fhys & Smilax aspera & Sasp \\
\hline Festuca indigesta & Find & Solidago virgaurea & Svir \\
\hline Festuca scariosa & Fsca & Sorbus aria & Sari \\
\hline Fraxinus angustifolia & Fang & Teucrium capitatum & Tcap \\
\hline Genista cinerea subsp. speciosa & Gcin & Teucrium similatum & Tsim \\
\hline Genista versicolor & Gver & Thymus mastichina & Tmas \\
\hline Halimium atriplicifolium & Hatr & Thymus serpylloides subsp. serpylloides & Tser \\
\hline Helianthemum hirtum & Hhir & Thymus zygis & Tzyg \\
\hline Helichrysum italicum subsp. serotinum & Hita & Vicia sp. & Vici \\
\hline Helleborus foetidus & Hfoe & Vinca difformis & Vdif \\
\hline
\end{tabular}

Tabla I.1. Listado de especies presentes en los inventarios florísticos de las parcelas del Inventario Forestal 


\subsection{Anexo II: Análisis preliminar ACP}

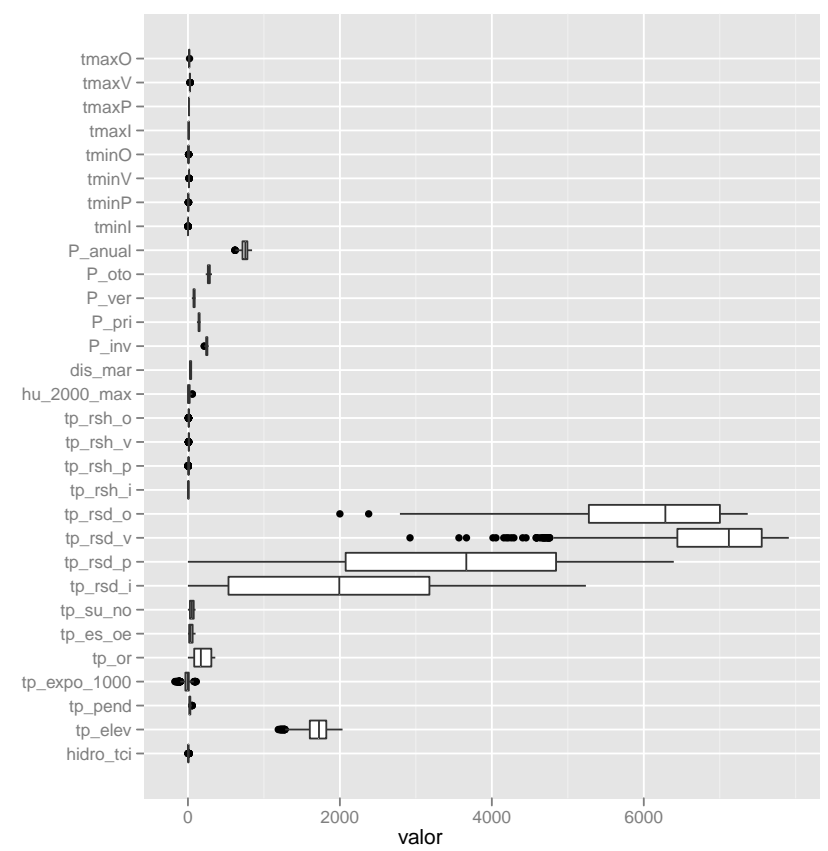

Figura II.1. Análisis preliminar de los datos de las variables ambientales. Observamos como presentan diferentes escalas de medida.

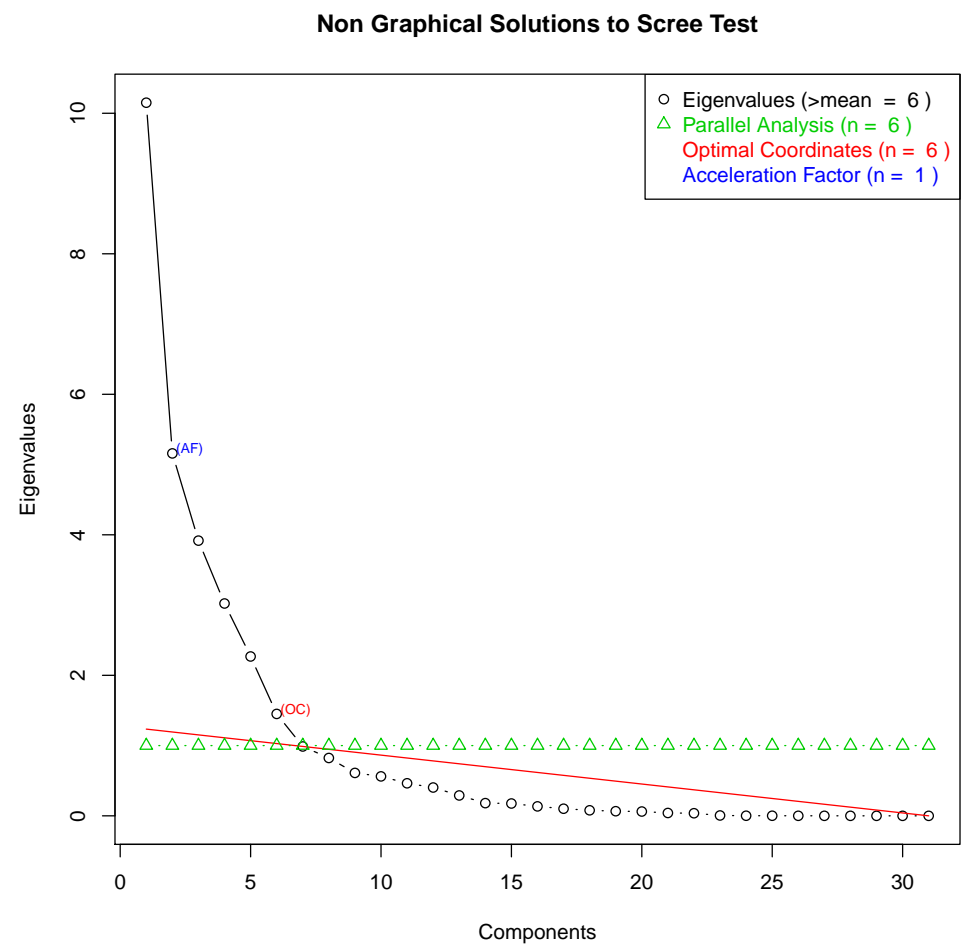

Figura II.2. Screeplot para determinar el número de componentes a retener en el ACP. Para información sobre los detalles ténicos ver Raiche \& Magis (2010) 


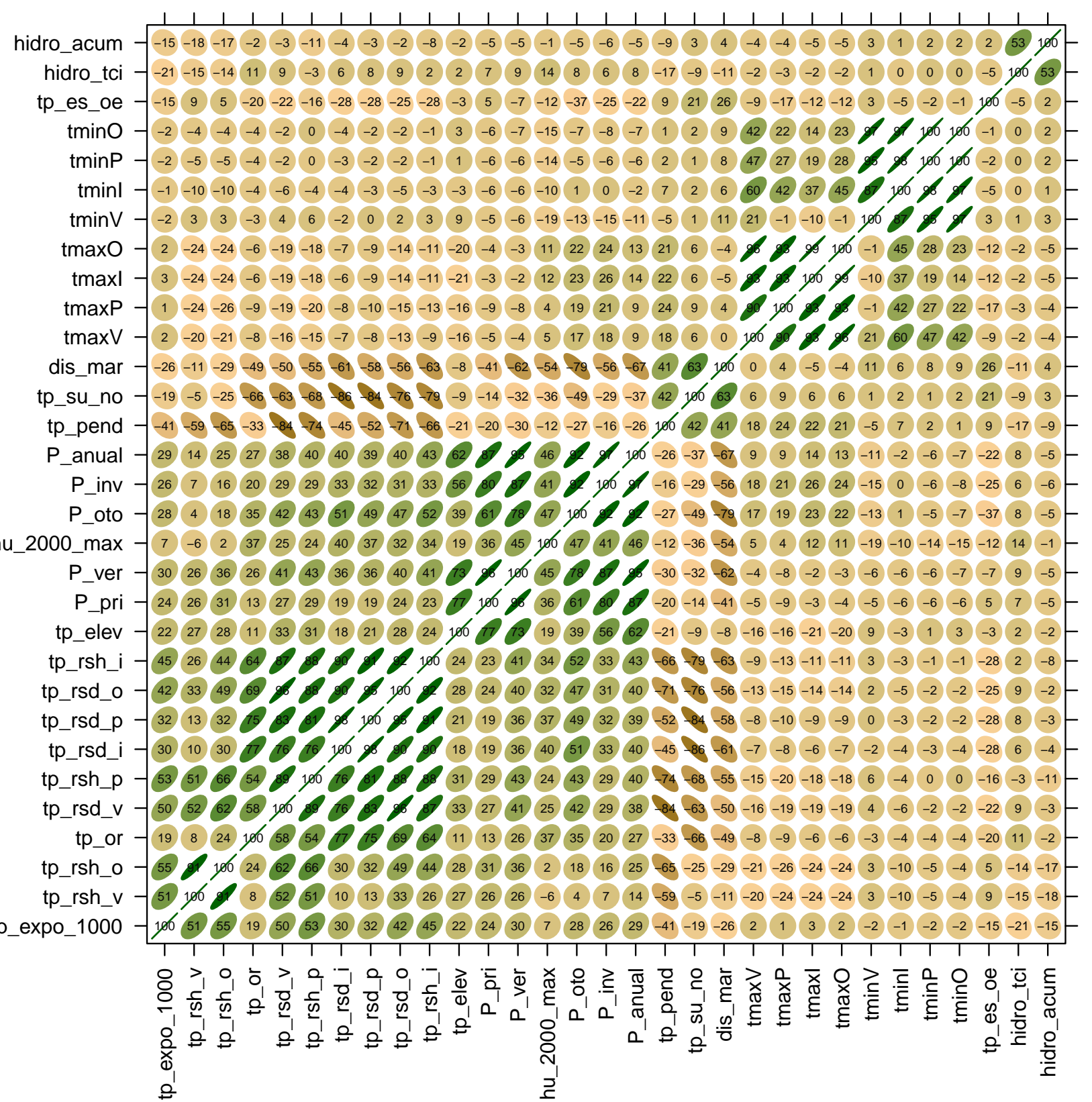

Figura II.3. Correlación entre las variables ambientales de los robledales de Sierra Nevada. Para cada correlación entre dos variables se muestra su valor escalado a 100, el sentido (positivo o negativo, también expresado en escala de colores) así como la magnitud de la correlación (mas ovalado, más correlación). 


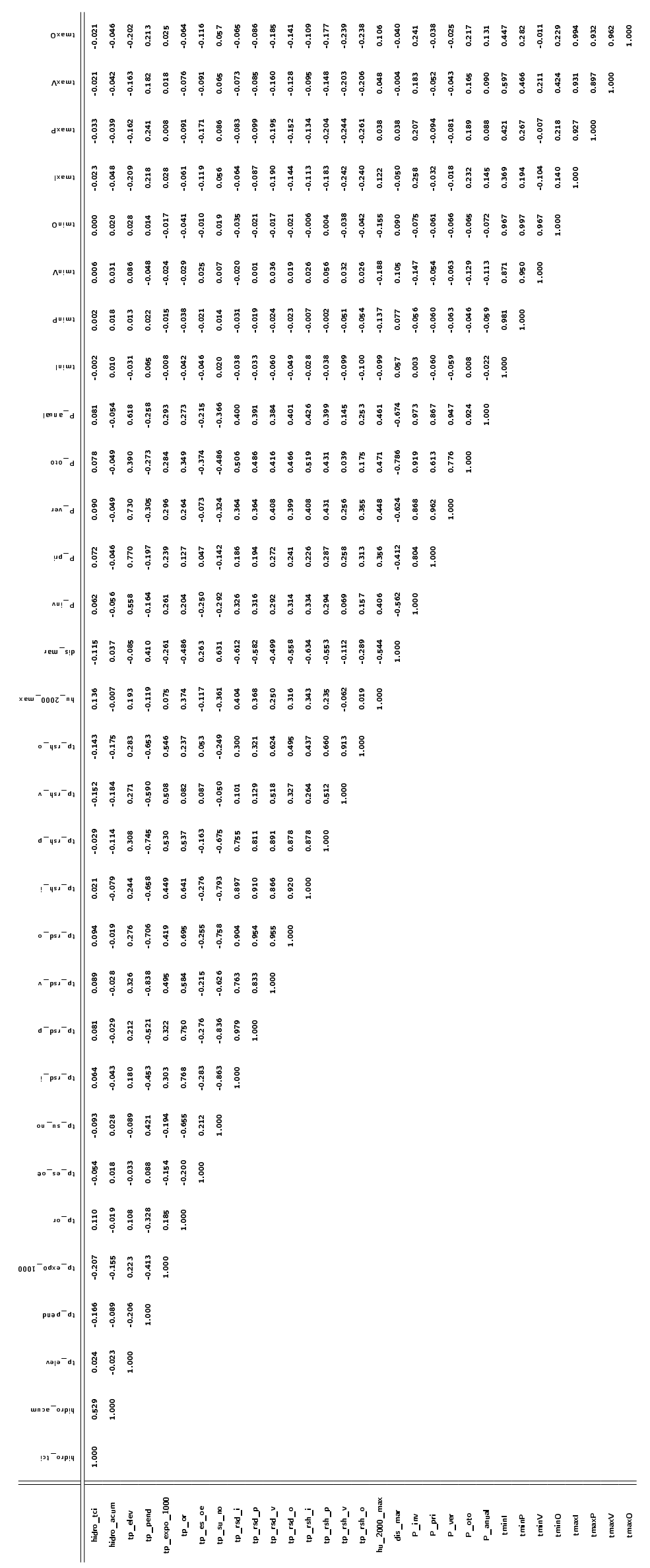

Tabla II.1. Coeficientes de correlación de sperman entre las variables ambientales de los robledales de Sierra Nevada. 


\subsection{Anexo III. Caracterización del hábitat óptimo y marginal de Quercus pyrenaica en Sierra Nevada}

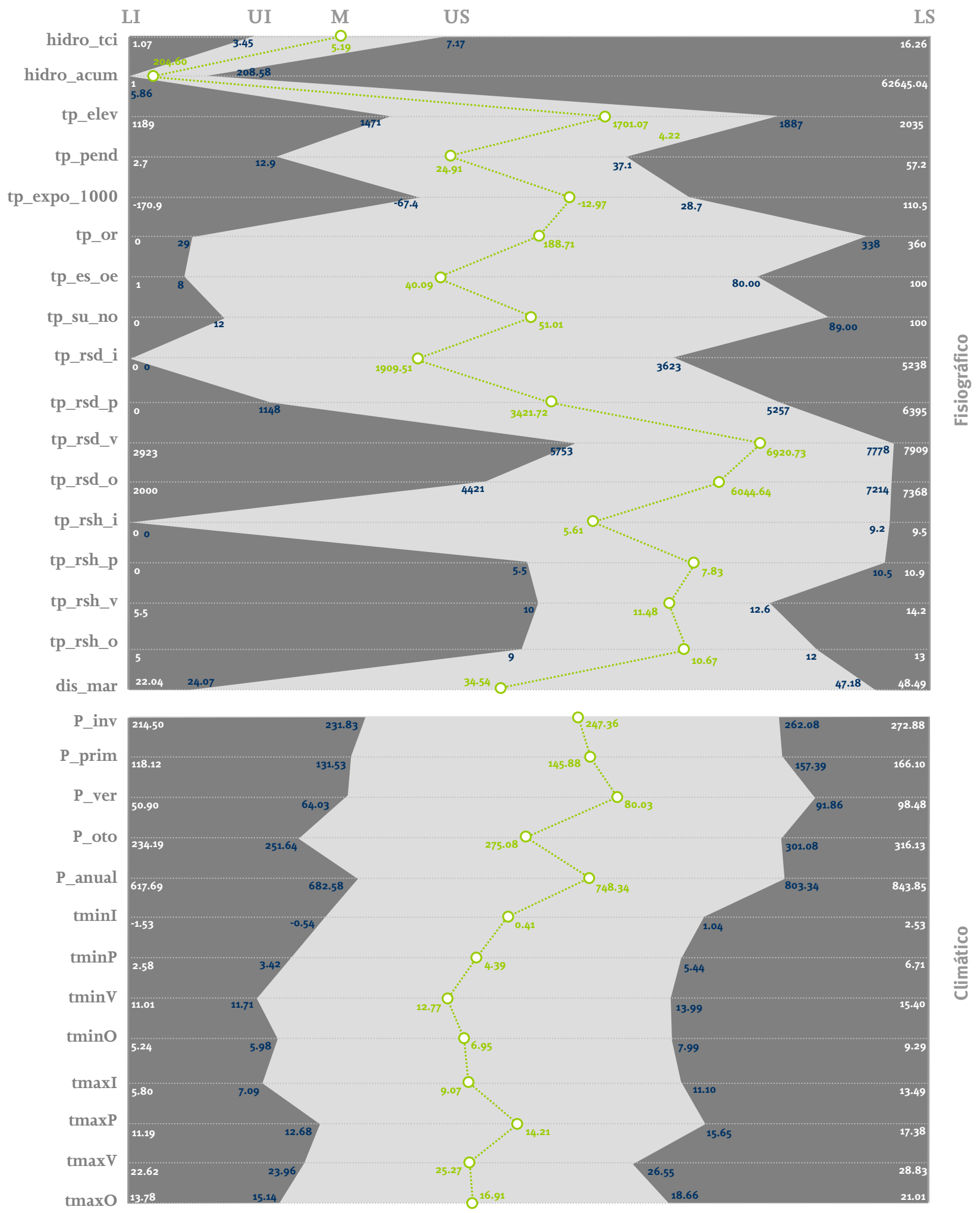

Figura III.1. Caracterización fisiográfica y climática de los robledales de Sierra Nevada. Para detalles ver apartado de resultados. 


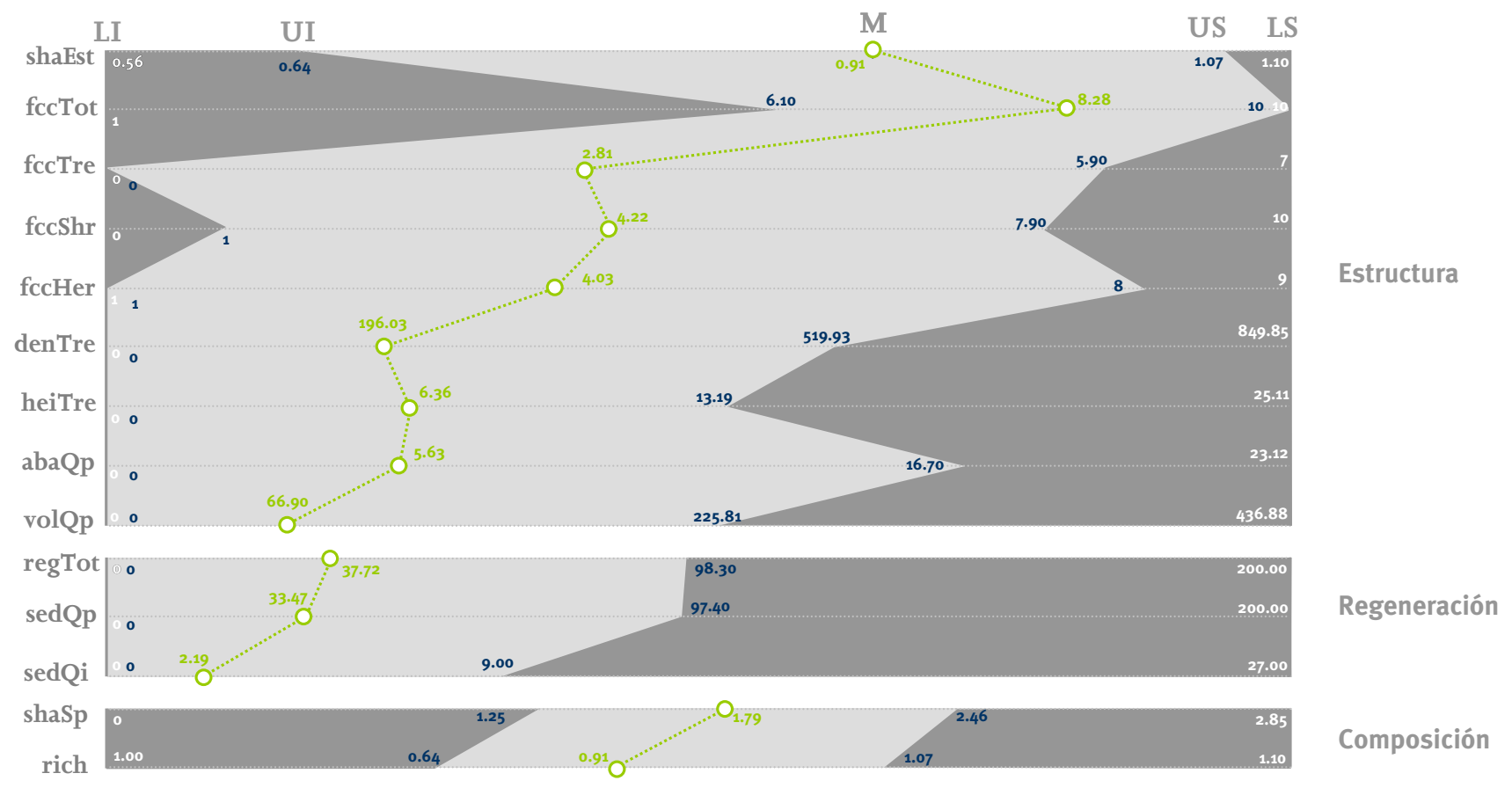

Figura III.2. Caracterización de los atributos forestales de los robledales de Sierra Nevada 


\subsection{Anexo IV. Análisis discriminante}

Pruebas de igualdad de las medias de los grupos

\begin{tabular}{|l|r|r|r|r|r|}
\hline & $\begin{array}{r}\text { Lambda de } \\
\text { Wilks }\end{array}$ & \multicolumn{1}{c|}{$\mathrm{F}$} & gl1 & gl2 & Sig. \\
\hline hidro_tci &, 967 & 11,958 & 7 & 2443 &, 000 \\
hidro_acum &, 993 & 2,306 & 7 & 2443 &, 024 \\
tp_elev &, 705 & 146,272 & 7 & 2443 &, 000 \\
tp_pend &, 712 & 141,175 & 7 & 2443 &, 000 \\
tp_expo_1000 &, 921 & 29,900 & 7 & 2443 &, 000 \\
tp_or &, 614 & 219,060 & 7 & 2443 &, 000 \\
tp_es_oe &, 723 & 133,440 & 7 & 2443 &, 000 \\
tp_su_no &, 389 & 548,343 & 7 & 2443 &, 000 \\
tp_rsd_i &, 411 & 499,571 & 7 & 2443 &, 000 \\
tp_rsd_p &, 450 & 426,654 & 7 & 2443 &, 000 \\
tp_rsd_v &, 575 & 257,837 & 7 & 2443 &, 000 \\
tp_rsd_o &, 488 & 366,436 & 7 & 2443 &, 000 \\
tp_rsh_i &, 393 & 539,187 & 7 & 2443 &, 000 \\
tp_rsh_p &, 536 & 301,547 & 7 & 2443 &, 000 \\
tp_rsh_v &, 923 & 29,192 & 7 & 2443 &, 000 \\
tp_rsh_0 &, 846 & 63,651 & 7 & 2443 &, 000 \\
hu_2000_max &, 394 & 535,904 & 7 & 2443 &, 000 \\
dis_mar &, 013 & 27432,362 & 7 & 2443 &, 000 \\
P_inv &, 423 & 475,773 & 7 & 2443 &, 000 \\
P_pri &, 511 & 334,097 & 7 & 2443 &, 000 \\
P_ver &, 433 & 457,525 & 7 & 2443 &, 000 \\
P_oto &, 197 & 1425,614 & 7 & 2443 &, 000 \\
P_anual &, 394 & 536,455 & 7 & 2443 &, 000 \\
tminl &, 954 & 16,913 & 7 & 2443 &, 000 \\
tminP &, 916 & 31,857 & 7 & 2443 &, 000 \\
tminV &, 776 & 100,772 & 7 & 2443 &, 000 \\
tminO &, 895 & 40,957 & 7 & 2443 &, 000 \\
tmaxl &, 482 & 375,235 & 7 & 2443 &, 000 \\
tmaxP &, 579 & 254,048 & 7 & 2443 &, 000 \\
tmaxV &, 702 & 148,413 & 7 & 2443 &, 000 \\
tmaxO & 297,308 & 7 & 2443 &, 000 \\
\hline
\end{tabular}

Figura IV.1. Prueba ANOVA de igualdad de las medias en el análisis discriminante. 


\begin{tabular}{|c|c|c|c|c|c|c|c|c|c|c|c|c|c|c|}
\hline & \multicolumn{2}{|c|}{1} & \multicolumn{2}{|c|}{2} & \multicolumn{2}{|c|}{3} & \multicolumn{2}{|c|}{4} & \multicolumn{2}{|c|}{5} & \multicolumn{2}{|c|}{6} & \multicolumn{2}{|c|}{7} \\
\hline & CE & CFCD & CE & CFCD & CE & CFCD & CE & CFCD & CE & CFCD & CE & CFCD & CE & CFCD \\
\hline hidrotci & -0.054 & -0.033 & -0.038 & -0.024 & -0.036 & -0.022 & -0.039 & -0.024 & -0.179 & -0.111 & -0.378 & -0.234 & 0.190 & 0.118 \\
\hline hidroacum & 0.050 & 0.000 & -0.099 & 0.000 & 0.017 & 0.000 & 0.024 & 0.000 & 0.051 & 0.000 & 0.253 & 0.000 & -0.085 & 0.000 \\
\hline tpelev & 4.505 & 0.033 & -8.146 & -0.061 & 3.170 & 0.024 & -5.721 & -0.043 & 0.032 & 0.000 & 0.586 & 0.004 & -2.579 & -0.019 \\
\hline tppend & -0.061 & -0.008 & 0.078 & 0.010 & 0.137 & 0.018 & 0.148 & 0.019 & 0.542 & 0.070 & 0.166 & 0.021 & -0.045 & -0.006 \\
\hline tpexpo1000 & -0.015 & 0.000 & 0.099 & 0.003 & -0.270 & -0.007 & -0.054 & -0.001 & -0.103 & -0.003 & -0.368 & -0.010 & 0.201 & 0.005 \\
\hline tpor & 0.013 & 0.000 & -0.081 & -0.001 & 0.083 & 0.001 & 0.087 & 0.001 & -0.127 & -0.001 & -0.112 & -0.001 & 0.022 & 0.000 \\
\hline tpesoe & 0.120 & 0.005 & -0.345 & -0.015 & 0.012 & 0.001 & -0.313 & -0.014 & 0.318 & 0.014 & 0.235 & 0.010 & -0.147 & -0.006 \\
\hline tpsuno & 0.000 & 0.000 & 0.056 & 0.003 & 0.162 & 0.009 & 0.107 & 0.006 & 0.413 & 0.023 & 0.190 & 0.011 & -0.330 & -0.019 \\
\hline tprsdi & -0.095 & 0.000 & 0.072 & 0.000 & 0.042 & 0.000 & -0.207 & 0.000 & -0.219 & 0.000 & 0.436 & 0.000 & 0.105 & 0.000 \\
\hline tprsdv & 0.086 & 0.000 & 0.283 & 0.000 & 0.002 & 0.000 & -0.175 & 0.000 & 0.404 & 0.001 & 1.092 & 0.002 & 0.518 & 0.001 \\
\hline tprsdo & 0.068 & 0.000 & -0.335 & 0.000 & 0.064 & 0.000 & 0.219 & 0.000 & 0.315 & 0.000 & -0.749 & -0.001 & -0.854 & -0.001 \\
\hline tprshi & -0.165 & -0.085 & 0.016 & 0.008 & -0.114 & -0.059 & 0.182 & 0.094 & -0.297 & -0.153 & 0.011 & 0.006 & 0.151 & 0.078 \\
\hline tprshp & 0.031 & 0.022 & 0.151 & 0.108 & -0.005 & -0.003 & 0.094 & 0.067 & -0.102 & -0.072 & -0.133 & -0.095 & 0.076 & 0.054 \\
\hline tprshv & 0.026 & 0.023 & -0.409 & -0.375 & 0.167 & 0.153 & -0.026 & -0.024 & 0.112 & 0.103 & -0.605 & -0.556 & -0.197 & -0.180 \\
\hline tprsho & -0.249 & -0.230 & -0.209 & -0.193 & -0.158 & -0.146 & 0.187 & 0.173 & -0.078 & -0.072 & 0.486 & 0.449 & 0.373 & 0.345 \\
\hline hu2000max & -0.202 & -0.022 & 0.253 & 0.028 & 0.492 & 0.054 & -0.171 & -0.019 & 0.345 & 0.038 & 0.211 & 0.023 & 0.878 & 0.097 \\
\hline dismar & 0.449 & 0.442 & 0.499 & 0.492 & -0.533 & -0.525 & 1.649 & 1.624 & 0.202 & 0.199 & -0.148 & -0.145 & 0.729 & 0.718 \\
\hline Pinv & 4.640 & 0.613 & -4.877 & -0.645 & -2.625 & -0.347 & -21.250 & -2.809 & -4.132 & -0.546 & 4.343 & 0.574 & -7.438 & -0.983 \\
\hline Ppri & -3.650 & -0.529 & 11.820 & 1.713 & 0.709 & 0.103 & 11.955 & 1.733 & 1.540 & 0.223 & -2.011 & -0.291 & 4.213 & 0.611 \\
\hline Poto & -5.539 & -0.697 & 1.232 & 0.155 & -1.221 & -0.154 & 15.116 & 1.902 & 2.867 & 0.361 & -2.297 & -0.289 & 5.314 & 0.669 \\
\hline $\operatorname{tmin} P$ & -3.054 & -4.118 & -2.964 & -3.996 & -4.977 & -6.710 & 1.660 & 2.238 & 2.930 & 3.950 & 2.369 & 3.194 & 0.645 & 0.870 \\
\hline $\operatorname{tmin} O$ & 3.011 & 4.124 & 3.084 & 4.224 & 4.981 & 6.822 & -1.618 & -2.216 & -3.199 & -4.382 & -2.290 & -3.137 & -0.604 & -0.827 \\
\hline tmaxl & -2.097 & -1.982 & -4.746 & -4.486 & -5.135 & -4.853 & -1.879 & -1.776 & 4.647 & 4.392 & 1.857 & 1.756 & 0.141 & 0.134 \\
\hline $\operatorname{tmax} P$ & -0.019 & -0.022 & -0.546 & -0.623 & 0.403 & 0.459 & 0.186 & 0.212 & 0.288 & 0.329 & -0.118 & -0.134 & 0.131 & 0.149 \\
\hline $\operatorname{tmax} V$ & -1.013 & -1.213 & -2.992 & -3.584 & -2.400 & -2.875 & 0.282 & 0.338 & 1.892 & 2.266 & 2.415 & 2.893 & 0.345 & 0.413 \\
\hline $\operatorname{tmax} 0$ & 3.260 & 3.332 & 8.258 & 8.441 & 7.102 & 7.260 & 1.252 & 1.279 & -6.346 & -6.487 & -4.650 & -4.753 & -0.642 & -0.657 \\
\hline cte. & & 28.544 & & -56.495 & & 58.517 & & -78.510 & & 8.178 & & -27.033 & & -24.799 \\
\hline
\end{tabular}

Tabla IV.1. Coeficientes de las funciones canónicas discriminantes (CFCD) y coeficientes estandalizados (CE) de las primeras 7 funciones discriminantes

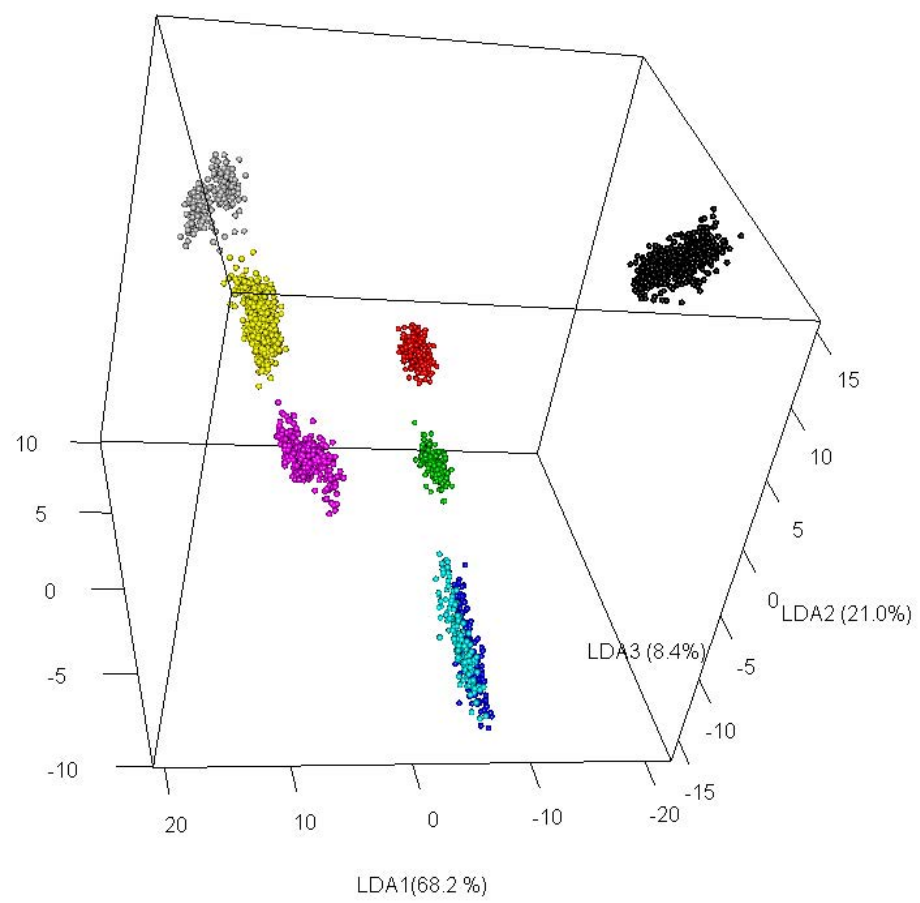

Figura IV.2. Representación tridimensional de las tres primeras funciones discriminantes. 


\subsection{Escalamiento multidimensional no métrico}
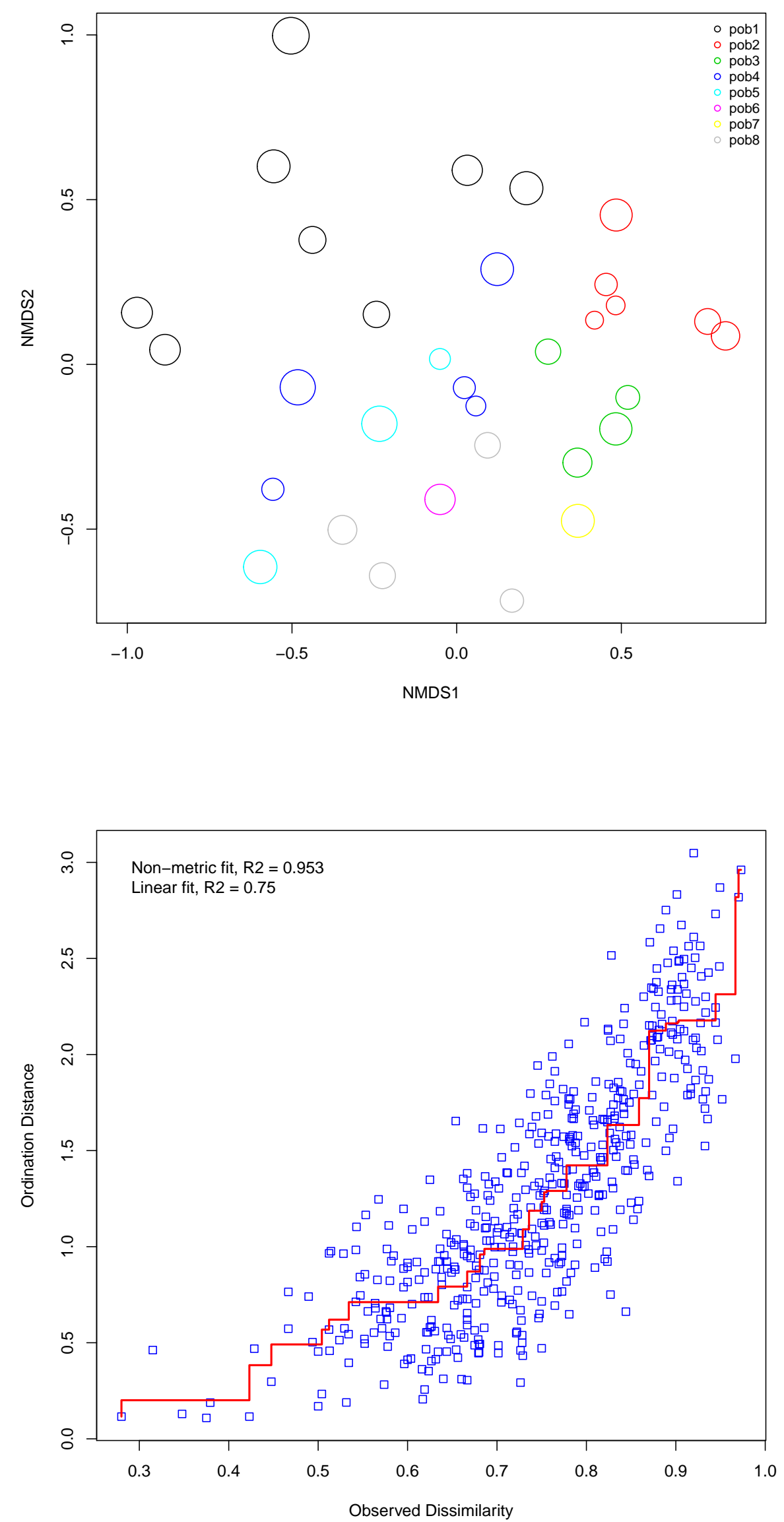

Figura V.1 Arriba: ordenación de las poblaciones en función de los ejes del NMDS. El tamaño del círculo es inversamente proporcioal al ajuste. Cuanto mayor es el tamaño del círculo peor es el ajuste (para detalles ver Oksanen et al 2010). Abajo: Diagrama de Sherpard donde se muestra la disimilaridad observada frente a la distancia de ordenación. 


\section{Agradecimientos}

En primer lugar, sin duda, agradezco enormemente a Mari Ángeles, mi mujer, y a Elena María, mi hija, todo el apoyo, paciencia y compresión que han mostrado siempre. Ellas han sido mi sustento durante este master. Nunca les ha faltado una sonrisa ni una palabra de ánimo. Han sido fuente de ánimos y consuelo. Al mismo tiempo os pido disculpas por mi ausencia durante este curso. Gracias familia. Agradezco enormemente a mis padres, Rafael y Carmen, el esfuerzo que han realizado siempre y su constante preocupación por sus hijos. Sois un gran ejemplo de vida. Gracias por ello. Igualmente agradezco a mi familia su cercanía y cariño, aunque no estemos en la misma ciudad.

Por otro lado tengo que agradecer al equipo humano del Laboratorio de Ecología del Centro Andaluz de Medio Ambiente (iEcoLab - CEAMA) de la Universidad de Granada y Junta de Andalucía su apoyo durante la realización de este master. Gracias a Curro, Ricardo, Irene, Ramón, Blas, Fabio, Pepa, Pablo S. Reyes, Regino, Susana y a aquellos que ya no están: Curro Cabezas, Nacho, Pablo González, Luis Cayuela. Gracias a todos porque de una u otra forma me habéis ayudado. Curro Bonet ha sido el principal culpable de que este metido en estos líos. Agradezco en este trabajo tus aportaciones y tu ayuda con la base de datos. Aprovecho y te agradezco por enseñarme tanto y por tu forma de tratar a las personas, es envidiable. Gracias por tu afanada tarea en mejorar la forma en la que trabajamos. Gracias Blas por aportarme parte de los datos utilizados en este trabajo. Gracias Pablo por los datos de clima. Gracias Fabio por tus comentarios en los análisis. Ricardo mil gracias por tu disponibilidad y tu ofrecimiento y por echarme una mano cuando no llegaba. Gracias Irene por tu ayuda con los datos de robledales. Gracias Pepa por ayudarnos con los papeleos. Ramón gracias por enseñarme cosas de redes neuronales. Gracias Curro y Regino por confiar en mí para hacer este master. Gracias a todos y cada uno de vosotros por compartir el día a día, lo bueno y lo malo. Juntos estamos caminando y construyendo un modo de trabajo en equipo admirable.

Por otro lado, sin ánimo de adular, agradezco a los profesores del master su dedicación y lo que me han enseñado durante este master. En primer lugar a mi tutor, Pedro Antonio García, por confiar en mi trabajo y por su apoyo como tutor de este trabajo de investigación. Gracias a Juan Eloy Ruiz, Paco Alonso Morales, José Fernándo Vera y Ana María Aguilera por vuestros comentarios y por vuestros ánimos. Al resto de profesores que he tenido oportunidad de conocer, gracias por enseñarme.

Agradezco a José Miguel Barea que me haya cedido la foto de la portada y a Rut Aspizua su ayuda con el inventario forestal. Finalmente agradezco al Ministerio de Educación y Ciencia que me concediera una beca de matrícula para realizar este master. 
Antonio Jesús Pérez Luque

Trabajo Fin de Master

Universidad de Granada

\section{Universidad}

de 